Check for updates

Cite this: Mater. Horiz., 2020, 7,762

Received 19th September 2019 Accepted 19th November 2019

DOI: 10.1039/c9mh01497g

rsc.li/materials-horizons

\title{
Graphitic carbon nitride and polymers: a mutual combination for advanced properties
}

\begin{abstract}
Qian Cao, ${ }^{a}$ Baris Kumru, ${ }^{a}$ Markus Antonietti (D) ${ }^{a}$ and Bernhard V. K. J. Schmidt (D) ab $^{a b}$
The sheet-like material graphitic carbon-nitride $\left(\mathrm{g}-\mathrm{C}_{3} \mathrm{~N}_{4}\right)$ is one of the most promising metal-free photocatalysts and utilized for various purposes, e.g. energy conversion, waste water remediation or organic synthesis. $\mathrm{g}-\mathrm{C}_{3} \mathrm{~N}_{4}$ features a suitable band gap in the visible light range and outstanding physicochemical stability. However, $\mathrm{g}-\mathrm{C}_{3} \mathrm{~N}_{4}$ features drawbacks such as structural disorder, low conductivity, poor dispersibility and in turn low processability. Amongst the strategies to improve g- $\mathrm{C}_{3} \mathrm{~N}_{4}$ properties, combination with polymers is a promising avenue toward advanced materials. The present critical review highlights the development and investigation of $\mathrm{g}-\mathrm{C}_{3} \mathrm{~N}_{4}$ /polymer combination, including (1) $\mathrm{g}-\mathrm{C}_{3} \mathrm{~N}_{4}$ as photoinitiator for polymer snythesis, (2) polymer modified $\mathrm{g}-\mathrm{C}_{3} \mathrm{~N}_{4}$ for improved dispersibility, (3) $\mathrm{g}-\mathrm{C}_{3} \mathrm{~N}_{4}$ /polymer hybrid materials fabricated via physical or covalent attachment and (4) g- $\mathrm{C}_{3} \mathrm{~N}_{4}$ based hydrogels. The fabrication methods and application of these areas will be critically reviewed and the advantage of $\mathrm{g}-\mathrm{C}_{3} \mathrm{~N}_{4}$ /polymer combination comprehensively presented. Moreover, the broad range of applications is highlighted, e.g. photocatalysis, batteries, biosensors, $\mathrm{H}_{2}$ evolution and films. Finally, the review will conclude with a summary and perspective on future directions as well as current challenges of this research area in order to stimulate new research regarding the design and construction of $\mathrm{g}-\mathrm{C}_{3} \mathrm{~N}_{4}$ /polymer materials.
\end{abstract}

\section{Introduction}

Sustainability has an increasing impact both on academia and industry, orienting many research fields such as biomass conversion, batteries, polymers and photochemistry. ${ }^{1-5} \mathrm{~A}$ significant direction

\footnotetext{
${ }^{a}$ Max Planck Institute of Colloids and Interfaces, Am Mühlenberg 1, 14476 Potsdam, Germany

${ }^{b}$ University of Glasgow, School of Chemistry, G12 8QQ, Glasgow, UK.

E-mail: bernhard.schmidt@glasgow.ac.uk; Tel: +44 (0)141 3308469
}

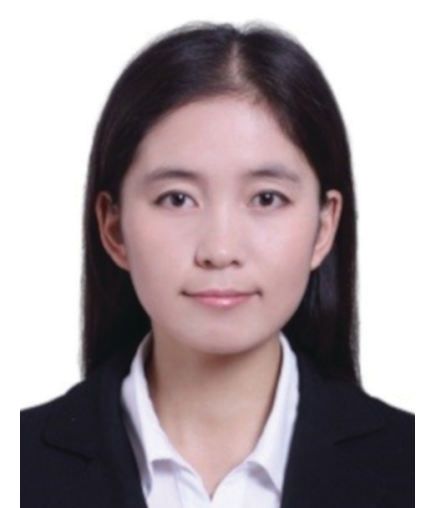

Qian Cao
Qian Cao received her $B S c$ in Inorganic Nonmetal Materials and Engineering and MSc in Material Science and Engineering from University of Science and Technology Beijing. She is currently a PhD student under the supervision of Prof. Markus Antonietti and $\mathrm{Dr}$ Bernhard V. K. J. Schmidt at the Max Planck Institute of Colloids and Interfaces. Her research interests focus on the synthesis and application of carbon nitride as well as polymer hybrid materials. is the integration of free and abundant sunlight into current technology, such as energy harvesting via photovoltaic devices or photo-mediated material synthesis. Semiconductors (such as $\mathrm{Si}$, $\mathrm{TiO}_{2}, \mathrm{CdS}$, hybrid perovskites, polythiophenes) absorb light which results in the formation of excited electrons, and are promising candidates for photovoltaic devices, transistors and for photoinduced reaction catalysis. ${ }^{6-8}$ Many factors should be considered for the efficiency of a semiconductor materials, such as suitable absorption and bandgap values, lifetime of excited electrons, and charge migration which delays recombination.

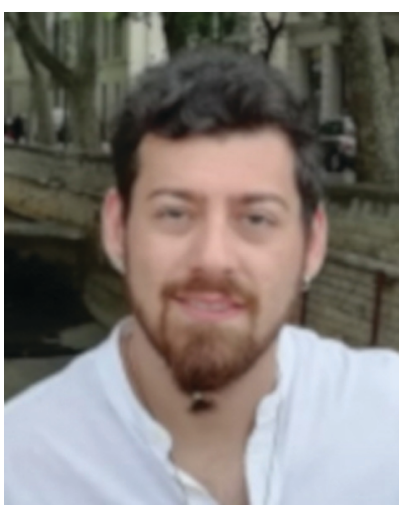

Dr Baris Kumru has obtained his chemistry bachelor degree in 2015 and master degree in 2016 at Istanbul Technical University. Later he earned his PhD degree in early 2019 at the Max Planck Institute of Colloids and Interfaces in Potsdam. He will be promoted as young Group Leader at the same institute focusing on colloids, polymers and photochemistry.
Baris Kumru 


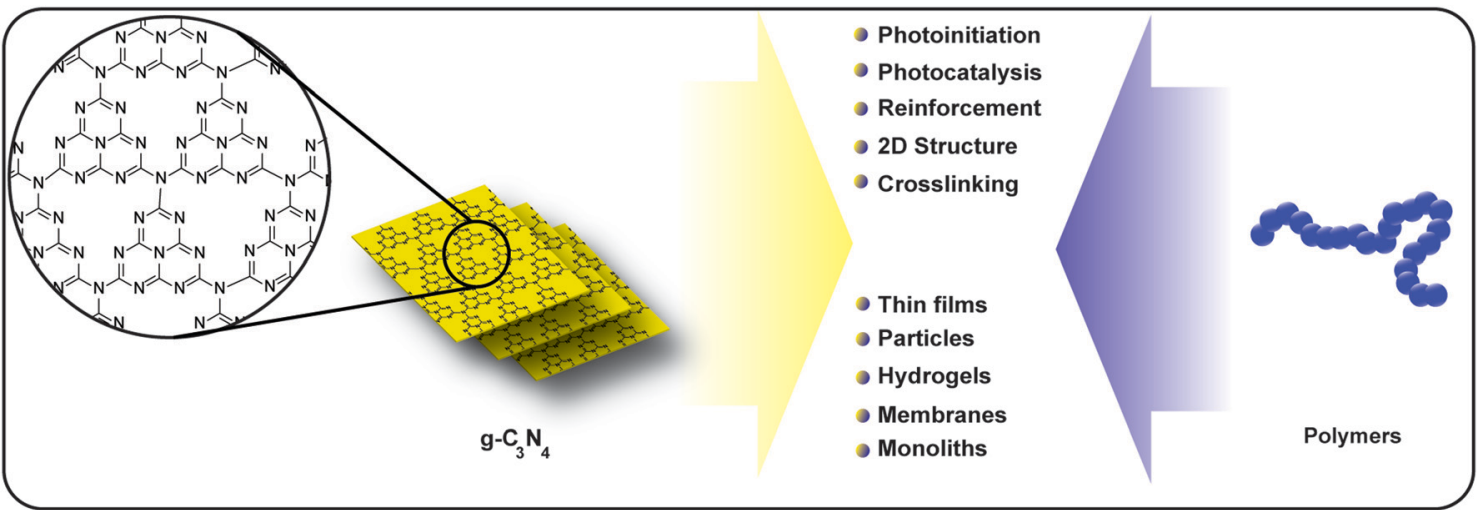

Scheme 1 Structure of $\mathrm{g}-\mathrm{C}_{3} \mathrm{~N}_{4}$ and properties/materials obtained in combination with polymers showing the features that g- $\mathrm{C}_{3} \mathrm{~N}_{4}$ introduces into polymer science (top) and the morphologies achievable via $\mathrm{g}-\mathrm{C}_{3} \mathrm{~N}_{4} /$ polymer combination (bottom).

Even though excessive research has been conducted on these materials, their metal content, possible toxicity and synthesis from non-abundant sources restrict applications. Therefore, suitable candidates which have at least similar photoactivity but are formed via sustainable synthetic conditions are highly sought. ${ }^{9}$

Graphitic carbon-nitride $\left(\mathrm{g}-\mathrm{C}_{3} \mathrm{~N}_{4}\right)$ is a sheet like material that is traditionally formed from a regular arrangement of tri-striazine units (Scheme 1)..$^{10,11}$ It features a variety of modifications, which have direct influence on the band gap resulting in photoactivity in the visible and UV range of light. ${ }^{12-15}$ Thus, $\mathrm{g}-\mathrm{C}_{3} \mathrm{~N}_{4}$ is utilized frequently as visible light induced heterogeneous photocatalyst, for example for organic transformations, ${ }^{16,17}$ hydrogen evolution, ${ }^{18-20}$ pollution degradation ${ }^{21}$ or $\mathrm{CO}_{2}$ reduction. ${ }^{22,23}$ Moreover, $\mathrm{g}-\mathrm{C}_{3} \mathrm{~N}_{4}$ is utilized in ion transport membranes, ${ }^{24,25}$ photoelectrochemistry ${ }^{26}$ or in organic photovoltaics ${ }^{27-29}$ as well as for emulsion stabilization. ${ }^{30}$ The synthesis of $\mathrm{g}-\mathrm{C}_{3} \mathrm{~N}_{4}$ is usually performed from metal-free, oxygen-free, abundant and nitrogenrich precursors, for example cyanamide, ${ }^{31,32}$ guanidine hydrochloride ${ }^{33,34}$ melamine ${ }^{35-37}$ or cyanuric acid. ${ }^{38}$ The process can be realized via several methods. Amongst them, thermal condensation is the most common method for fabrication of bulk g- $\mathrm{C}_{3} \mathrm{~N}_{4}$, which proceeds under inert atmosphere between 400 and $600{ }^{\circ} \mathrm{C}$. Recently, other methods like chemical vapor deposition or electrochemical deposition were introduced for fabricating film or membrane g- $\mathrm{C}_{3} \mathrm{~N}_{4} \cdot{ }^{39}$ The microwave method was utilized as well, e.g. to produce fluorescent g- $\mathrm{C}_{3} \mathrm{~N}_{4} \cdot{ }^{40,41}$ However, the type of the precursors and treatment can significantly influence the physicochemical properties of as-prepared g- $\mathrm{C}_{3} \mathrm{~N}_{4}$. Compared to traditional semiconductors which have defined formulas, g- $\mathrm{C}_{3} \mathrm{~N}_{4}$ represents a large family of materials with a variety of properties. For example, one way to obtain welldefined $\mathrm{g}-\mathrm{C}_{3} \mathrm{~N}_{4}$ is the utilization of a supramolecular precursor complex of cyanuric acid and melamine that already resembles the final $\mathrm{g}-\mathrm{C}_{3} \mathrm{~N}_{4}$ structure. ${ }^{42,43}$ As such, porosity, ${ }^{44-46}$ surface charge, ${ }^{47}$ light absorption, photoluminescence, and band gap ${ }^{48}$ can be tailored according to the needs. Recently, also the overall shape of $\mathrm{g}-\mathrm{C}_{3} \mathrm{~N}_{4}$ could be tuned via various synthetic methodologies, e.g. a control over precursor crystal structures/shapes. ${ }^{49-52}$ As summary, g- $\mathrm{C}_{3} \mathrm{~N}_{4}$ seems to satisfy sustainability requirement as semiconductor by being metal free and synthesized from benign precursors, in addition it possesses tunable properties,

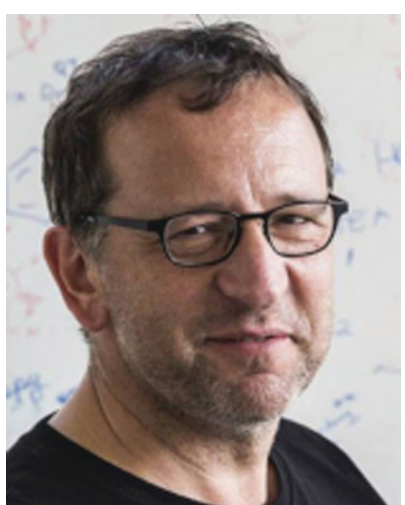

Markus Antonietti
Markus Antonietti is director of Colloid Chemistry of the Max Planck Institute of Colloids and Interfaces. Starting from polymer science, he now works on modern materials chemistry, with sustainable processes and materials are a central theme. Carbon and Carbon-Nitrogen Materials exert a special fascination to him. Besides being a devoted scientist and an academic teacher, he is a passionate chef specialized in fusion cuisine and plays in a Rock'n'Roll band.

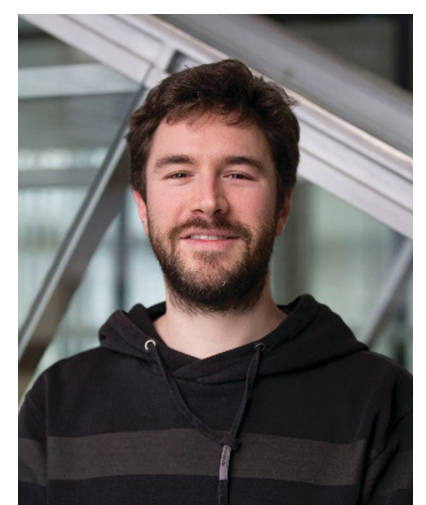

Bernhard V. K. J. Schmidt

Bernhard V. K. J. Schmidt completed his PhD in 2013 with Prof. BarnerKowollik at the Karlsruhe Institute of Technology and a PostDoc with Prof. Hawker at the University of California, Santa Barbara. Afterwards he joined the department of Prof. Antonietti at the Max Planck Institute of Colloids and Interfaces as a Group Leader. Recently, he was appointed as Lecturer in Synthetic Polymer Chemistry at the University of Glasgow. His research focusses on block copolymer self-assembly, metal-organic framework/polymer hybrids and carbon nitride/polymer hybrid materials. 
however it has some major drawbacks such as structural disorder, as well as being non-processable in bulk.

In that sense, a combination of carbon nitride with polymers seems to be a promising avenue for advanced materials (Scheme 1). Polymers can introduce processability (e.g. film formation) into materials as well as enhancing dispersibility. Moreover, a plethora of conducting polymers allows a fine tuning of electron transport process in materials. Therefore, polymers can be utilized to introduce new properties to g- $\mathrm{C}_{3} \mathrm{~N}_{4}$ or to enhance existing properties (e.g. photocatalysis or conductivity). Likewise, incorporation of $g-\mathrm{C}_{3} \mathrm{~N}_{4}$ into polymer materials is an avenue to tailor mechanical properties of the polymer, e.g. in the bulk or in hydrogels. Another promising property of $g-\mathrm{C}_{3} \mathrm{~N}_{4}$ that is of significant interest for polymer science is its inherent property to form radicals under irradiation with visible light. As such it acts as photoinitiator and can be used for polymer synthesis (e.g. polymer particles) in a convenient way. Polymers and $\mathrm{g}-\mathrm{C}_{3} \mathrm{~N}_{4}$ have various points of contact, and by hybridization improved or novel materials properties can be synthesized.

In the following review, this combination is discussed. The research in recent years is divided into four parts. At first the photoinitiator properties of $\mathrm{g}-\mathrm{C}_{3} \mathrm{~N}_{4}$ and its application in various polymerization systems is discussed. Next, the dispersibility of $\mathrm{g}^{-} \mathrm{C}_{3} \mathrm{~N}_{4}$ and polymer- or functionalization-based routes towards improved dispersibility are highlighted. As the main part, g- $\mathrm{C}_{3} \mathrm{~N}_{4}$ / polymer hybrid and composite materials are presented with emphasis on $\mathrm{H}_{2}$ evolution, photocatalysis, biosensors, electrochemical energy storage and solar cells, films, nano particles and polymer properties. Finally, the area of $\mathrm{g}-\mathrm{C}_{3} \mathrm{~N}_{4}$-based hydrogels is introduced with a focus on mechanical properties as well as photocatalytic properties. The review is closed with a summary and discussion of future aspects.

\section{Carbon nitride as polymerization initiator}

Commonly, g- $\mathrm{C}_{3} \mathrm{~N}_{4}$ has been employed as a highly active photocatalyst. As g- $\mathrm{C}_{3} \mathrm{~N}_{4}$ features a suitable bandgap to absorb visible light, it generates electrons and holes under visible light irradiation. In these cases, the formation of reactive species (e.g., ${ }^{\bullet} \mathrm{OH}, \mathrm{O}_{2}^{-\bullet}$, and $\mathrm{HO}_{2}{ }^{\bullet}$, or also $\mathrm{CN}$-centered species) takes place, which is not only of interest for photocatalysis but for polymerization processes as well (Scheme 2). Therefore, two ways are depicted in Scheme 2 where g- $\mathrm{C}_{3} \mathrm{~N}_{4}$ acts as initiator for photopolymerization, which is accompanied with various advantages. First of all, g- $\mathrm{C}_{3} \mathrm{~N}_{4}$ polymerizations can be operated in the visible light region, which is a benign and abundant trigger. Several monomers were investigated for polymerization via $\mathrm{g}-\mathrm{C}_{3} \mathrm{~N}_{4}$ as photoinitiator, such as styrene, ${ }^{53}$ methyl methacrylate (MMA), ${ }^{54} \alpha$-methylene- $\gamma$-valerolactone (MeGVL), ${ }^{55}$ methyl acrylate (MA). ${ }^{56}$ On top, photopolymerizations have various useful features, like spatial and temporal control. Moreover, g- $\mathrm{C}_{3} \mathrm{~N}_{4}$ is a heterogenous catalyst, which allows easy separation and recycling. Albeit, the conditions can be altered in a way that the growing polymer chains are grafted from $g-\mathrm{C}_{3} \mathrm{~N}_{4}$ and as such recycling or separation is not straight-forward. In this case grafting polymers from g- $\mathrm{C}_{3} \mathrm{~N}_{4}$ opens up various opportunities for hybrid material formation, which also broadens the utilization in bioapplications due to the inherent photoluminescent properties of $\mathrm{g}-\mathrm{C}_{3} \mathrm{~N}_{4}$.

As a proof of concept, Yagci and coworkers utilized g- $\mathrm{C}_{3} \mathrm{~N}_{4}$ as visible light photoinitiator for free radical polymerization. ${ }^{57}$ Mesoporous g- $\mathrm{C}_{3} \mathrm{~N}_{4}\left(\mathrm{mpg}-\mathrm{C}_{3} \mathrm{~N}_{4}\right)$ was employed as heterogeneous visible light photoinitiator in the presence of tertiary amine as reactive co-initiator, conducting free radical polymerization with

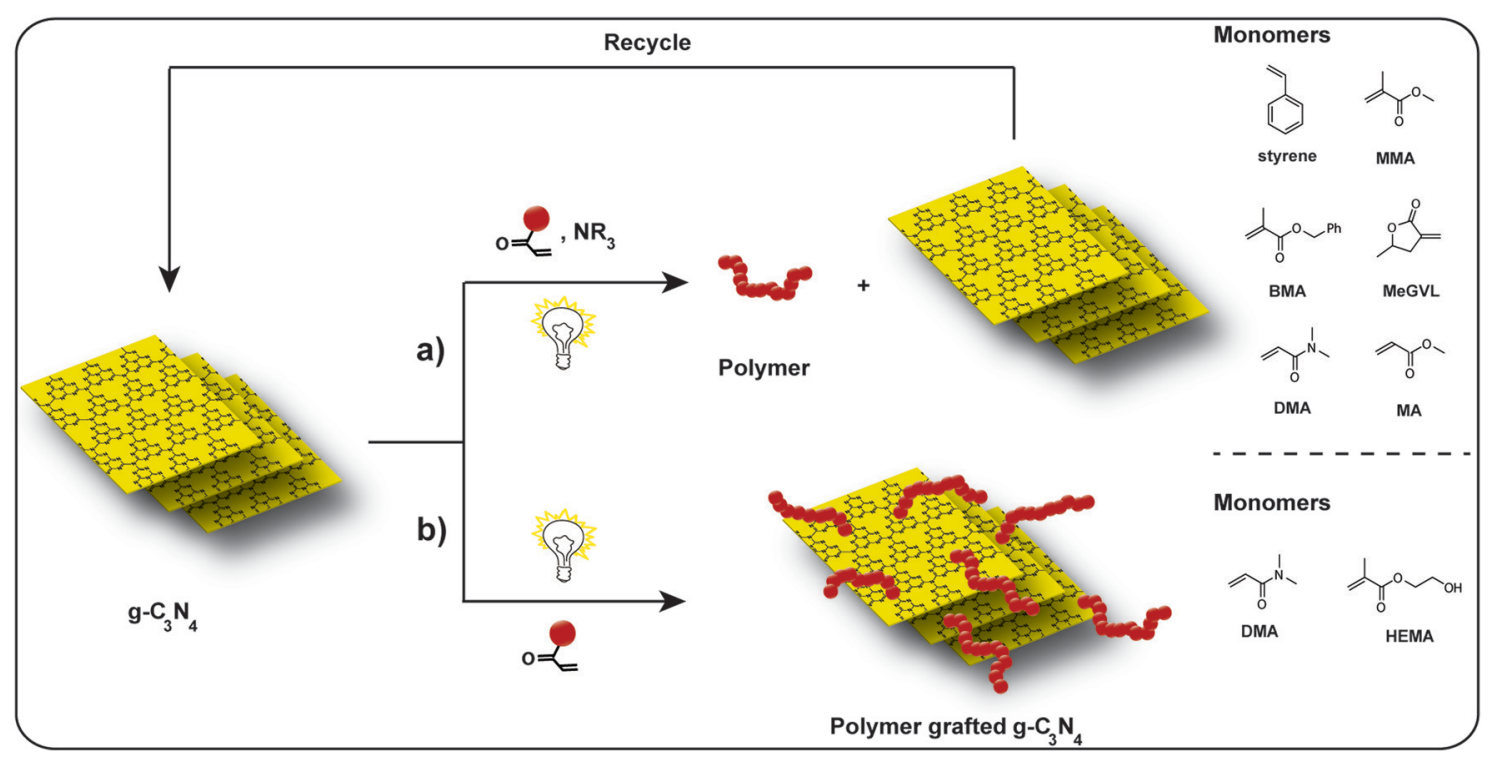

Scheme 2 Schematic overview of $\mathrm{g}-\mathrm{C}_{3} \mathrm{~N}_{4}$ mediated photopolymerization and monomers used in the two approaches: utilization of g- $\mathrm{C}_{3} \mathrm{~N}_{4}$ as recyclable photoinitiator via radical transfer to an amine compound (top) and g- $\mathrm{C}_{3} \mathrm{~N}_{4}$ initiated grafting of polymers onto the initiator (bottom) (MMA: methyl methacrylate; BMA: benzyl methacrylate; MeGVL: $\alpha$-methylene- $\gamma$-valerolactone; DMA: $N, N$-dimethylacrylamide; MA: methyl acrylate; HEMA: 2-hydroxyethyl methacrylate). 
vinyl monomers such as methyl methacrylate (MMA). Based on the photoredox chemistry of $m p g-\mathrm{C}_{3} \mathrm{~N}_{4}$, the photopolymerization process was realized by exposing the monomer mixture to visible light in the absence of $\mathrm{O}_{2}$. The initiation mechanism is presumably the transfer of the $\mathrm{CN}$-based hole and the amine. The photochemically formed holes oxidize amines to the corresponding radical cations which abstract hydrogen from another amine leading to the formation of initiating radicals. Moreover, mpg- $\mathrm{C}_{3} \mathrm{~N}_{4}$ demonstrated enhanced activity in the polymerization process due to a larger external surface compared to non-porous bulk g- $\mathrm{C}_{3} \mathrm{~N}_{4}$.

Recently, our group employed $\mathrm{g}-\mathrm{C}_{3} \mathrm{~N}_{4}$ as radical photoinitiator for emulsion photopolymerization. ${ }^{58}$ Emulsions of aromatic monomers (styrene and benzyl methacrylate) and MMA in water were formed via g- $\mathrm{C}_{3} \mathrm{~N}_{4}$ (cyanuric acid-melamine-derived g- $\mathrm{C}_{3} \mathrm{~N}_{4}$ (CM) or 1-decene modified CM) as stabilizer. Subsequently, the mixture was exposed to visible light to conduct polymerization. Radicals were formed on the surface of $\mathrm{g}-\mathrm{C}_{3} \mathrm{~N}_{4}$. Kinetic studies and in-depth studies of the polymer particles indicated that the g- $\mathrm{C}_{3} \mathrm{~N}_{4}$ surface acted as the reaction locus for polymer chain growth and particle formation. The polymerization mechanism was investigated by addition of hole or electron scavenger to the reaction system, respectively, and it was demonstrated that the emulsion photopolymerization was mainly initiated by the hole. Overall, very well-defined latexes were obtained, which was attributed to the fast nucleation of the latex particles. Moreover, compared to previous works, radicals were formed via holes on the $\mathrm{g}-\mathrm{C}_{3} \mathrm{~N}_{4}$ surface directly without co-initiator addition. The direct radical formation leads to crosslinked latex particles directly due to the multifunctionality of $\mathrm{g}-\mathrm{C}_{3} \mathrm{~N}_{4}$. Furthermore, our team has employed $\mathrm{g}-\mathrm{C}_{3} \mathrm{~N}_{4}$ as heterogeneous photocatalyst for free radical polymerization of MeGVL. ${ }^{55}$ At first MeGVL is efficiently synthesized from renewable resources via continuous flow reaction from $\gamma$-valerolactone over hierarchical basic zeolite. MeGVL is structurally similar to methacrylic monomers, and further valorization of this compound via efficient polymerization demonstrates the ability to make novel biomassderived polymer with significant industrial interest.

As a semiconductor, $\mathrm{g}-\mathrm{C}_{3} \mathrm{~N}_{4}$ possesses a quite high negative position of the conduction band, thus contributing to a high activity of oxygen capture and reduction. Meanwhile, the moderate oxidation potential of $\mathrm{g}-\mathrm{C}_{3} \mathrm{~N}_{4}$ efficiently prevents the decomposition of the prepared polymer by the photogenerated holes. Both effects play a crucial role in the photopolymerization process. ${ }^{59,60}$ Thus researchers introduced $\mathrm{g}-\mathrm{C}_{3} \mathrm{~N}_{4}$ as a promoter for electron transfer in reversible deactivation radical polymerization (RDRP). For example, Yagci and coworkers ${ }^{56}$ utilized mpg- $\mathrm{C}_{3} \mathrm{~N}_{4}$ as photoactivator for reduction of initially loaded copper(II) species, for the in situ formation of copper(I) species, which act as catalytic species in atom transfer radical polymerization (ATRP). Subsequently, polymerization was successfully conducted under sunlight or UV-light irradiation. It was shown that the light-induced electron transfer from $\mathrm{g}-\mathrm{C}_{3} \mathrm{~N}_{4}$ is due to the large reduction potential $\left(E_{\mathrm{CB}}\right)$ of $-1.2 \mathrm{eV}$. Vinyl monomers such as, methyl acrylate (MA), MMA and styrene were successfully polymerized during the reaction with precise control on
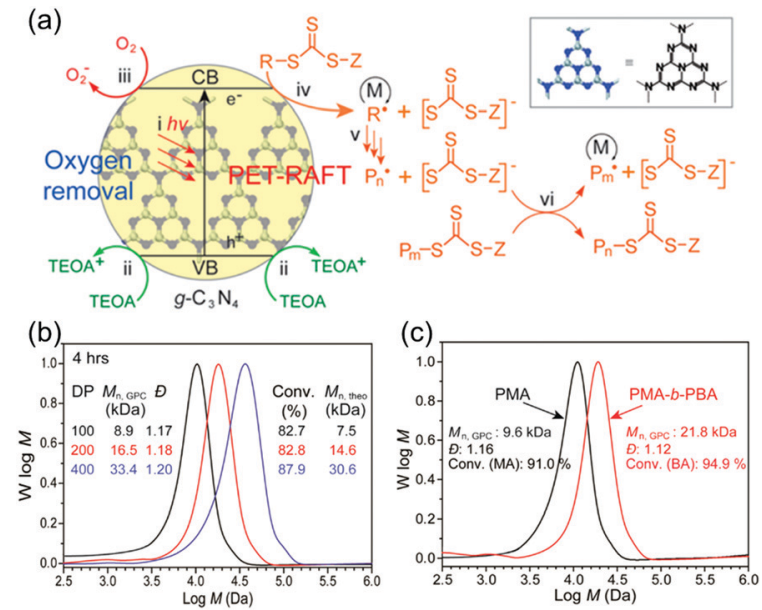

Fig. 1 (a) Schematic overview over the mechanism of deoxygenation and photoinduced electron/energy transfer-reversible addition-fragmentation chain transfer (PET-RAFT) polymerization employing $\mathrm{g}-\mathrm{C}_{3} \mathrm{~N}_{4}$ : (i) photoinduced activation of $\mathrm{g}-\mathrm{C}_{3} \mathrm{~N}_{4}$, (ii-iv) electron transfers from amine to $\mathrm{g}-\mathrm{C}_{3} \mathrm{~N}_{4}$, from $\mathrm{g}-\mathrm{C}_{3} \mathrm{~N}_{4}$ to $\mathrm{O}_{2}$, and from $\mathrm{g}-\mathrm{C}_{3} \mathrm{~N}_{4}$ to the trithiocarbonate (TTC), respectively; ( $v$ ) initiation and chain propagation of monomers (M); and (vi) reversible degenerative chain transfer (RAFT process). (b) size exclusion chromatography (SEC) traces of PET-RAFT polymerization derived poly(methyl acrylate) (PMA) with different degree of polymerization (DP) (DP $=100,200$, and 400). (c) SEC traces of PMA-b-poly(n-butyl acrylate) (PBA) diblock copolymer product and precursor (Reprinted with permission. ${ }^{61}$ Copyright 2017 American Chemical Society).

molecular dispersity $(Ð)$. A work reported by Qiao and coworkers introduced $\mathrm{g}-\mathrm{C}_{3} \mathrm{~N}_{4}$ /amine cocatalysts to a photoinduced electron/ energy transfer (PET) oxygen-tolerant reversible additionfragmentation chain transfer (RAFT) polymerization (Fig. 1). ${ }^{61}$ $\mathrm{g}-\mathrm{C}_{3} \mathrm{~N}_{4}$ was employed directly without prior deoxygenation of the reaction mixture to enable electron transfer from added tertiary amines (i.e. triethanolamine TEOA) to dissolved molecular oxygen. Thus, the trithiocarbonate (TTC) chain transfer agents were activated via oxygen reduction, followed by polymerization of acrylic species such as MA, n-butyl acrylate (BA) and watersoluble monomer $N, N$-dimethylacrylamide (DMA) (Fig. 1a). In the mechanism, molecular oxygen takes a prominent part in the photoredox cycle. Thus, benign reaction conditions under visible light, without deoxygenation of monomer solution, are achieved that are time consuming in the common case. Polymers with different polymerization degree could be achieved easily with this process as shown via size exclusion chromatography (SEC) (Fig. 1b). Moreover, block copolymers could be synthesized, e.g. PMA- $b$-PBA (Fig. 1c). Such PET-RAFT approach had merits of low toxicity, organic solvent tolerance and facile postpolymerization removal of the catalyst. ${ }^{62}$

Very recently, our group conducted dithiol-ene click reactions between lignocellulosic biomass-derived 4-pentenoic acid (4-PEA) and different dithiols using $\mathrm{g}-\mathrm{C}_{3} \mathrm{~N}_{4}$ as photocatalyst. ${ }^{63}$ Visible light induced click chemistry was utilized for the reactions between 4-PEA and 1,2-ethanedithiol (EDT), 2,2-(ethylenedioxy)-diethanethiol (EDDT), and 1,4-benzenedimethanethiol (BDT) leading to polymers in high yields and purities in order to reduce the dependence on petroleum-derived monomers. 
Moreover, $\mathrm{g}-\mathrm{C}_{3} \mathrm{~N}_{4}$ has been utilized as photoinitiator to fabricate $\mathrm{g}-\mathrm{C}_{3} \mathrm{~N}_{4}$-based polymer composites under light irradiation via a "grafting from" method, which is defined as chain growth via monomer propagation starting from a surface, i.e. here a g- $\mathrm{C}_{3} \mathrm{~N}_{4}$ surface. As radicals are produced by $\mathrm{g}-\mathrm{C}_{3} \mathrm{~N}_{4}$ under visible light irradiation, the grafting occurs presumably via the presence of uncondensed $-\mathrm{NH}_{2}$ or $-\mathrm{NH}$ groups at $\mathrm{g}-\mathrm{C}_{3} \mathrm{~N}_{4}$. These groups act as active sites to initiate polymer chain growth from $\mathrm{g}-\mathrm{C}_{3} \mathrm{~N}_{4}$ surface. In such a way, g- $\mathrm{C}_{3} \mathrm{~N}_{4}$-based polymer hybrid materials are fabricated, with the firmly attachment of polymer on to $\mathrm{g}-\mathrm{C}_{3} \mathrm{~N}_{4}$ surface, which facilitates further applications.

Another area where $\mathrm{g}-\mathrm{C}_{3} \mathrm{~N}_{4}$ photoinitiation is widely utilized is hydrogel formation. For hydrogel formation the same initiation mechanisms are exploited, i.e. radicals are formed on the surface of g- $\mathrm{C}_{3} \mathrm{~N}_{4}$ with phototreatment and $\mathrm{g}-\mathrm{C}_{3} \mathrm{~N}_{4}$ directly participates in the hydrogelation without electron transfer or co-initiator addition. The formation of hydrogels will be covered in detail in Section 5. Most notably, hydrogels could be formed without addition of external crosslinker, which indicates initiation from the $\mathrm{g}-\mathrm{C}_{3} \mathrm{~N}_{4}$ surface and covalent incorporation of $\mathrm{g}-\mathrm{C}_{3} \mathrm{~N}_{4}$ into the gel network. ${ }^{64}$ As such, these findings support the mechanism found for $\mathrm{g}-\mathrm{C}_{3} \mathrm{~N}_{4}$ initiated polymerization without addition of radical transfer agent.

\section{Carbon nitride dispersibility}

A major issue for the application of $\mathrm{g}-\mathrm{C}_{3} \mathrm{~N}_{4}$ is its poor dispersibility of the pure material. As the strong van der Waals interactions $(\pi-\pi$ stacking) of $\mathrm{g}-\mathrm{C}_{3} \mathrm{~N}_{4}$ sheets causes the agglomeration in the liquid phase. Thus, dispersibility in organic as well as aqueous environment is rather low, ${ }^{65}$ and results in restricted applicability as well as activity. ${ }^{65,66}$ Especially the formation of thin $(2-3 \mathrm{~nm})$ semiconductor films are of great interest for optoelectronics and photovoltaics. However, to form such g- $\mathrm{C}_{3} \mathrm{~N}_{4}$ films rather elaborate methods like chemical vapor deposition have to be utilized. ${ }^{67,68}$ A solution based process would be simpler and suitable for many real life applications, and therefore, attention has been addressed to enhance dispersibility of $\mathrm{g}-\mathrm{C}_{3} \mathrm{~N}_{4}$ powder. Several researchers focused on exfoliation of the bulk g- $\mathrm{C}_{3} \mathrm{~N}_{4}$ into thin sheets, in which the electrostatic repulsion between g- $\mathrm{C}_{3} \mathrm{~N}_{4}$ sheets can enable the formation of well-dispersed $\mathrm{g}-\mathrm{C}_{3} \mathrm{~N}_{4}$ colloids. Hence, stable dispersions of $\mathrm{g}-\mathrm{C}_{3} \mathrm{~N}_{4}$ can be prepared, yet the achievable concentration of dispersed $\mathrm{g}-\mathrm{C}_{3} \mathrm{~N}_{4}$ is rather low. A route to disperse $\mathrm{g}-\mathrm{C}_{3} \mathrm{~N}_{4}$ is via additives or physical treatment, e.g. via addition solvents in the dispersion step, ${ }^{69,70}$ hydrothermal treatment, ${ }^{71}$ chemical oxidation, ${ }^{72}$ thermal oxidation ${ }^{73}$ or ultrasonication. ${ }^{74}$ The other option is chemical modification via attachment of molecular moieties. On one hand, with the attachment of charged groups to the $\mathrm{g}-\mathrm{C}_{3} \mathrm{~N}_{4}$ surface, the stability of dispersed $\mathrm{g}-\mathrm{C}_{3} \mathrm{~N}_{4}$ nanosheets can be increased in aqueous environment via electrostatic repulsion. On the other hand, attachment of hydrophilic polymers can stabilize g- $\mathrm{C}_{3} \mathrm{~N}_{4}$ in dispersion via steric repulsion in aqueous dispersion. In organic solvent, the dispersibility of $\mathrm{g}-\mathrm{C}_{3} \mathrm{~N}_{4}$ can be increased via the attachment of organo soluble small molecules or polymers, where steric repulsion leads to enhanced stability of the dispersion.

A reported option is the complex formation with organic modified montmorillonite to facilitate enhanced stability in organic environment, which was utilized to form poly(styrene) (PS)/g- $\mathrm{C}_{3} \mathrm{~N}_{4}$ composites. ${ }^{77}$ Exfoliating $\mathrm{g}-\mathrm{C}_{3} \mathrm{~N}_{4}$ in 1,3-butanediol results in graphene-like $\mathrm{g}-\mathrm{C}_{3} \mathrm{~N}_{4}$ with around 2-6 layers of $\mathrm{g}-\mathrm{C}_{3} \mathrm{~N}_{4}$ with a thickness of circa 1-2 nm. However, ultrasonication for 24 hours and possibility to exfoliate only low amount of $g-\mathrm{C}_{3} \mathrm{~N}_{4}$ is the drawback of the approach. ${ }^{31}$

Another functionalization route to enhance dispersibility of $\mathrm{g}-\mathrm{C}_{3} \mathrm{~N}_{4}$ is by pre-condensation or post-condensation. In the case of pre-condensation a specific monomer mixture is used, for example additional phenyl moieties are introduced into the system. ${ }^{78}$ The utilization of a phenyl-functional precursor for g- $\mathrm{C}_{3} \mathrm{~N}_{4}$ synthesis prevents growth of larger $\mathrm{g}-\mathrm{C}_{3} \mathrm{~N}_{4}$ sheets which results in quantum dot structure that possess enhanced dispersibility compared to traditional g- $\mathrm{C}_{3} \mathrm{~N}_{4}$ sheets. Another approach is post-condensation functionalization that allows the introduction of various functional groups via chemical treatment, e.g. oligo(ethylene glycol) (oligoEG) (Fig. 2). ${ }^{75}$ Well dispersed colloids (Fig. 2a) with high biocompatibility and bioimaging properties could be achieved in that way (Fig. 2b). As such Kim and coworkers firstly oxidized $\mathrm{g}-\mathrm{C}_{3} \mathrm{~N}_{4}$ via $\mathrm{KMnO}_{4}$ and exfoliated it via ultrasonication, followed by covalent modification with monomesylated oligoEG. Attachment of oligoEG resulted in oligoEG-modified $\mathrm{g}-\mathrm{C}_{3} \mathrm{~N}_{4}$ sheets, which exhibited water dispersibility to be utilized for bioimaging. Oxygen plasma can be employed for introducing protonated hydroxylamine functional groups to $\mathrm{g}-\mathrm{C}_{3} \mathrm{~N}_{4}$ surface, which provides extreme hydrophilic character. ${ }^{79}$ Other functional groups such as sulfonic acid, ${ }^{80}$ hydroxyl $^{81}$ or aromatic groups ${ }^{48}$ can also be introduced for enhancing dispersibility of $\mathrm{g}-\mathrm{C}_{3} \mathrm{~N}_{4}$ sheets. However, alternative facile and less stringent routes to enhance dispersibility with high $\mathrm{g}-\mathrm{C}_{3} \mathrm{~N}_{4}$ solid content yields would be beneficial.

To improve dispersibility, we investigated solvent mixtures (Scheme 3a). The mixture of water and EG in equal volume enabled dispersion with significant $\mathrm{g}-\mathrm{C}_{3} \mathrm{~N}_{4}$ weight contents of up to $4 \mathrm{wt} \%$, compared to a maximum of $0.6 \mathrm{wt} \%$ in pure water. $\mathrm{g}-\mathrm{C}_{3} \mathrm{~N}_{4}$ is a photoactive compound that is a semiconductor and thus forms electron/hole pairs via light irradiation. This feature was exploited to perform photo-initiated polymerization reactions (Scheme $3 \mathrm{~b}$ ). Thus, to improve dispersibility of $\mathrm{g}-\mathrm{C}_{3} \mathrm{~N}_{4}$ further, a polymerization approach was introduced via $\mathrm{g}-\mathrm{C}_{3} \mathrm{~N}_{4}$ photoinitiation. DMA was added to a $\mathrm{g}-\mathrm{C}_{3} \mathrm{~N}_{4}$ dispersion in EG/water and treated with visible light, which led to a weakly associated gel. The viscous gel was formed from PDMA grafted $\mathrm{g}-\mathrm{C}_{3} \mathrm{~N}_{4}$ and could be easily dispersed in water. In addition, such dispersions possess high stability (up to 2 months) due to steric stabilization of g- $\mathrm{C}_{3} \mathrm{~N}_{4}$ colloids. $^{82}$

Furthermore, pre-formed ene end functionalized polymers could be grafted onto g- $\mathrm{C}_{3} \mathrm{~N}_{4}$ as well (Scheme 3c, refer to Section 4 as well). A way to obtain dispersible-CN via a more exact approach that does not rely on polymerization was also studied. For that, the parent $\mathrm{g}-\mathrm{C}_{3} \mathrm{~N}_{4}$ is dispersed in aqueous or organic solution, an ene-compound is added, and the mixture subjected to visible 
(a)

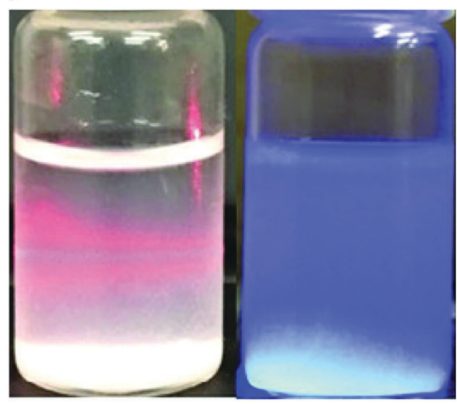

(b)

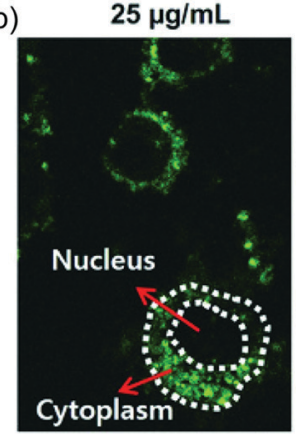

$50 \mu \mathrm{g} / \mathrm{mL}$

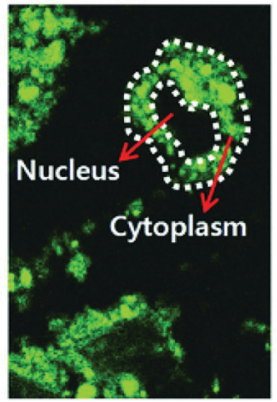

$100 \mu \mathrm{g} / \mathrm{mL}$

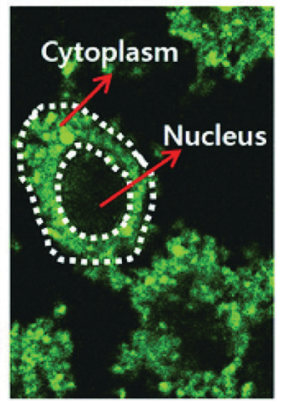

(c)
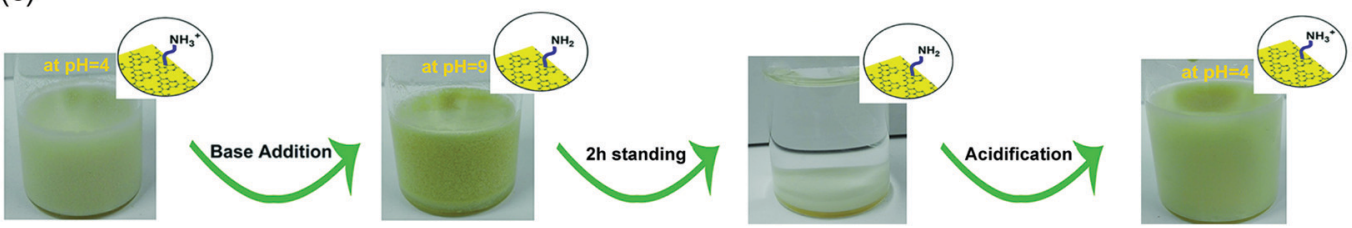

Fig. 2 (a) A photo of suspensions of oligo(ethylene glycol) (oligoEG)-grafted g- $\mathrm{C}_{3} \mathrm{~N}_{4}$ in water showing the Tyndall effect (left) and fluorescence (right). (b) Confocal fluorescence microscopy image of RAW264.7 cells after incubation at different concentrations with the oligoEG-g- $\mathrm{C}_{3} \mathrm{~N}_{4}$ nanodots $(25,50$, and $100 \mu \mathrm{g} \mathrm{mL}{ }^{-1}$ ) for $24 \mathrm{~h}$ at $37{ }^{\circ} \mathrm{C}$ (Reprinted with permission. ${ }^{75}$ Copyright 2018 John Wiley and Sons). (c) Allylamine-modified g- $\mathrm{C}_{3} \mathrm{~N}_{4}$ in water (1 wt\%) at acidic $\mathrm{pH}(\mathrm{pH}=4)$, observation of immediate precipitation after base addition $(\mathrm{pH}=9)$, complete sedimentation after standing for $2 \mathrm{~h}$, and redispersion after reacidification $\left(\mathrm{pH}=4\right.$ ) (Reprinted with permission. ${ }^{76}$ Copyright 2017 American Chemical Society).

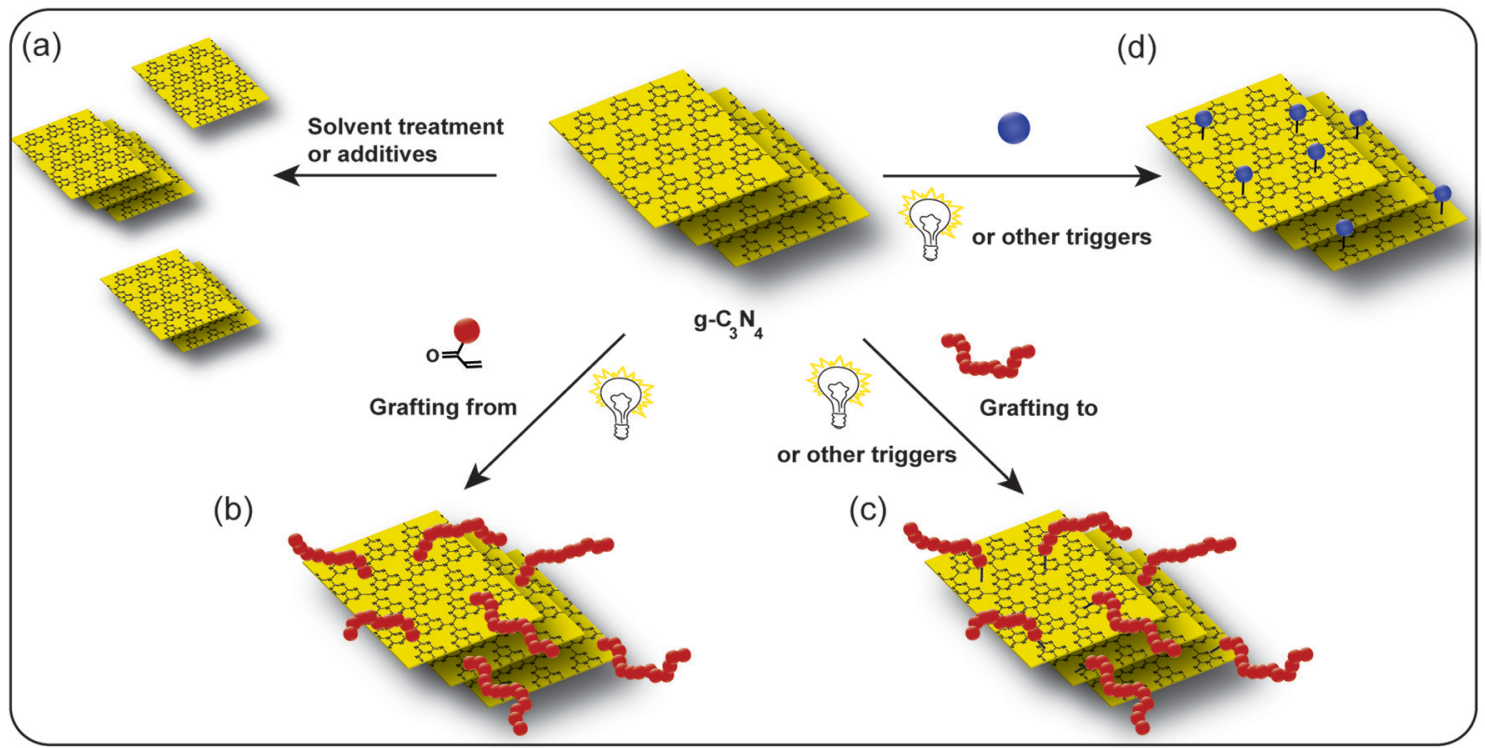

Scheme 3 Approaches towards improvement of $\mathrm{g}-\mathrm{C}_{3} \mathrm{~N}_{4}$ dispersibility: (a) utilization of solvent mixtures (e.g. water/ethylene glycol (EG)), (b) grafting polymers from $\mathrm{g}-\mathrm{C}_{3} \mathrm{~N}_{4}$ via free radical polymerization, (c) grafting polymers to $\mathrm{g}-\mathrm{C}_{3} \mathrm{~N}_{4}$ via double bond containing preformed polymers and (d) photofunctionalization with ene containing small molecules.

light (Scheme $3 \mathrm{~d}$ ) ${ }^{76}$ Due to the radical formation at the $\mathrm{g}-\mathrm{C}_{3} \mathrm{~N}_{4}$ surface, addition of the ene-compound takes place. To prevent polymerization of the added small molecule, allylic compounds were utilized as they possess no propagation tendency. Hence, the molecules are grafted on $\mathrm{g}-\mathrm{C}_{3} \mathrm{~N}_{4}$ directly. Notable, the modification of the $\mathrm{g}-\mathrm{C}_{3} \mathrm{~N}_{4}$ surface chemistry significantly influences the dispersion properties of $\mathrm{g}-\mathrm{C}_{3} \mathrm{~N}_{4}$. For example, 3-allyloxy-2-hydroxy-1-propanesulfonic acid sodium salt (AHPA) was grafted on $\mathrm{g}-\mathrm{C}_{3} \mathrm{~N}_{4}$ to improve water dispersibility with up to $10 \mathrm{wt} \%$ while stable dispersions were obtained, e.g. for 48 hours.
Grafting of 11-decene led to organo dispersibility of up to $2 \mathrm{wt} \%$ $\mathrm{g}^{-} \mathrm{C}_{3} \mathrm{~N}_{4}$ in solvents like THF, DCM or toluene. In addition, $\mathrm{pH}-$ sensitive dispersibility could be introduced via allylamine that leads to dispersibility in acidic solution and precipitation at basic $\mathrm{pH}$ (Fig. 2c). Recently, methyl vinyl thiazole was grafted onto g- $\mathrm{C}_{3} \mathrm{~N}_{4}$, which led to a significant improvement of organo dispersibility via an intrinsic electrostatic stabilization mechanism. The two components create an autonomous donor-acceptor type structure and enhance excited electron-hole separation. ${ }^{83}$ Moreover, surface functionality has a profound effect on photocatalytic activity as well. 


\section{Carbon nitride/polymer hybrid materials}

Polymers are playing a significant role in industry as well as daily life and are widely investigated. Especially, polymer materials with functional properties are of focal interest today, such as self-healing, ${ }^{84}$ stimuli response, ${ }^{85}$ biodegradability ${ }^{86}$ or electrical conductivity. ${ }^{87}$ A combination of traditional polymers with the novel metal-free semiconductor $\mathrm{g}-\mathrm{C}_{3} \mathrm{~N}_{4}$ materials is highly worthwhile (Scheme 4 ). $\mathrm{g}-\mathrm{C}_{3} \mathrm{~N}_{4}$ is widely investigated as a metal-free semiconductor, but poor processing inhibits a scale-up of utilization, which is an issue for applicability. ${ }^{88,89}$ A combination of $\mathrm{g}-\mathrm{C}_{3} \mathrm{~N}_{4}$ with polymers appears to be a useful solution, ${ }^{90,91}$ as properties of both material classes can be coupled via combination of the individual parts. ${ }^{92}$ Due to $g-\mathrm{C}_{3} \mathrm{~N}_{4}$, photocatalytic, photoluminescence, as well as enhanced physical and mechanical properties are obtained, while the polymers bring improved processability or conductivity. There are several ways to fabricate g- $\mathrm{C}_{3} \mathrm{~N}_{4} /$ polymer hybrid materials (Scheme 4a). (1) Physical absorption or deposition, mostly prepared in the liquid phase. In the same way, one can also list blending of both materials. (2) "Grafting from" method, in which monomers are polymerized from the $\mathrm{g}-\mathrm{C}_{3} \mathrm{~N}_{4}$ surface. (3) "Grafting to" method that is based on chemical bond formation between reactive sites on $\mathrm{g}-\mathrm{C}_{3} \mathrm{~N}_{4}$ and active polymer end groups.

Such $\mathrm{g}-\mathrm{C}_{3} \mathrm{~N}_{4}$ /polymer hybrid materials can be utilized for various applications as discussed in Section 4.1, e.g. photocatalytic $\mathrm{H}_{2}$ evolution, photocatalysis, biosensors, electrochemical energy storage according to different type of the hybrids (Scheme 4b). As film and membrane materials are commonly applied to electrochemical area and particles are mostly used in biosensors, Table 1 shows the summary of specific g- $\mathrm{C}_{3} \mathrm{~N}_{4} /$ polymer compositions and their application area as well as the specific enhanced properties and performance compared to the single component $\mathrm{g}-\mathrm{C}_{3} \mathrm{~N}_{4}$. In addition, polymers can be utilized to include $\mathrm{g}-\mathrm{C}_{3} \mathrm{~N}_{4}$ into specific material morphologies, e.g. spherical particles or thin films as presented in Section 4.2. Moreover, g- $\mathrm{C}_{3} \mathrm{~N}_{4}$ /hybridization enables the improvement of polymer properties, especially mechanical properties as shown in Section 4.3. As such, polymers and $\mathrm{g}-\mathrm{C}_{3} \mathrm{~N}_{4}$ can be utilized for mutual benefit. On one hand, polymers improve processing of $g-\mathrm{C}_{3} \mathrm{~N}_{4}$ amongst other properties. On the other hand, g- $\mathrm{C}_{3} \mathrm{~N}_{4}$ improves the properties of polymer materials, e.g. the mechanical properties.

A significant issue with polymer hybrids and composites is the compatibility of polymer and the mixed-in material. In the case of $\mathrm{g}-\mathrm{C}_{3} \mathrm{~N}_{4}$, favorable interactions are present in many cases. For example, $\mathrm{g}-\mathrm{C}_{3} \mathrm{~N}_{4}$ is prone to establish $\pi-\pi$ interactions with polymers like PS or poly(benzyl methacrylate) (PBMA). On the other hand, $\mathrm{g}-\mathrm{C}_{3} \mathrm{~N}_{4}$ contains polar groups at the edges, which allows interactions (mostly hydrogen bonding) with polar polymers like PDMA or poly(2-hydroxyethyl methacrylate) (PHEMA).

\subsection{Applications of $\mathrm{g}-\mathrm{C}_{3} \mathrm{~N}_{4} /$ polymer hybrid materials}

g- $\mathrm{C}_{3} \mathrm{~N}_{4}$ /polymer hybrids as photocatalysts for $\mathrm{H}_{2}$ evolution and $\mathrm{CO}_{2}$ reduction. One of the major applications of $\mathrm{g}-\mathrm{C}_{3} \mathrm{~N}_{4}$ for photocatalysis is their employment as visible-light-driven water splitting photocatalyst for $\mathrm{H}_{2}$ evolution. Low conductivity and high recombination rates of photoinduced electrons and holes significantly limits the production of $\mathrm{H}_{2}$ and merging $\mathrm{g}-\mathrm{C}_{3} \mathrm{~N}_{4}$ with conductive polymers is one of the efficient strategies to

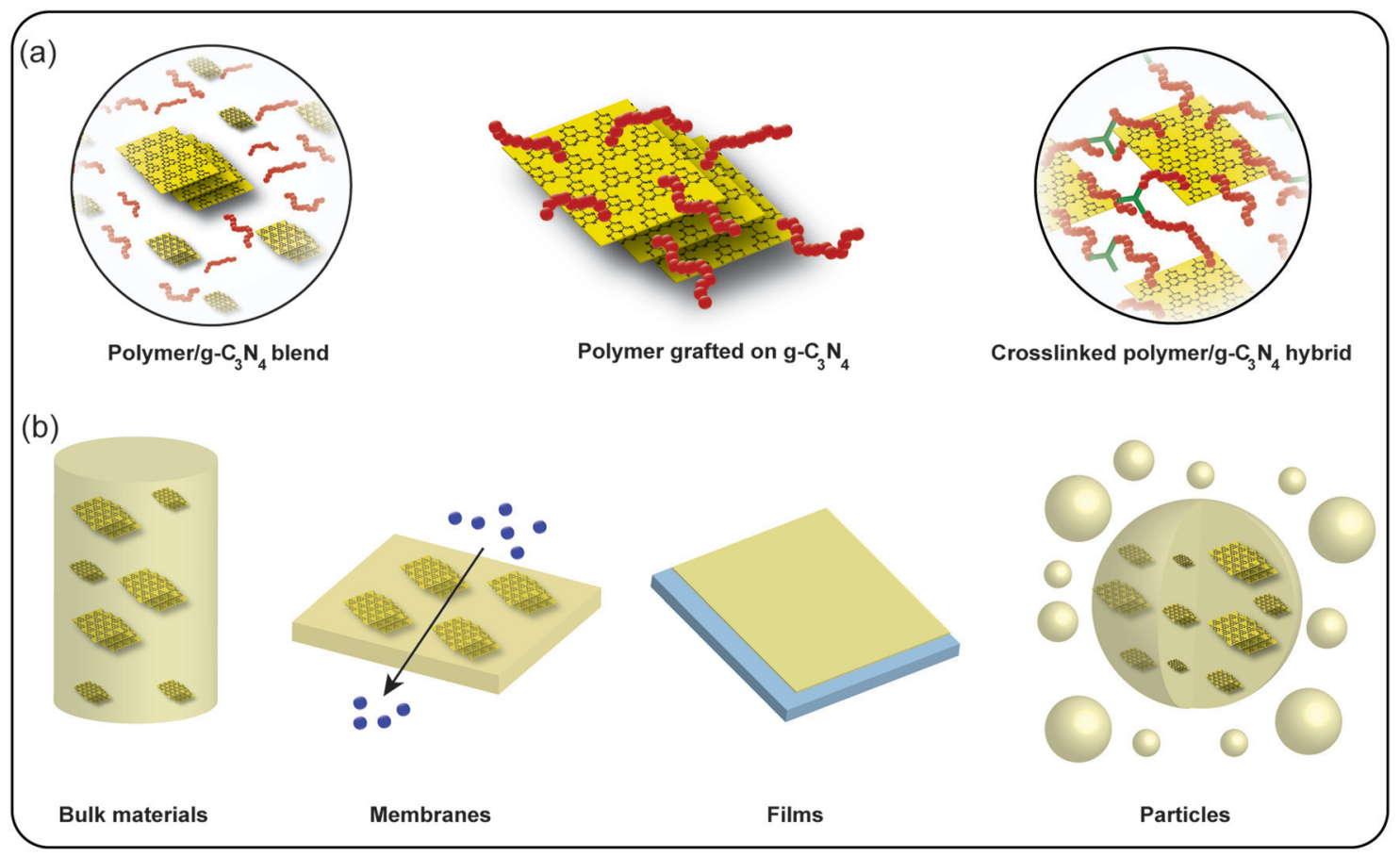

Scheme 4 Approaches for polymer/g- $C_{3} N_{4}$ modification: (a) strategies of embedding $g-C_{3} N_{4}$ in polymers via blending, grafting as well as grafting/ crosslinking approaches and (b) morphology types of $\mathrm{g}-\mathrm{C}_{3} \mathrm{~N}_{4} /$ polymer hybrids, i.e. bulk materials, membranes, films and particles. 


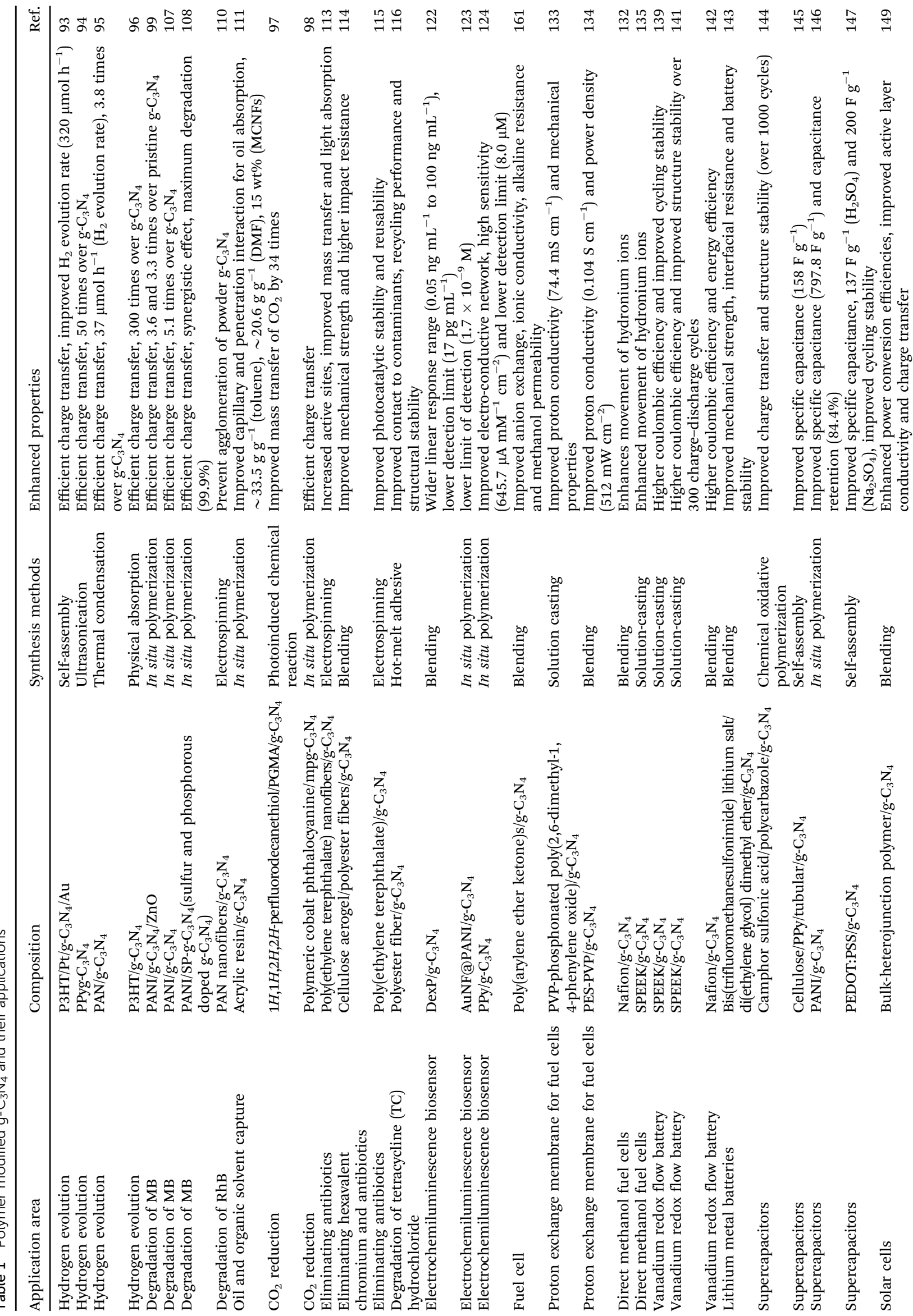


overcome these issues. Due to the excellent solubility, processability and long-term stability of polymer semiconductors, such hybrid materials can significantly improve the photoelectric properties of $\mathrm{g}-\mathrm{C}_{3} \mathrm{~N}_{4}$. The combination of $\mathrm{g}-\mathrm{C}_{3} \mathrm{~N}_{4}$ with conductive polymers, e.g. poly(3-hexylthiophene) (P3HT), ${ }^{93}$ poly(pyrrole) $(\mathrm{PPy})^{94}$ or poly(aniline) (PANI), ${ }^{95}$ is usually achieved via physical interactions, self-assembly or thermal deposition methods. As g- $\mathrm{C}_{3} \mathrm{~N}_{4}$ possesses a stacked 2-dimensional (2D) structure and van der Waals interactions between $g-\mathrm{C}_{3} \mathrm{~N}_{4}$ sheets, with the presence of $-\mathrm{NH}_{2},-\mathrm{NH}$ or $-\mathrm{OH}$ on the edge with a slight negative surface charge, physisorption of polymers to $\mathrm{g}-\mathrm{C}_{3} \mathrm{~N}_{4}$ surface via weak van der Waals or electrostatic interactions is enabled.

For example, Yan and coworkers combined P3HT and g- $\mathrm{C}_{3} \mathrm{~N}_{4}$ by impregnating $\mathrm{g}-\mathrm{C}_{3} \mathrm{~N}_{4}$ with a chloroform solution of $\mathrm{P} 3 \mathrm{HT}$ overnight, followed by evaporation of the solvent, which resulted in physical attachment of $\mathrm{P} 3 \mathrm{HT}$ to $\mathrm{g}-\mathrm{C}_{3} \mathrm{~N}_{4}$ surface (Fig. 3a). ${ }^{96}$ With the increased deposition of P3HT, a remarkable increase of $\mathrm{H}_{2}$ evolution of 300 times was achieved utilizing $\mathrm{Na}_{2} \mathrm{~S}$ and $\mathrm{Na}_{2} \mathrm{SO}_{3}$ as electron donors. The improved catalytic activity was attributed to the enhanced electron conductivity after P3HT incorporation. Later, the same group established a $\mathrm{g}-\mathrm{C}_{3} \mathrm{~N}_{4} / \mathrm{Au} / \mathrm{P} 3 \mathrm{HT} / \mathrm{Pt}$ layer structure using a self-assembly method. ${ }^{93}$ A tight $\mathrm{g}-\mathrm{C}_{3} \mathrm{~N}_{4} / \mathrm{Au}$ conjunction was formed by photodeposition, then P3HT/Pt was combined with $\mathrm{g}-\mathrm{C}_{3} \mathrm{~N}_{4} / \mathrm{Au}$ due to the formation of $\mathrm{Au}$-sulfur association between $\mathrm{Au}$ on $\mathrm{g}-\mathrm{C}_{3} \mathrm{~N}_{4}$ and sulfur in the P3HT structure. Thus, chemical bonds were used instead of physical adsorption to ensure a tight junction between the individual $\mathrm{g}^{-} \mathrm{C}_{3} \mathrm{~N}_{4}$ and P3HT layers. Such layered structures were demonstrated to be efficient for the separation of photoinduced electron-hole pairs and for $\mathrm{H}_{2}$ evolution. (a) vs. SHE

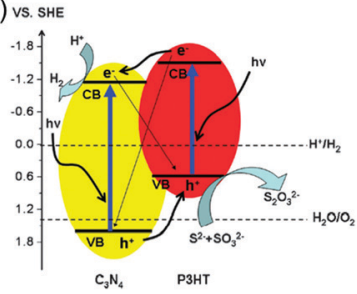

(c)

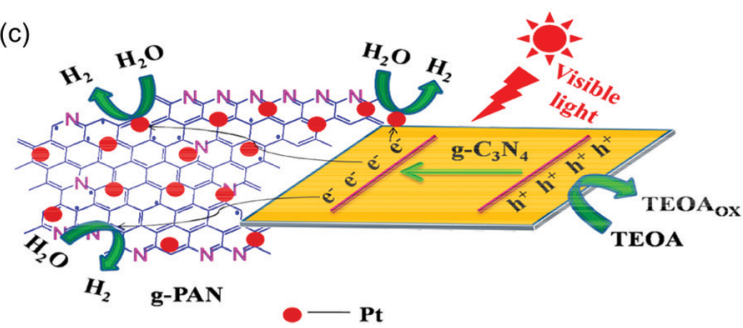

Fig. 3 (a) A proposed mechanism of visible light-induced $\mathrm{H}_{2}$ evolution on g- ${ }_{3} \mathrm{~N}_{4}$-poly(3-hexylthiophene) (P3HT) polymer composite photocatalysts (Reprinted with permission. ${ }^{96}$ Copyright 2011 Royal Society of Chemistry). (b) The mechanism to understand the role of the dispersed poly(pyrrole) (PPy) nanoparticles in enhancing the photocatalytic activity of PPy-g- $\mathrm{C}_{3} \mathrm{~N}_{4}$ for $\mathrm{H}_{2}$ evolution (Reprinted with permission. ${ }^{94}$ Copyright 2013 Royal Society of Chemistry.) (c) Illustration for the enhanced photogenerated charge carriers separation and transfer in graphitized-poly(acrylonitrile) (g-PAN)/g- $\mathrm{C}_{3} \mathrm{~N}_{4}$ composites under visible light irradiation $(\lambda>400 \mathrm{~nm}$ ) (Reprinted with permission. ${ }^{95}$ Copyright 2014 American Chemical Society).
Nevertheless, P3HT has the drawback of a limited processability in aqueous media, which is the preferred choice for $\mathrm{g}-\mathrm{C}_{3} \mathrm{~N}_{4}$ so far. An option to circumvent that problem is to switch to PPy, which possesses high stability in the oxidized state as well as high conductivity. For example, Chen and coworkers reported the loading of highly dispersed PPy nanoparticles onto the g- $\mathrm{C}_{3} \mathrm{~N}_{4}$ surface via sonochemical approach in a physical attachment (Fig. 3b). ${ }^{94}$ PPy-g- $\mathrm{C}_{3} \mathrm{~N}_{4}$ suspension was treated with ultrasonication for 12 hours and drying at $80{ }^{\circ} \mathrm{C}$. The addition of PPy nanoparticles showed no effects on the absorption edge of $\mathrm{g}-\mathrm{C}_{3} \mathrm{~N}_{4}$ but influenced the intensity of the $\mathrm{g}-\mathrm{C}_{3} \mathrm{~N}_{4}$ emission peak, indicating the more effective separation of photogenerated electrons and holes in PPy-g- $\mathrm{C}_{3} \mathrm{~N}_{4}$ compared to pristine $\mathrm{g}-\mathrm{C}_{3} \mathrm{~N}_{4}$. The activity of $\mathrm{H}_{2}$ evolution was dramatically improved with the increasing loading amount of PPy. Furthermore, graphitized-poly(acrylonitrile) (g-PAN) nanosheets were deposited on $\mathrm{g}-\mathrm{C}_{3} \mathrm{~N}_{4}$ via one step thermal condensation method as reported by Hao and coworkers (Fig. 3c). ${ }^{95}$ Simple mixing of $\mathrm{g}-\mathrm{C}_{3} \mathrm{~N}_{4}$ precursors with PAN and thermal treatment under $650{ }^{\circ} \mathrm{C}$ led to graphitization of PAN. Thus, a layered structure of g-PAN $/ \mathrm{g}-\mathrm{C}_{3} \mathrm{~N}_{4}$ was obtained. Compared to aggregated polymer morphologies, the g-PAN with aromatic conjugated structure possesses more reactive sites and short diffusion distance, which decreases the recombination rate of photogenerated charge carriers. Hence g-PAN acts as an effective electron transfer channel in the g-PAN/g- $\mathrm{C}_{3} \mathrm{~N}_{4}$ composites and obviously enhanced the photocatalytic performance for $\mathrm{H}_{2}$ evolution.

Very recently, hydrophobic polymer grafted g- $\mathrm{C}_{3} \mathrm{~N}_{4}$ was employed as a three-phase photocatalyst for enhanced selectivity and activity of $\mathrm{CO}_{2}$ reduction. ${ }^{97}$ Hydrophobic $1 \mathrm{H}, 1 \mathrm{H}, 2 \mathrm{H}, 2 \mathrm{H}$-perfluorodecanethiol was utilized to modify poly(glycidyl methacrylate) (PGMA) grafted on CM (pDFe-PGMA/CM) via thiol-epoxy addition reaction. Subsequently, an in situ photoloading method was applied for loading Pt on the pDFe-PGMA/CM surface. A threephase contact photocatalyst of $\mathrm{CO}_{2}$ (gas), $\mathrm{H}_{2} \mathrm{O}$ (liquid) and catalyst (solid) was fabricated to enable a high concentration of $\mathrm{CO}_{2}$ molecules on the catalyst surface directly. Moreover, the mass transfer limitation of $\mathrm{CO}_{2}$ was overcome due to the hydrophobic catalytic surface, which contributed to an enhanced $\mathrm{CO}_{2}$ reduction reaction and suppressed hydrogen evolution reaction. The observed efficiency was about 34 times higher than commonly achieved by hydrophilic catalysts. Reisner and Roy showed an avenue to $\mathrm{CO}_{2}$ reduction as well. ${ }^{98}$ In their experiments, mpg- $\mathrm{C}_{3} \mathrm{~N}_{4}$ was combined with a polymeric cobalt phthalocyanine catalyst. To obtain a good interfacial contact, 1,2,4,5-tetracyanobenzene together with $\mathrm{Co}^{2+}$ was polymerized directly in the presence of mpg- $\mathrm{C}_{3} \mathrm{~N}_{4}$. A synergistic effect of $\mathrm{CN}$ porosity, solar energy harvesting and photosensitization facilitated remarkable activity of the phthalocyanine catalyst in $\mathrm{CO}_{2}$ reduction under visible light.

g- $\mathrm{C}_{3} \mathrm{~N}_{4}$ /polymer hybrids as photocatalysts for water contamination degradation. In addition to $\mathrm{H}_{2}$ evolution, other photocatalytic tasks can be performed with $\mathrm{g}-\mathrm{C}_{3} \mathrm{~N}_{4} /$ polymer hybrids as well. g- $\mathrm{C}_{3} \mathrm{~N}_{4}$ /polymer hybrid materials show improved performance towards water contaminant degradation too. ${ }^{99}$ For example, organic dyes like Methyl red, Congo red or methylene blue (MB) ${ }^{100}$ are responsible for wastewater contamination, as they have been 
used for dyeing fabrics. Due to their high solubility in water, effective purification processes are needed as otherwise these dyes cause significant contamination in wastewater. Moreover, they act as easy recognizable substances to probe photocatalytic activity. Several strategies were attempted to degrade dyes so far, such as ion exchange, electrochemical treatment, adsorption, membrane separation and catalytic reduction. ${ }^{101-103}$ Amongst the approaches to degrade dyes in water, g- $\mathrm{C}_{3} \mathrm{~N}_{4}$ based polymer hybrid composites via photocatalytic means show remarkable advantages such as being low-cost, ease of processability and recyclability as well as activity under visible light. ${ }^{104,105} \mathrm{Zhu}$ and coworkers synthesized PANI nanofibers between $\mathrm{g}-\mathrm{C}_{3} \mathrm{~N}_{4}$ nanosheets by polymerizing aniline in the presence of ammonium persulfate (APS). ${ }^{106}$ Coral-like PANI nanofibers were grown between $\mathrm{g}-\mathrm{C}_{3} \mathrm{~N}_{4}$ sheets as monomers were in situ polymerized on the surface of $\mathrm{g}-\mathrm{C}_{3} \mathrm{~N}_{4}$ to form a hydrogel material (Fig. 4a). Thus, a 3D hierarchical structure of the composite hydrogel was constructed with excellent contaminants degradation properties, 5.1-fold higher than that of pure g- $\mathrm{C}_{3} \mathrm{~N}_{4}$ (Fig. 4b). In a similar way, Liu and coworkers fabricated PANI-g- $\mathrm{C}_{3} \mathrm{~N}_{4}$ composite photocatalysts by in situ oxidative polymerization of aniline onto g- $\mathrm{C}_{3} \mathrm{~N}_{4}$ powder in the presence of APS as initiator. ${ }^{107}$ There, g- $\mathrm{C}_{3} \mathrm{~N}_{4}$ was employed as a substrate and to serve as loci for monomer propagation and polymer chains propagated on the $\mathrm{g}-\mathrm{C}_{3} \mathrm{~N}_{4}$ surface. Finally, improved photodegradation properties toward MB were found due to the enhanced electron-hole separation induced by the synergistic effect between PANI and $\mathrm{g}-\mathrm{C}_{3} \mathrm{~N}_{4}$. Another hybrid material of PANI and $\mathrm{g}-\mathrm{C}_{3} \mathrm{~N}_{4}$ was synthesized by Prakash and coworkers, who used sulfur and phosphorous co-doped g- $\mathrm{C}_{3} \mathrm{~N}_{4}$ ( $\left.\mathrm{SP}-\mathrm{g}-\mathrm{C}_{3} \mathrm{~N}_{4}\right)$ and covalently grafted PANI via oxidative polymerization. The SP-g- $\mathrm{C}_{3} \mathrm{~N}_{4}$-grafted with PANI also featured a tuned band gap structure with extended light absorption. Hence, more active sites for photogeneration of charge carriers at the interfaces were formed. Moreover, PANI possesses unique electron and hole transport property and excellent chemical stability, which leads to an improved utilization of visible light. Therefore, the as-prepared metal-free nanocomposite showed an outstanding photocatalytic activity for the degradation of $\mathrm{MB}^{108}$ Other water contamination can also be removed by $\mathrm{g}-\mathrm{C}_{3} \mathrm{~N}_{4} /$ polymer composites. Qian and coworkers combined porous $\mathrm{g}-\mathrm{C}_{3} \mathrm{~N}_{4}$ foams with acrylic resin for efficient oil and organic solvent capture. ${ }^{109}$ The $\mathrm{g}-\mathrm{C}_{3} \mathrm{~N}_{4}$ /acrylic resin showed high adsorption capacity, fast capture rate and good recyclability toward removing oils and organic solvent from water.

A good way to improve efficiency of $\mathrm{g}-\mathrm{C}_{3} \mathrm{~N}_{4}$-based waste water remediation by improved transport engineering is the incorporation into fiber structures. The group of Chen fabricated visible light responsive nanofibers based on PAN dispersed $\mathrm{g}-\mathrm{C}_{3} \mathrm{~N}_{4}$ via electrospinning, to disperse $\mathrm{g}-\mathrm{C}_{3} \mathrm{~N}_{4}$ and immobilized by PAN fiber structure. ${ }^{110}$ The $g-\mathrm{C}_{3} \mathrm{~N}_{4} / \mathrm{PAN}$ hybrids demonstrated efficient photocatalytic properties of Rhodamine B (RhB) degradation over a wide $\mathrm{pH}$ range and were recycled in a simple way. Othman and coworkers incorporated $\mathrm{g}-\mathrm{C}_{3} \mathrm{~N}_{4}$ into PAN nanofibers using electrospinning as well. ${ }^{111} \mathrm{~A}$ liquid-permeable self-supporting photocatalytic nanofiber was fabricated, demonstrating $85 \%$ degradation capability for purification of oil contaminated water under visible light irradiation. Liu and coworkers utilized electrospun PAN nanofibers to immobilize a g- $\mathrm{C}_{3} \mathrm{~N}_{4} / \mathrm{BiOI}$ heterojunction via a facile in site synthesis strategy. ${ }^{112}$ The efficient separation of the electron-hole pairs and strong absorption in the visible region of $\mathrm{PAN} / \mathrm{g}-\mathrm{C}_{3} \mathrm{~N}_{4} / \mathrm{BiOI}$ hybrids resulted in superior photocatalytic activity in the degradation of $\mathrm{RhB}$ and toxic $\mathrm{Cr}(\mathrm{vI})$ ions under visible-light. Moreover, the film-like and selfsupporting nanostructure enabled the hybrids for floating photocatalyst application.

An issue of growing interest is the removal of antibiotic contaminations in water, which can be tackled via g- $\mathrm{C}_{3} \mathrm{~N}_{4}$ photocatalysis as well. For example, g- $\mathrm{C}_{3} \mathrm{~N}_{4}$ @poly(ethylene terephthalate) nanofibers were fabricated using poly(ethylene terephthalate) as a support and polyethylene glycol (PEG) as a porogen via electrospinning, ${ }^{113}$ which is beneficial for catalyst-substrate contact. This work demonstrated high photocatalytic activity for the degradation of antibiotics such as sulfaquinoxaline and sulfadiazine under solar irradiation. Polyester fibers (from poly(ethylene terephthalate)) (a)

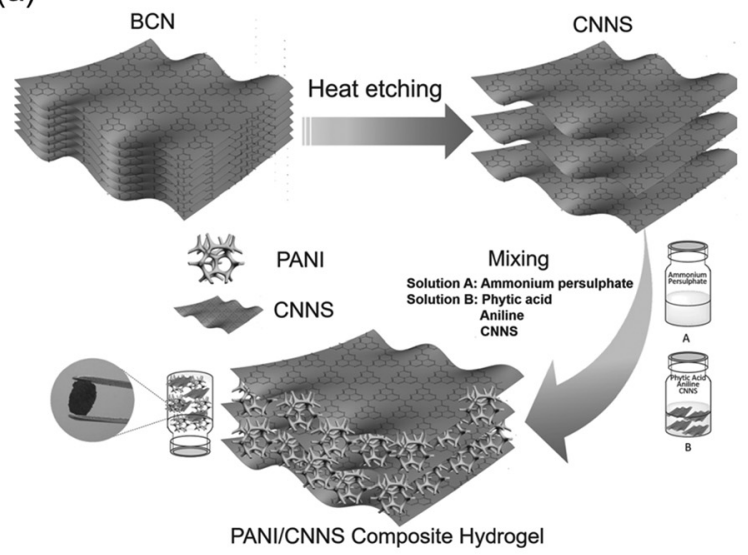

(b)

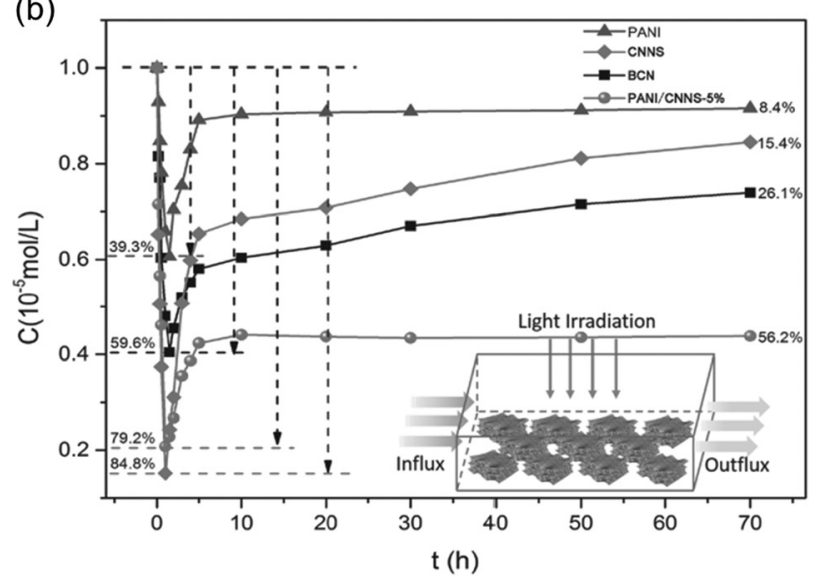

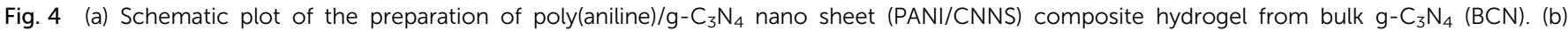

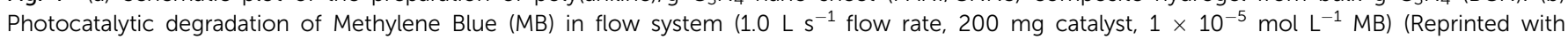
permission. ${ }^{106}$ Copyright 2016 John Wiley and Sons). 
were utilized to support cellulose (CA) containing nanosheet g- $\mathrm{C}_{3} \mathrm{~N}_{4}$ in another work as well, ${ }^{114}$ aerogel g- $\mathrm{C}_{3} \mathrm{~N}_{4} @ \mathrm{CA} /$ poly(ethylene terephthalate) for enhanced photocatalytic activity towards the removal of hexavalent chromium and antibiotics, simultaneously. Chen and coworkers used poly(ethylene terephthalate) as support for $\mathrm{g}-\mathrm{C}_{3} \mathrm{~N}_{4}$ via electrospinning and subsequently hydrothermal treatment, which enabled the exposure of $\mathrm{g}-\mathrm{C}_{3} \mathrm{~N}_{4}$ on the poly(ethylene terephthalate) surface, avoided aggregation and improved recyclability. ${ }^{115}$ Low melting sheath-core composite polyester fibers were immobilized with $\mathrm{g}-\mathrm{C}_{3} \mathrm{~N}_{4}$ to induce recyclability as well as enhanced photocatalytic degradation capability. ${ }^{116}$

g- $\mathrm{C}_{3} \mathbf{N}_{4}$ /polymer hybrids as photocatalysts for sterilization. The combination of polymers and $\mathrm{g}-\mathrm{C}_{3} \mathrm{~N}_{4}$ leads to improved antibacterial performance. In addition to the antibacterial properties of $\mathrm{g}-\mathrm{C}_{3} \mathrm{~N}_{4},{ }^{117}$ polymer fibers improve recyclability and sterilization ability as well. Zhang and coworkers fabricated self-cleaning and antibacterial membranes via filtering $\mathrm{g}-\mathrm{C}_{3} \mathrm{~N}_{4}$ nanosheets onto PAN porous substrates. ${ }^{118}$ The membrane showed high water permeability $\left(11.7 \mathrm{~L} \mathrm{~m}^{-2} \mathrm{~h}^{-1}\right)$ and good antibacterial activity. Moreover, the $\mathrm{g}-\mathrm{C}_{3} \mathrm{~N}_{4} / \mathrm{PAN}$ membrane preserved its original permeability, e.g. rejecting dyes, and the surface was close to its initial color after three cycles via post treatment under visible light irradiation. A poly(ether sulfone) (PES) microfiltration membrane was combined with $\mathrm{g}-\mathrm{C}_{3} \mathrm{~N}_{4}$ and $\mathrm{Ag}_{3} \mathrm{PO}_{4}$ by Vatanpour and coworkers. ${ }^{119}$ Significant antifouling behavior was observed that was ascribed to the synergistic effects of photocatalytic activity, hydrophilicity and porosity.

g- $\mathbf{C}_{3} \mathbf{N}_{4}$ /polymer hybrid materials for biosensors. Although the formation of $\mathrm{g}-\mathrm{C}_{3} \mathrm{~N}_{4}$ hybrids has been widely investigated, the applications of $\mathrm{g}-\mathrm{C}_{3} \mathrm{~N}_{4}$ in the field of sensing are still in the initial stage. Since the first report of the cathodic electrochemiluminescence (ELC) behaviors of $\mathrm{g}-\mathrm{C}_{3} \mathrm{~N}_{4}$ nanosheets, ${ }^{120}$ it has attracted an increasing attention as a promising luminophore candidate for ELC biosensor systems. Especially as g- $\mathrm{C}_{3} \mathrm{~N}_{4}$ presents many favorable advantages, such as nontoxicity, excellent biocompatibility, high thermal and chemical stability, ${ }^{53,121}$ polymer functionalized $\mathrm{g}-\mathrm{C}_{3} \mathrm{~N}_{4} \mathrm{~S}$ are investigated for improving the sensitivity and selectivity of ECL sensors. A combination of $\mathrm{g}-\mathrm{C}_{3} \mathrm{~N}_{4}$ with phenoxy dextran (DexP) and bovine serum albumin was applied to obtain a ECL sensor for concanavalin A by Wei and coworkers. ${ }^{122}$ In this study, DexP and g- $\mathrm{C}_{3} \mathrm{~N}_{4}$ nanocomposites were fabricated via simple overnight stirring to induce physical adsorption via $\pi-\pi$ stacking between g- $\mathrm{C}_{3} \mathrm{~N}_{4}$ and DexP. Later, biosensor performance was investigated, and it was shown that the DexP-g- $\mathrm{C}_{3} \mathrm{~N}_{4}$ composites not only serve as an excellent ECL signal probe, but also form specific carbohydrate-Con A interaction, which demonstrated a novel sandwichtype scheme with a signal-on ECL detection strategy. Chen and coworkers introduced PANI to the g- $\mathrm{C}_{3} \mathrm{~N}_{4}$ sheet structure by an in situ deposition oxidative polymerization using APS as initiator, then gold nanoflowers (AuNF) were in situ formed on the $\mathrm{g}-\mathrm{C}_{3} \mathrm{~N}_{4}$ PANI composite to achieve AuNF@g- $\mathrm{C}_{3} \mathrm{~N}_{4}$-PANI hybrids. ${ }^{123}$ The hybrid components were utilized for ECL biosensor construction, showing high sensitivity and low limit of detection for dopamine. Hence the sensors might be a potential material for determination of dopamine in the field of clinical disease diagnosis. Kim and coworkers attached cylindrical spongy shaped PPy onto protonated g- $\mathrm{C}_{3} \mathrm{~N}_{4} \quad\left(\mathrm{~g}-\mathrm{C}_{3} \mathrm{~N}_{4} \mathrm{H}^{+}\right)$in situ using oxidative polymerization. ${ }^{124}$ Cholesterol oxidase (ChOx) was immobilized on the as-prepared nanohybrids to construct cholesterol biosensor electrodes. Various features were demonstrated, e.g. long-term stability and good selectivity for cholesterol detection during electrochemical characterization. Wei and coworkers presented a CdS/PPy/g- $\mathrm{C}_{3} \mathrm{~N}_{4}$ aptasensor for adenosine detection. ${ }^{125}$ Therefore, a SH-aptamer was adsorbed on $\mathrm{CdS} / \mathrm{PPy} / \mathrm{g}-\mathrm{C}_{3} \mathrm{~N}_{4}$ modified electrodes that formed bioaffinity complexes with adenosine. The readout of photocurrent changed according to adenosine concentration in a linear fashion in the range of $0.3 \mathrm{nmol} \mathrm{L}^{-1}$ to $200 \mathrm{nmol} \mathrm{L}^{-1}$.

g- $\mathrm{C}_{3} \mathrm{~N}_{4}$ /polymer nanocomposites applied in electrochemical energy storage and solar cells. Electrochemical energy storage and energy generation is one of the major current research areas. Hence, also $\mathrm{g}-\mathrm{C}_{3} \mathrm{~N}_{4}$ has found its way into materials for fuel cells, batteries and solar cells. Fuel cells are one of the main devices that can convert chemical into electrical energy. In particular, polymer electrolyte membrane fuel cells (PEMFCs) are of interest for electrochemistry and polymer chemistry. Commonly utilized polymers include poly(benzimidazole) (PBI), ${ }^{126}$ poly(vinyl pyrrolidone) (PVP), ${ }^{127}$ PVP-poly(vinyl alcohol) (PVP-PVA) ${ }^{128}$ or PVP-PES. ${ }^{129}$ However, PEMFC research faces several challenges. For example, high cost, low durability and degradation of PEMFCs, which are due to the instability of membrane materials, seriously inhibit the widespread utilization of the technique. ${ }^{130,131}$ Regarding these challenges, researchers introduced $\mathrm{g}-\mathrm{C}_{3} \mathrm{~N}_{4}$ nanosheets to the polymer matrix. ${ }^{132}$ One particular reason to employ a combination with $\mathrm{g}-\mathrm{C}_{3} \mathrm{~N}_{4}$ is its decent thermal stability with chemical bond energy of $\mathrm{C}-\mathrm{N}$ and $\mathrm{C}=\mathrm{N}$ of $305 \mathrm{~kJ} \mathrm{~mol}^{-1}$ and $615 \mathrm{~kJ} \mathrm{~mol}^{-1}$, respectively. ${ }^{133}$ Another reason is that the amino $\left(-\mathrm{NH}_{2}\right)$ and imino $(-\mathrm{NH})$ groups of $g-\mathrm{C}_{3} \mathrm{~N}_{4}$ can interact with acid groups in the polymer matrix, which leads to enhancement of the Grotthuss-mechanism proton transfer. For instance, Zhou and coworkers blended PVPphosphonated-poly(2,6-dimethyl-1,4-phenylene oxide) (PVP/pPPO) with $\mathrm{g}-\mathrm{C}_{3} \mathrm{~N}_{4}$ nanosheets via a solution casting method, ${ }^{133}$ by mixing a certain amount of $\mathrm{g}-\mathrm{C}_{3} \mathrm{~N}_{4}$ in $70 \% \mathrm{PVP} / \mathrm{pPPO}$ solution, then the solution was casted onto a glass plate to obtain the nanocomposite membranes. Improved proton conductivity and mechanical properties were realized due to the proton accepting sites provided by $\mathrm{NH}_{2}$ and the interaction of $g-\mathrm{C}_{3} \mathrm{~N}_{4}$ with polymer chains, thus leading to higher proton conductivity $\left(74.4 \mathrm{mS} \mathrm{cm}^{-1}\right)$ and power density $\left(294 \mathrm{~mW} \mathrm{~cm}{ }^{-2}\right.$ ) at $180{ }^{\circ} \mathrm{C}$ with a content of $\mathrm{g}-\mathrm{C}_{3} \mathrm{~N}_{4}$ nanosheets of $5 \mathrm{wt} \%$.

To improve the proton conductivity of PA doped PES-PVP membrane material, $\mathrm{Lu}$ and coworkers introduced $\mathrm{g}-\mathrm{C}_{3} \mathrm{~N}_{4}$ nanosheets to the polymer composite matrix through a blending method (Fig. 5). ${ }^{134}$ The as-prepared nanocomposites have shown a significantly improved proton conductivity of $0.104 \mathrm{~S} \mathrm{~cm}^{-1}$ and power density of $512 \mathrm{~mW} \mathrm{~cm} \mathrm{~cm}^{-2}$ with $0.5 \%$ content of $\mathrm{g}-\mathrm{C}_{3} \mathrm{~N}_{4}$. Meanwhile, due to the physical reinforcement effect of $2 \mathrm{D} \mathrm{g}-\mathrm{C}_{3} \mathrm{~N}_{4}$ nanosheets, the mechanical properties of the composite membranes were enhanced compared to PES-PVP without g- $\mathrm{C}_{3} \mathrm{~N}_{4}$. Jiang and coworkers introduced $\mathrm{g}^{-} \mathrm{C}_{3} \mathrm{~N}_{4}$ nanosheets to sulfonated poly(ether ether ketone) composites (SPEEK), ${ }^{135}$ exhibiting a 68\% increase of tensile strength of nanocomposite membranes with 


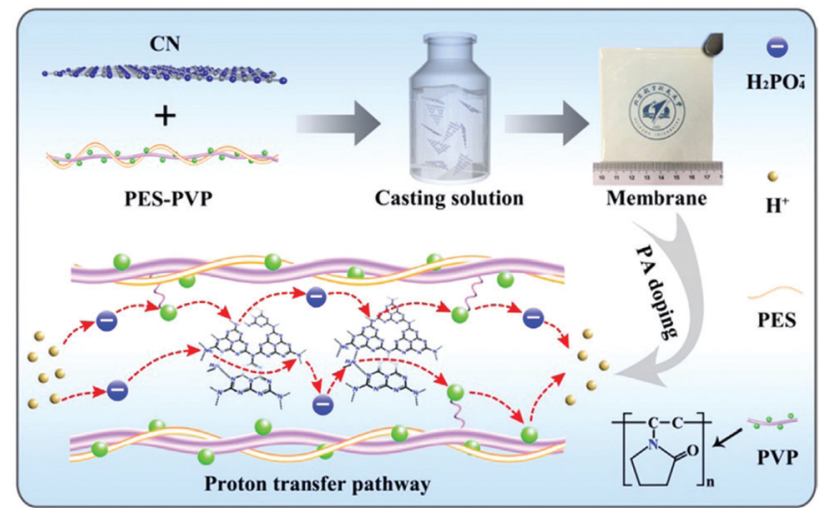

Fig. 5 The preparation and proton conductivity mechanism of the $\mathrm{g}-\mathrm{C}_{3} \mathrm{~N}_{4}$ incorporated PES-PVP composite membranes. (PVP: poly(vinyl pyrrolidone); PES: poly(ether sulfone)) (Reprinted with permission. ${ }^{134}$ Copyright 2019 Elsevier.)

g- $\mathrm{C}_{3} \mathrm{~N}_{4}$ content of $0.5 \mathrm{wt} \%$ due to the intrinsic mechanical stability of $\mathrm{g}-\mathrm{C}_{3} \mathrm{~N}_{4}$ nanosheets and favorable interfacial interactions of $\mathrm{g}-\mathrm{C}_{3} \mathrm{~N}_{4}$ nanosheets with the SPEEK matrix. The $\mathrm{g}-\mathrm{C}_{3} \mathrm{~N}_{4} /$ SPEEK composites were applied to PEMFCs demonstrating a $39 \%$ increase in maximum power density at a $\mathrm{g}-\mathrm{C}_{3} \mathrm{~N}_{4}$ content of $0.5 \mathrm{wt} \%$.

Other energy storage devices such as vanadium redox flow battery (VRB), lithium metal batteries and supercapacitors were also combined with $\mathrm{g}-\mathrm{C}_{3} \mathrm{~N}_{4}$ for improved stability and battery efficiency. Particularly, for VRB, sulfonated aromatic polymers such as SPEEK, ${ }^{136}$ sulfonated poly(sulfone) (SPSF) ${ }^{137}$ or sulfonated polyimide (SPI) ${ }^{138}$ are widely used for fabrication of membranes due to excellent proton conductivity and mechanical properties.
However, improved proton conductivity and ion selectivity are still required. Incorporation of $\mathrm{g}-\mathrm{C}_{3} \mathrm{~N}_{4}$ regulates the interfacial interaction of the membrane materials, thus the ion selectivity, and vanadium ion permeation and structure stability could be effectively controlled. ${ }^{139-141}$ Xiang and coworkers introduced g- $\mathrm{C}_{3} \mathrm{~N}_{4}$ nanosheets into a Nafion matrix membrane to reduce vanadium ion crossover (Fig. 6a). ${ }^{142}$ Crosslinking interaction between Nafion matrix and $\mathrm{g}-\mathrm{C}_{3} \mathrm{~N}_{4}$ nanosheets efficiently induced the shrinkage of the Nafion membrane (Fig. $6 \mathrm{~b}$ and c), resulting in a lamellar structure, thus the vanadium ion crossover is significantly reduced. An improved coulombic efficiency of $97 \%$ and energy efficiency of $85 \%$ at a current density of $80 \mathrm{~mA} \mathrm{~cm}^{-2}$ was achieved (Fig. 6d). Moreover, Li and coworkers proposed a lightweight polymer-reinforced electrolyte based on $\mathrm{g}-\mathrm{C}_{3} \mathrm{~N}_{4}$ mesoporous microspheres as electrolyte filler in lithium metal batteries. ${ }^{143}$ Due to the high mechanical strength and nanosheet-built hierarchical structure of g- $\mathrm{C}_{3} \mathrm{~N}_{4}$, this electrolyte can effectively suppress lithium dendrite growth during cycling. The Li/Li symmetrical cell based on this electrolyte exhibited a long-term cycling of at least 120 cycles with a high capacity of $6 \mathrm{~mA} \mathrm{~h} \mathrm{~cm}{ }^{-2}$. Additionally, g- $\mathrm{C}_{3} \mathrm{~N}_{4}$ was embedded onto conductive polymers as an efficient electrode material for supercapacitors to improve electrochemical and mechanical stability. ${ }^{144-146}$ Yang and coworkers prepared a novel electrode material for supercapacitors composed of poly(3,4-ethylenedioxythiophene) (PEDOT):poly(styrenesulfonate) (PSS) and g- $\mathrm{C}_{3} \mathrm{~N}_{4}$ by the layer-by-layer assembly method. ${ }^{147}$ Compared with pure PEDOT, the PEDOT/g- $\mathrm{C}_{3} \mathrm{~N}_{4}$ composite demonstrated excellent electrochemical stability in neutral electrolyte and enhanced electrochemical performance of capacitance of $137 \mathrm{~F} \mathrm{~g}^{-1}$ in $\mathrm{H}_{2} \mathrm{SO}_{4}$ and $200 \mathrm{~F} \mathrm{~g}^{-1}$ in $\mathrm{Na}_{2} \mathrm{SO}_{4}$, respectively.
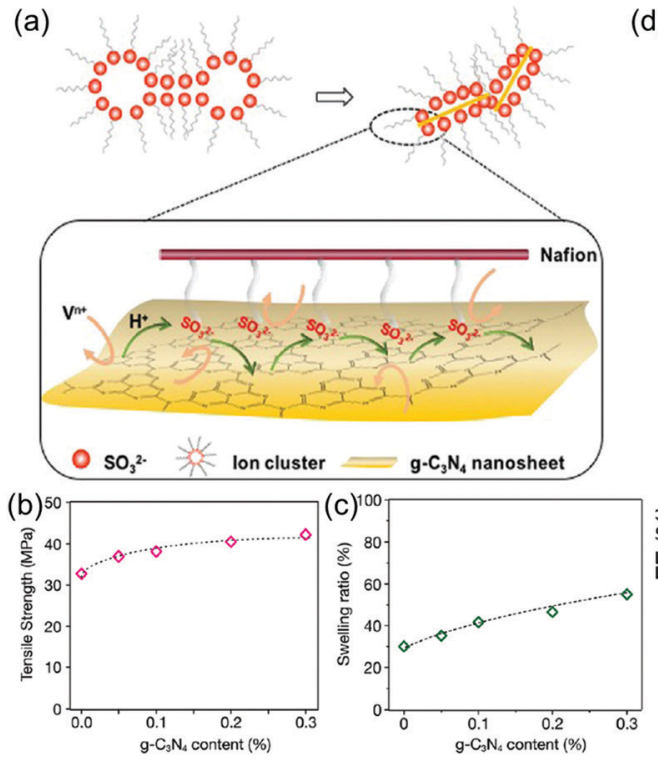

(d)

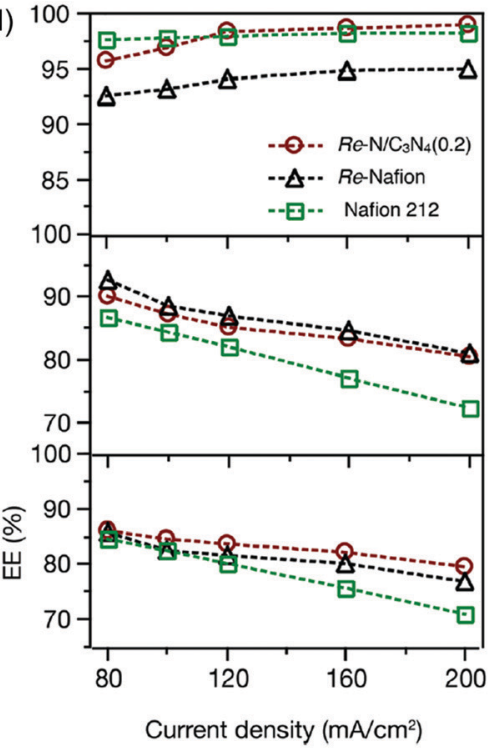

Fig. 6 (a) Proton and vanadium ion transport behaviors of the Re-N/CN(x) composite membrane. (b) Tensile strength and (c) swelling ratio of the composite Re-N/CN(x) membranes with various amounts of $\mathrm{g}-\mathrm{C}_{3} \mathrm{~N}_{4}$ nanosheets compared to that of Re-Nafion membranes. (d) Single battery efficiency performance. Coulombic efficiency (CE), voltage efficiency (VE), and energy efficiency (EE) at current densities of $80-200 \mathrm{~mA} \mathrm{~cm}^{-2}$ of the Vanadium redox flow battery (VRB) with the Re- $\mathrm{N} / \mathrm{g}-\mathrm{C}_{3} \mathrm{~N}_{4}$ (0.2) membrane compared to those of the VRB with the Re-Nafion membrane and the commercial Nafion 212 membrane (Reprinted with permission. ${ }^{142}$ Copyright 2018 Royal Society of Chemistry). 
Additionally, few studies reported the combination of $\mathrm{g}-\mathrm{C}_{3} \mathrm{~N}_{4}$ with polymers for solar cell utilization. ${ }^{148}$ Yang and coworkers for the first time introduced $\mathrm{g}-\mathrm{C}_{3} \mathrm{~N}_{4}$ quantum dots $\left(\mathrm{C}_{3} \mathrm{~N}_{4} \mathrm{QDs}\right)$ into the active layer of bulk-heterojunction $(\mathrm{BHJ})$ polymer solar cells (PSCs). ${ }^{149}$ Solution-processable $\mathrm{C}_{3} \mathrm{~N}_{4}$ QDs were prepared by acid treatment of bulk $\mathrm{g}-\mathrm{C}_{3} \mathrm{~N}_{4}$, followed by a solvothermal treatment. Finally, they were doped to the active layers of the PSC with a doping ratio of $0.2 \mathrm{mg} \mathrm{mL}^{-1}$. The different active layers of the $\mathrm{C}_{3} \mathrm{~N}_{4}$ QDs doped $\mathrm{BHJ}$-PSC device demonstrated an obvious enhancement of power conversion efficiencies from $17.5 \%$ to $11.6 \%$, depending on the utilized active layer compared to the reference device in the absence of $\mathrm{C}_{3} \mathrm{~N}_{4}$ QDs. The effect of $\mathrm{C}_{3} \mathrm{~N}_{4}$ QDs on surface morphology, optical absorption, PL properties as well as charge transfer properties was specifically studied, hence the mechanism for such efficiency enhancement was proposed. Very recently, following our recent discovery of modifying g- $\mathrm{C}_{3} \mathrm{~N}_{4}$ with 4-methyl-5-vinylthiazole (vTA), in which the grafting of vTA led to spontaneous polarization and migration of negative charges on thiazole rims whereas g- $\mathrm{C}_{3} \mathrm{~N}_{4}$ remained positive. Thus significantly influencing the electron transport process, ${ }^{83}$ which was exploited in another work of our group that applied vTA-grafted g- $\mathrm{C}_{3} \mathrm{~N}_{4}$ nanosheets ( $\mathrm{g}$ - $\mathrm{C}_{3} \mathrm{~N}_{4}$-vTA) as interfacial transporting layers (ETLs) for inverted perovskite solar cells (PVSCs). ${ }^{29}$ Homogenous films of $\mathrm{g}$ - $\mathrm{C}_{3} \mathrm{~N}_{4}$-vTA were formed via facile spin-coating on two different layers to study the influence of $\mathrm{g}-\mathrm{C}_{3} \mathrm{~N}_{4}$-vTA on the electronic properties of methylammonium lead iodide based PVSCs. The implementation of g- $\mathrm{C}_{3} \mathrm{~N}_{4}$-vTA enabled interface enhancement via suppression of charge recombination, achieving $1.09 \mathrm{~V}$ in $V_{\mathrm{oc}}$ and a rise to $20.17 \mathrm{~mA} \mathrm{~cm} \mathrm{~cm}^{-2}$ in short circuit current. Besides, enhanced carrier collection due to the extra light absorption at short wavelengths was observed. Moreover, the introduction of $\mathrm{g}-\mathrm{C}_{3} \mathrm{~N}_{4}$-vTA as alternative interface layer featured metal-free, cheap and benign photophysical properties with high tenability.

\section{$4.2 \mathrm{~g}-\mathrm{C}_{3} \mathrm{~N}_{4} /$ polymer hybrids for designed material morphologies}

g- $\mathrm{C}_{3} \mathrm{~N}_{4}$ /polymer hybrid film materials. As g- $\mathrm{C}_{3} \mathrm{~N}_{4}$ is a very promising photocatalytic material, application of $\mathrm{g}-\mathrm{C}_{3} \mathrm{~N}_{4}$ in films is of significant interest, ${ }^{67}$ especially in the utilization of solar cells, ${ }^{150}$ sensors $^{151}$ or in ionic transport. ${ }^{25,152}$ Nevertheless, common methods of film formation and processing, e.g. spin coating or inkjet printing, ${ }^{153}$ have been achieved with minor success only for a longer time, which is to a large extent due to the limited colloidal dispersibility of $\mathrm{g}-\mathrm{C}_{3} \mathrm{~N}_{4}$ and necessity of harsh processing conditions. ${ }^{154}$ Thus several studies investigated formation of $\mathrm{g}-\mathrm{C}_{3} \mathrm{~N}_{4}$ film materials. ${ }^{68}$ One effective strategy is to combine $\mathrm{g}-\mathrm{C}_{3} \mathrm{~N}_{4}$ with polymers for improved dispersibility and processability. In such a way, thin films and coatings based on g- $\mathrm{C}_{3} \mathrm{~N}_{4}$ could be fabricated, which enables processing of g- $\mathrm{C}_{3} \mathrm{~N}_{4}$ and access to novel applications. One way for such combination is "grafting to", which used surface functionalities on $\mathrm{g}-\mathrm{C}_{3} \mathrm{~N}_{4}$ (e.g. $-\mathrm{NH}_{2},-\mathrm{NH}$ or $-\mathrm{OH}$ ) for amide formation or hydrogen bond formation. The other way is "grafting from" method, which was described above (Section 3).

For example, $\mathrm{Hu}$ and coworkers fabricated a series of sodium alginate (SA) nanocomposite films with different $\mathrm{g}-\mathrm{C}_{3} \mathrm{~N}_{4}$ loading levels via casting technology. ${ }^{156} \mathrm{~A}$ physical adsorption method was utilized here to fabricate $\mathrm{SA} / \mathrm{g}-\mathrm{C}_{3} \mathrm{~N}_{4}$ composites, SA and $\mathrm{g}-\mathrm{C}_{3} \mathrm{~N}_{4}$ mixture were ultrasonicated at $40{ }^{\circ} \mathrm{C}$ to form hydrogen bonds between $-\mathrm{OH}$ on $\mathrm{SA}$ and uncondensed $-\mathrm{NH}_{2}$ on $\mathrm{g}-\mathrm{C}_{3} \mathrm{~N}_{4}$. Subsequently, the mixture was poured onto a transparent flat dish and left undisturbed for $36 \mathrm{~h}$ at $40{ }^{\circ} \mathrm{C}$. The hydrogen bonding behaviour, thermal stability and mechanical performance of the g- $\mathrm{C}_{3} \mathrm{~N}_{4} / \mathrm{SA}$ film were studied. Recently, our group investigated a "grafting to" method to graft allyl-end functionalized polymers onto g- $\mathrm{C}_{3} \mathrm{~N}_{4}$ under visible light irradiation (Fig. 7). Decene end functionalized PMMA, poly(isobornyl methacrylate) (PIBA) and PGMA were firstly synthesized via ATRP. ${ }^{155}$ In the next step the polymers were mixed with $\mathrm{g}-\mathrm{C}_{3} \mathrm{~N}_{4}$ dispersed in THF and irradiated with visible light to form a covalent bond. The as-prepared polymer/g- $\mathrm{C}_{3} \mathrm{~N}_{4}$ with different grafting density could be easily processed for fabrication of polymer/g- $\mathrm{C}_{3} \mathrm{~N}_{4}$ film by dispersing the composites in THF and spin coating on glass slides (Fig. 7b). As such, smooth thin polymer/g- $\mathrm{C}_{3} \mathrm{~N}_{4}$ films with thicknesses in the range of $60 \mathrm{~nm}$ were obtained (Fig. 7c). In addition, the PGMA-based materials could be further modified via nucleophilic ring-opening of the epoxides with thiol compounds (Fig. 7d). In such a way, sodium 2-mercaptoethanesulfonate or $1 \mathrm{H}, 1 \mathrm{H}, 2 \mathrm{H}, 2 \mathrm{H}$-perfuorodecanethiol were further grafted on the g- $\mathrm{C}_{3} \mathrm{~N}_{4}$-brushes, which led to significant changes in surface hydrophilicity as shown via contact angle measurements after film formation.

Another work from our group described a g- $\mathrm{C}_{3} \mathrm{~N}_{4}$-based polymer thermoset coating, and thicker films were obtained via a prepolymer route, which is similar to already discussed g- $\mathrm{C}_{3} \mathrm{~N}_{4}$-PDMA prepolymers. ${ }^{157}$ In this case, a prepolymer of PHEMA on $\mathrm{g}-\mathrm{C}_{3} \mathrm{~N}_{4}$ was formed in EG/water mixture that led to the formation of a viscous precursor material composed of PHEMA grafted $\mathrm{g}-\mathrm{C}_{3} \mathrm{~N}_{4}$, EG and water. The viscosity of the precursor was tuned in way that injectable material was obtained. As such, the precursor could be applied to various surfaces, including PS, wood and copper, with spatial control. After addition of citric acid and film formation on a glass slide, crosslinking was performed via heating. The so-formed thermosets formed smooth hydrophobic coatings that could be used for further processing. As the $\mathrm{g}-\mathrm{C}_{3} \mathrm{~N}_{4}$ in the coating retains its photoactivity, PDMA or PS could be modified to the surface via the "grafting from" method to tailor the surface polarity, as shown via contact angle measurements. Moreover, the photoactive surfaces could be used in dye degradation experiments as well as photoelectrochemistry.

g- $\mathbf{C}_{3} \mathbf{N}_{4}$ /polymer nanoparticle composites. A very common and useful structure in polymer and materials science are latexes based on nanoparticles. Therefore, research regarding the introduction of $\mathrm{g}-\mathrm{C}_{3} \mathrm{~N}_{4}$ into or onto polymer particles is another major topic. As it was found that $\mathrm{g}-\mathrm{C}_{3} \mathrm{~N}_{4}$ can act as emulsifier to stabilize oil in water $(\mathrm{o} / \mathrm{w})$ emulsions, ${ }^{30,158}$ one way to fabricate g- $\mathrm{C}_{3} \mathrm{~N}_{4}$ /polymer nanoparticles is to utilize g- $\mathrm{C}_{3} \mathrm{~N}_{4}$ as stabilizer in a Pickering emulsion polymerization. ${ }^{159}$ The approach was utilized by $\mathrm{Li}$ and coworkers to form $\mathrm{g}-\mathrm{C}_{3} \mathrm{~N}_{4}$ based latexes. ${ }^{53}$ Pickering emulsion polymerization was conducted using $\mathrm{g}-\mathrm{C}_{3} \mathrm{~N}_{4}$ as stabilizer and potassium persulfate (KPS) as initiator. 
(a)
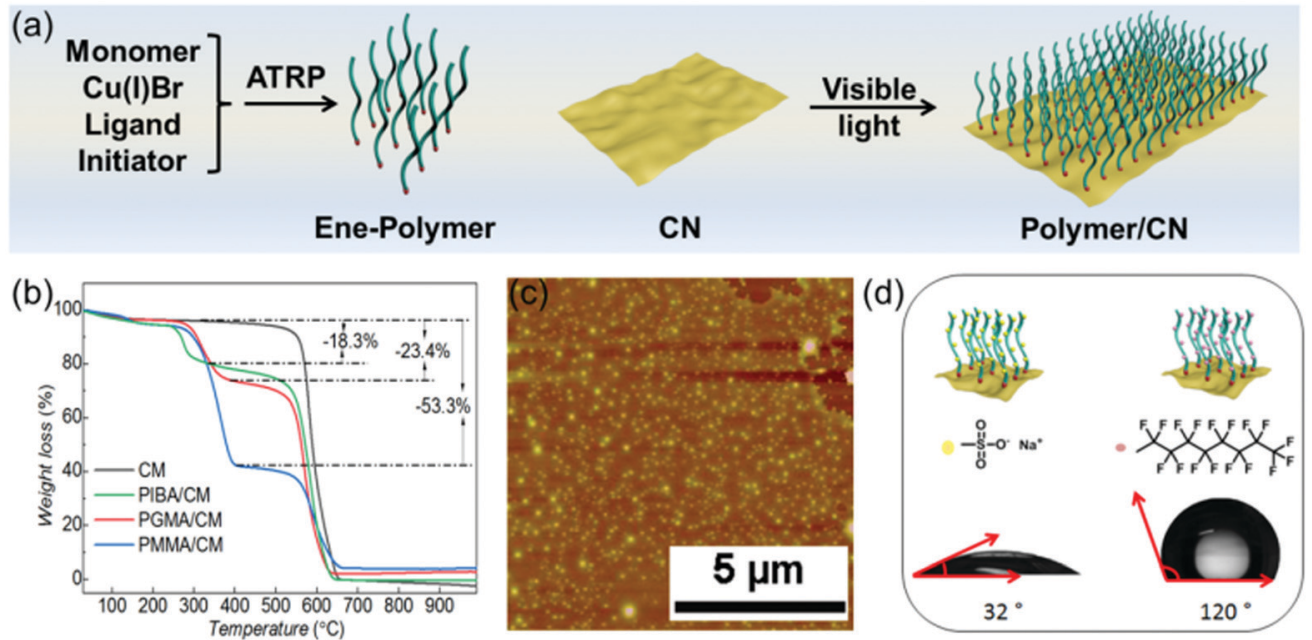

Fig. 7 (a) Overview for atom transfer radical polymerization and grafting of polymer brushes onto g- $\mathrm{C}_{3} \mathrm{~N}_{4}$ under visible light irradiation, (b) thermogravimetric analysis of cyanuric acid-melamine-derived $\mathrm{g}-\mathrm{C}_{3} \mathrm{~N}_{4}$ (CM) precursor and ene-polymer grafted CM, (c) atomic force microscopy profile of spin coated poly(isobornyl acrylate)(PIBA)/CM film, (d) modification of poly(glycidyl methacrylate)(PGMA)/CM via thiol-addition mediated epoxy ring-opening, with sodium 2-mercaptoethanesulfonate and $1 \mathrm{H}, 1 \mathrm{H}, 2 \mathrm{H}, 2 \mathrm{H}$-perfluorodecanethiol, respectively (Licensed under CC-BY). ${ }^{155}$

Hence, monodisperse PS microspheres with tunable size down to the $100 \mathrm{~nm}$ diameter region, surface charge and morphology were obtained. Herein, $\mathrm{g}-\mathrm{C}_{3} \mathrm{~N}_{4}$ located in the continuous phase and adhered to the monomer droplet surface forming a network structure preventing the emulsion from coalescence. The as-prepared $\mathrm{PS} / \mathrm{g}-\mathrm{C}_{3} \mathrm{~N}_{4}$ possessed photoluminescence properties owing to the existence of $\mathrm{g}_{-} \mathrm{C}_{3} \mathrm{~N}_{4}$ sheets, and both $\mathrm{g}-\mathrm{C}_{3} \mathrm{~N}_{4}$ and PS latex showed excellent biocompatibility during standard MTT assays. Nanoparticles were incubated with HeLa cells for $12 \mathrm{~h}$ and observed with confocal laser scanning microscopy. The particles were internalized by HeLa cells, indicating that the fluorescent PS/g$\mathrm{C}_{3} \mathrm{~N}_{4}$ hybrid particles are promising materials for bioimaging. Recently, sialic acid was introduced into the $\mathrm{g}-\mathrm{C}_{3} \mathrm{~N}_{4}$ stabilized Pickering polymerization system, which is an important indicator of some types of cancer. The $\mathrm{g}-\mathrm{C}_{3} \mathrm{~N}_{4}$ contained and sialic acid-imprinted polymer nanoparticles exhibited good biocompatibility and excellent targeted image of DU 145 cells (sialic acid-overexpressed surface). ${ }^{159}$

Additionally, as discussed in Section 2, g- $\mathrm{C}_{3} \mathrm{~N}_{4}$ can effectively produce radical species under visible light irradiation, thus polymerization can be conducted on g- $\mathrm{C}_{3} \mathrm{~N}_{4}$ and g- $\mathrm{C}_{3} \mathrm{~N}_{4} /$ polymer nanocomposites can be obtained. For example, Weber and coworkers reported the formation of $\mathrm{g}-\mathrm{C}_{3} \mathrm{~N}_{4}$-based PBA composites via an aerosol polymerization process (Fig. 8a) ${ }^{160}$ Spherical mesoporous g- $\mathrm{C}_{3} \mathrm{~N}_{4}$ (SMCN) was initially prepared with mesoporous silica nanoparticles as template (Fig. $8 \mathrm{~b}$ ), then monomer was continuously added via the gas phase and polymerized in proximity of $\mathrm{g}-\mathrm{C}_{3} \mathrm{~N}_{4}$ via photoinitiation under UV light irradiation. Later, spherical $\mathrm{g}-\mathrm{C}_{3} \mathrm{~N}_{4} /$ polymer composite particles (Fig. 8c) were obtained without solvent or surfactant. Such a strategy is suitable for fabrication of spherical nanocomposites with hydrophobic polymers. The as-prepared mesoporous CN acts not only as photoinitiator but also as filler and template.

Very recently, our team attempted to utilize g- $\mathrm{C}_{3} \mathrm{~N}_{4}$ as emulsifier and photoinitiator at the same time to conduct emulsion
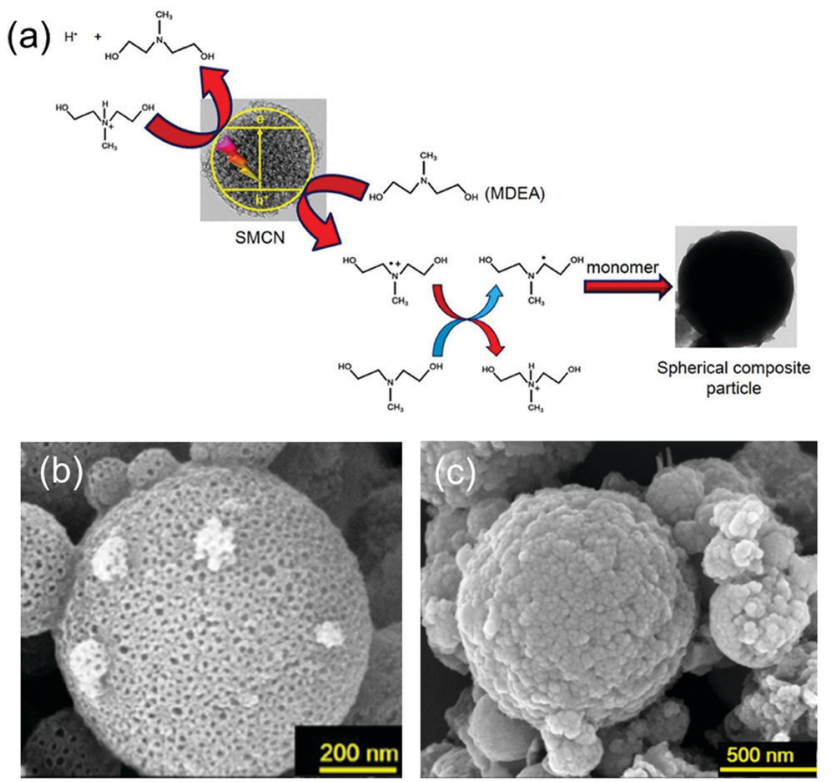

Fig. 8 (a) Initiation mechanism of the photopolymerization using spherical mesoporous $\mathrm{g}-\mathrm{C}_{3} \mathrm{~N}_{4}$ (SMCN) in the presence of the methyl diethanolamine (MDEA) as CO-initiator. (b) SEM image of SMCN replicas. (c) SEM image of PBA-SMCN composites produced by aerosol-photopolymerization (Reprinted with permission. ${ }^{160}$ Copyright 2016 American Chemical Society).

photopolymerization..$^{58}$ Herein, the emulsion photopolymerization of styrene was studied with non-functionalized g- $\mathrm{C}_{3} \mathrm{~N}_{4}$, which led to PS latexes with particle diameters around $170 \mathrm{~nm}$. Nevertheless, no satisfying MMA latexes could be obtained that way albeit BMA formed latexes with narrowly distributed particle sizes. Apparently, the monomer structure has a significant impact on the polymerization process, i.e. the interactions of monomer and g- $\mathrm{C}_{3} \mathrm{~N}_{4}$ seem to play a significant role to create the particle nucleation site. It is very likely that styrene and BMA feature enhanced interactions 
with $\mathrm{g}-\mathrm{C}_{3} \mathrm{~N}_{4}$ due to $\pi-\pi$ interactions, while MMA interacts to a lesser extent. Notably, the utilization of decene-functionalized g- $\mathrm{C}_{3} \mathrm{~N}_{4}$ enabled the formation of PMMA latexes, probably due to the improved interaction of the initiating stabilizer with the monomer. The formed latexes feature polymer particles that incorporated g- $\mathrm{C}_{3} \mathrm{~N}_{4}$ and were crosslinked directly. The specific location of $\mathrm{g}-\mathrm{C}_{3} \mathrm{~N}_{4}$ was investigated, demonstrating that g- $\mathrm{C}_{3} \mathrm{~N}_{4}$ nanosheets ranging from 50-100 $\mathrm{nm}$ appeared to be inside of the latex with STEM tilt observation, and small pieces attached outside of latexes with a negative surface charge that grants a stable emulsion latex/g- $\mathrm{C}_{3} \mathrm{~N}_{4}$ composite. The combination of the traditional PS latex with the outstanding features of environmentally friendly $\mathrm{g}-\mathrm{C}_{3} \mathrm{~N}_{4}$ provides novel polymer composites with multifunctional modern applications, e.g. in bioimaging or $3 \mathrm{D}$ printing.

\subsection{Improved properties of polymer materials via combination with $\mathrm{g}-\mathrm{C}_{3} \mathrm{~N}_{4}$}

It is reported that hybridizing $\mathrm{g}-\mathrm{C}_{3} \mathrm{~N}_{4}$ and polymers on one side significantly improves surface and photocatalytic properties of $\mathrm{g}-\mathrm{C}_{3} \mathrm{~N}_{4}$, on the other side also enhances the thermal and mechanical properties of polymers as well as surface properties. ${ }^{162-164}$ Few studies reported that the introduction of $\mathrm{g}-\mathrm{C}_{3} \mathrm{~N}_{4}$ to polymers also lead to the improvement of mechanical properties of polymers. ${ }^{165}$ Myllymaa and coworkers deposited Si-doped CN (CN-Si) on poly(propylene) (PP) disc samples via pulsed laser deposition. ${ }^{166}$ The coating of CN-Si can significantly convert the PP surface from being hydrophobic to hydrophilic, leading to enhanced adherence of Saos-cells on PP. Hu and coworkers reported a mix of PP-grafted maleic anhydride (PP-g-MA) with $\mathrm{g}-\mathrm{C}_{3} \mathrm{~N}_{4}$ by refluxing the mixture for 4 hours in xylene. ${ }^{167}$ It was reported that the incorporation of $\mathrm{g}-\mathrm{C}_{3} \mathrm{~N}_{4}$ with PP-g-MA significantly improved the storage modulus, i.e. $2445 \mathrm{MPa}$ for neat PP-g-MA and $2784 \mathrm{MPa}$ for $\mathrm{pp}$-g-MA/g- $\mathrm{C}_{3} \mathrm{~N}_{4}$, respectively. Moreover, optical results showed that the hybrid materials possessed fascinating UV absorption. Cai and coworker introduced $\mathrm{g}-\mathrm{C}_{3} \mathrm{~N}_{4}$ as reinforcing filler for wood plastic compositions (WPCs), pp-g-MA was added as a coupling agent to increase the interaction between different components. ${ }^{168}$ The tensile modulus indicating an increase of $143 \%$ with g- $\mathrm{C}_{3} \mathrm{~N}_{4}$ contents of $5 \mathrm{wt} \%$, and the thermal tests demonstrated that the degradation temperature shifted to higher values after g- $\mathrm{C}_{3} \mathrm{~N}_{4}$ addition. Lin and coworker fabricated g- $\mathrm{C}_{3} \mathrm{~N}_{4} /$ poly(vinyl alcohol) (PVA) nanocomposites by solution casting using water as solvent, demonstrating that the $\mathrm{g}-\mathrm{C}_{3} \mathrm{~N}_{4}$ could be well dispersed in PVA matrix. ${ }^{169}$ The introduction of $\mathrm{g}-\mathrm{C}_{3} \mathrm{~N}_{4}$ nanosheets increased the glass transition temperature and crystallinity of the nanocomposites, leading to improved mechanical performance with $\sim 71 \%$ enhancement of tensile strength. ${ }^{169}$ Very recently, Guo and coworkers synthesized $\mathrm{g}-\mathrm{C}_{3} \mathrm{~N}_{4}$ on carbon fiber surfaces in situ in order to enhance interfacial properties of carbon fiber reinforced epoxy resin composites. ${ }^{170}$ The g- $\mathrm{C}_{3} \mathrm{~N}_{4}$ on the carbon fiber surface greatly increased the roughness, the content of polar functional groups and wettability of carbon fibers. Thus, significant enhancement of interfacial properties of the composites was obtained.

\section{Carbon nitride-based hydrogels}

Hydrogels constitute an important class of polymeric materials due to their unique features such as swelling properties or soft character while being shape persistent. ${ }^{171}$ Consisting of a crosslinked hydrophilic network, hydrogels contain significant amounts of water. Their similarity to natural tissues is another important point for the frequent investigation of hydrogels, especially when biomedical applications like tissue-engineering or drug-delivery are targeted. ${ }^{172,173}$ Other discussed applications comprise actuators, ${ }^{174}$ self-healing, ${ }^{175}$ absorption of contaminants ${ }^{176}$ or shape-memory materials. ${ }^{177}$ Commonly, hydrogels possess rather weak mechanical properties but research has introduced reinforced hydrogels with partly extraordinary properties. For that, several methods are utilized, e.g. double network hydrogels, ${ }^{178,179}$ topological (slide-ring) gels, ${ }^{180,181}$ nanofiber reinforced hydrogels ${ }^{182}$ or the introduction of charged supports. ${ }^{183-185}$ Especially, the introduction of particles as reinforcer provides increased stress dissipation, in some cases charge-charge repulsion between the single filler particles or sheets leads to an additional stabilization especially against compression. ${ }^{20}$ One common example are clay nanosheets that combine ionic interaction and hydrogen bonding with polymeric chains acting as additional crosslinking points. ${ }^{186-188}$

As mentioned before, $\mathrm{g}-\mathrm{C}_{3} \mathrm{~N}_{4}$ can be utilized as photoinitiator for polymerization reactions. As such $\mathrm{g}-\mathrm{C}_{3} \mathrm{~N}_{4}$ can be utilized as well for the formation of hydrogels under visible light. Most notably, these hydrogels incorporate $\mathrm{g}-\mathrm{C}_{3} \mathrm{~N}_{4}$, which might have various effects on materials properties. ${ }^{189}$ For example, g- $\mathrm{C}_{3} \mathrm{~N}_{4}$ based hydrogels feature remarkable mechanical properties like compressibility and high storage moduli as discussed in Section 5.1. In addition, $\mathrm{g}-\mathrm{C}_{3} \mathrm{~N}_{4}$-based hydrogels retain the photocatalytic properties of $\mathrm{g}-\mathrm{C}_{3} \mathrm{~N}_{4}$, which allows utilization in contaminant degradation or $\mathrm{H}_{2}$ evolution (Section 5.2). Besides the formation of hydrogels via covalent bonds, $\mathrm{g}-\mathrm{C}_{3} \mathrm{~N}_{4}$ can be utilized in supramolecular hydrogels as well as blended into hydrogel scaffolds to improved mechanical properties for instance, which is discussed in Section 5.3.

\subsection{Hydrogels with tailored mechanical properties}

It was already stated that the photoactive properties of $\mathrm{g}-\mathrm{C}_{3} \mathrm{~N}_{4}$ enable the formation of radicals in aqueous dispersion. ${ }^{190}$ Thus, after addition of monomer and crosslinker, hydrogels can be formed with greatest ease via visible light irradiation (Scheme 5a and Table 2). For example, water-soluble acrylamidederivatives can be utilized, which feature fast gelation rates and a broad spectrum of functionalities. $\mathrm{g}-\mathrm{C}_{3} \mathrm{~N}_{4}$ then indeed does not only act as photoinitiator but also as reinforcer. The reinforcement effect is due to the lateral extension of the $\mathrm{g}-\mathrm{C}_{3} \mathrm{~N}_{4}$ sheets that dissipate mechanical stress throughout the network and thus improve mechanical properties, very similar to the previously mentioned clay nano sheets.

As a first example our group employed DMA and $N, N^{\prime}-$ methylene bisacrylamide (MBA) with a dispersion of $0.6 \mathrm{wt} \%$ $\mathrm{CM}$ in water for hydrogel formation. ${ }^{191}$ Hydrogels were obtained after several hours of visible light irradiation. Notably, the hydrogels retained the photocatalytic properties of $\mathrm{g}-\mathrm{C}_{3} \mathrm{~N}_{4}$. In addition, 


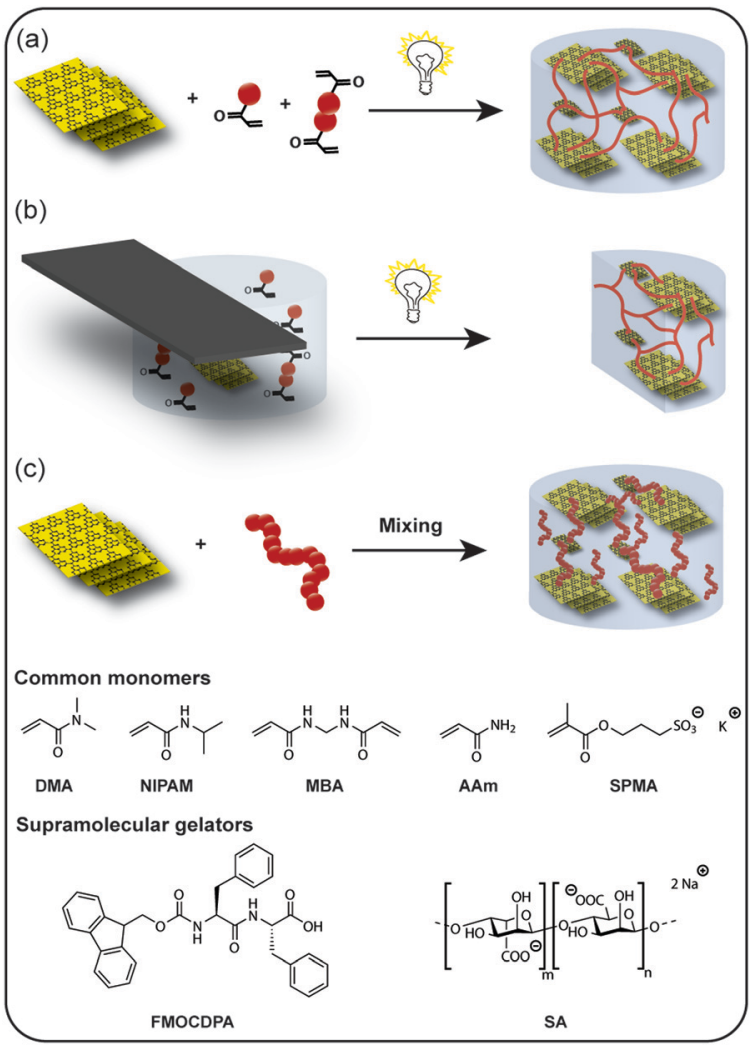

Scheme 5 Overview of $\mathrm{g}-\mathrm{C}_{3} \mathrm{~N}_{4}$ based hydrogels: (a) formation via visible light induced polymerization of a water-soluble monomer and crosslinker, (b) spatially controlled hydrogel formation via application of a photomask leading to polymerization in the illuminated part only and (c) formation via physical interactions (DMA: N,N-dimethylacrylamide; NIPAM: $N$-isopropylacrylamide; MBA: $N, N^{\prime}$-methylene bisacrylamide; AAm: acrylamide; SPMA: 3-sulfopropyl methacrylate potassium salt; FMOCDPA: Fmoc-diphenylalanine; SA: sodium alginate).

remarkable mechanical properties were observed, such as superstretchability or being very tough and flexible at the same time. Such behavior opens up a completely new field of applications. In the next step the mechanical properties and origin of gel formation were studied in more detail (Fig. 9). ${ }^{64}$ To investigate the role of g- $\mathrm{C}_{3} \mathrm{~N}_{4}$ in the network formation, control reactions were performed, i.e. hydrogel formation with a common photoinitiator/without g- $\mathrm{C}_{3} \mathrm{~N}_{4}$ (Fig. 9a), which lead to very weak hydrogels. Furthermore, hydrogelation employing $\mathrm{g}-\mathrm{C}_{3} \mathrm{~N}_{4}$ without external crosslinker and non-nitrogen containing monomers was investigated as well. Indeed, hydrogelation took place even without addition of external crosslinker, which indicates the incorporation of $\mathrm{g}-\mathrm{C}_{3} \mathrm{~N}_{4}$ into the network. Moreover, hydrogels could be formed from non-nitrogen containing monomers and crosslinkers, which indicates that the reaction is not dependent on radical transfer from $\mathrm{g}-\mathrm{C}_{3} \mathrm{~N}_{4}$ to amines as instrumentalized in various other reactions. ${ }^{56,57}$ Moreover, remarkable mechanical properties were obtained ( $G^{\prime}$ up to $8.3 \mathrm{kPa}$ at solid contents of $11 \mathrm{wt} \%$ ) (Fig. 9c). One reason is the particular structure of g- $\mathrm{C}_{3} \mathrm{~N}_{4}$ that acts as colloidal filler via formation of a secondary network of inorganic sheets inside of the hydrogel providing additional strength to the structure. In addition, g- $\mathrm{C}_{3} \mathrm{~N}_{4}$ introduces additional crosslinking points, which strengthens the hydrogel further. This effect could be analyzed via a control experiment of hydrogel formation in $\mathrm{g}-\mathrm{C}_{3} \mathrm{~N}_{4}$ dispersion but with redox initiation in the absence of light (Fig. 9b). Compared to a reference sample without g- $\mathrm{C}_{3} \mathrm{~N}_{4}$, improved mechanical properties were found albeit the mechanical properties from visible light g- $\mathrm{C}_{3} \mathrm{~N}_{4}$ mediated hydrogels were not reached. Thus, both reinforcement via inorganic secondary network as well as via additional crosslinking points are important. The fabricated hydrogels showed a significant shear thinning effect. Such an effect is common to reinforced hydrogels as shear leads to alignment of the polymer network as well as $\mathrm{g}-\mathrm{C}_{3} \mathrm{~N}_{4}$ particles, and such ordering is weakening the g- $\mathrm{C}_{3} \mathrm{~N}_{4}-\mathrm{g}-\mathrm{C}_{3} \mathrm{~N}_{4}$ interactions.

Liu and coworkers showed the formation of a g- $\mathrm{C}_{3} \mathrm{~N}_{4} / \mathrm{NIPAM}$ hydrogel. ${ }^{190} \mathrm{~A}$ hydrogel was formed via visible light mediated photopolymerization albeit no external crosslinker was added. The NIPAM-based hydrogels showed thermoresponsive properties. For example, the viscosity, storage and loss modulus of the obtained hydrogels decreased until the lower critical solution temperature (LCST) of PNIPAM and increased again above the LCST. Moreover, the authors could form the hydrogels in specific patterns that changed transparency reversibly according to temperature (Fig. 9d). Farzaneh and coworkers physically

Table 2 Hydrogels based on $\mathrm{g}-\mathrm{C}_{3} \mathrm{~N}_{4}$ and their properties

\begin{tabular}{|c|c|c|c|}
\hline Synthesis method & Monomers/gelators & Properties/applications & Ref. \\
\hline Photopolymerization & DMA/MBA & Photocatalytic dye degradation and $\mathrm{H}_{2}$ evolution & 191 \\
\hline Photopolymerization & DMA/MBA & High $G^{\prime}$ (up to $8.3 \mathrm{kPa}$ ), salt and $\mathrm{pH}$ response & 64 \\
\hline Photopolymerization & NIPAM/MBA & Thermoresponse & 190 \\
\hline Photopolymerization & AAm/DMA/MBA & High compressibility & 193 \\
\hline Photopolymerization in water/EG & DMA/MBA & High $G^{\prime}$ (up to $729 \mathrm{kPa}$ ) & 196 \\
\hline Photopolymerization with g- $\mathrm{C}_{3} \mathrm{~N}_{4}$ prepolymer & DMA/SPMA/MBA & Low friction & 197 \\
\hline Photopolymerization & AAm/MBA & Tetracycline degradation & 200 \\
\hline Photopolymerization & AAm/MBA & Photooxidation of $\mathrm{Cr}(\mathrm{vI})$ & 201 \\
\hline Redox polymerization & $\mathrm{AAm} / \mathrm{MBA}$ & Gel electrophoresis & 192 \\
\hline Thermal polymerization & AAm/acrylic acid/MBA & $\mathrm{Ag}^{+}$sensing and $\mathrm{pH}$ sensitivity & 203 \\
\hline Blending & Graphene/PPy & Photooxidation of $\mathrm{Cr}(\mathrm{vI})$ and degradation of phenol & 202 \\
\hline Blending & FMOCDPA & Photo- and enzymatic catalysis & 204 \\
\hline Blending & SA & 3D printing and photocatalysis & 205 \\
\hline Blending & IL & $\mathrm{H}_{2} \mathrm{~S}$ gas sensor & 206 \\
\hline Blending & Agar & Photocatalytic dye degradation & 208 and 209 \\
\hline Supramolecular & Partially hydrolyzed g- $\mathrm{C}_{3} \mathrm{~N}_{4}$ & Selective dye adsorption & 207 \\
\hline
\end{tabular}




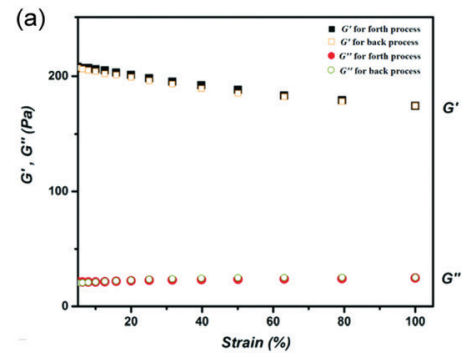

(d)

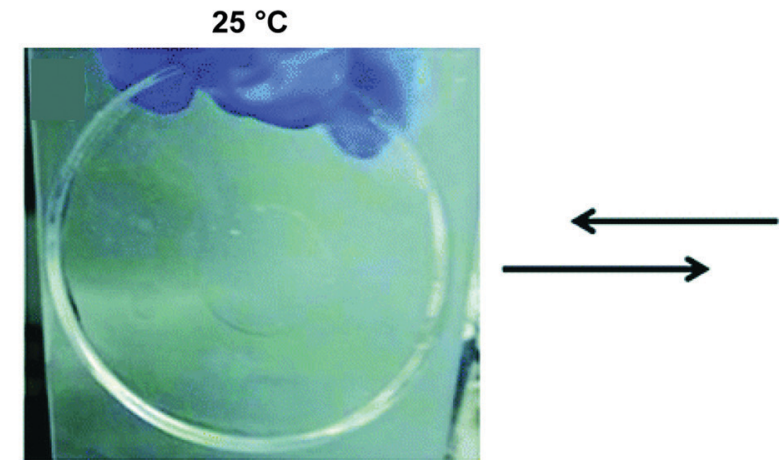

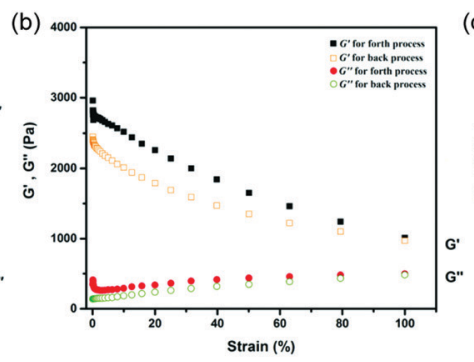

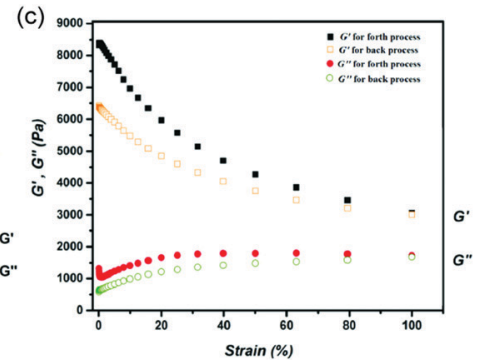

$40^{\circ} \mathrm{C}$

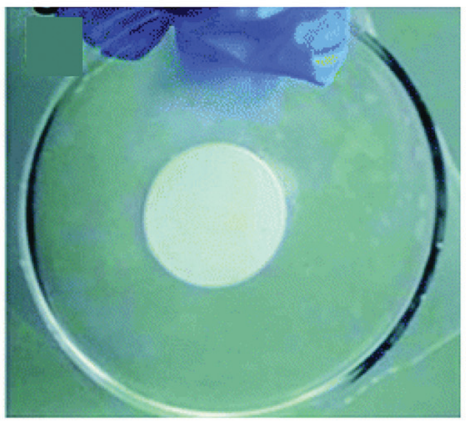

Fig. 9 Comparison of storage $\left(G^{\prime}\right.$, black and orange) and loss modulus ( $G^{\prime \prime}$, red and green) values of g- $C_{3} N_{4}$ free $N, N$-dimethylacrylamide (DMA) hydrogel (a), $g-C_{3} N_{4}$ embedded DMA hydrogel without covalent bonding (b), and $g-C_{3} N_{4}$ derived DMA hydrogels with nanosheet integration (c) (Reprinted with permission. ${ }^{64}$ Copyright 2017 American Chemical Society). (d) Pictures of a monolithic NIPAM/g- $\mathrm{C}_{3} \mathrm{~N}_{4}$ hydrogel at ambient temperature and elevated temperature, respectively (Licensed under CC-BY). ${ }^{190}$

incorporated g- $\mathrm{C}_{3} \mathrm{~N}_{4}$ into acrylamide hydrogels for gel electrophoresis via a redox polymerization of AAm and MBA. ${ }^{192}$ Due to the thermal conductivity of $\mathrm{g}-\mathrm{C}_{3} \mathrm{~N}_{4}$, Joule heating in the hydrogels was reduced and band broadening in the electrophoresis was lowered. Moreover, the presence of $g-\mathrm{C}_{3} \mathrm{~N}_{4}$ allowed to refrain from utilization of tetramethyl ethylenediamine as polymerization catalyst, which can be a disadvantage for some analytes.

As $g-\mathrm{C}_{3} \mathrm{~N}_{4}$ provides the opportunity to modify the surface charge (zeta potential), surface area and light absorption via variation in the precursor composition, ${ }^{43,194,195}$ effects of the precursor composition on mechanical properties were investigated as well. Notably, the zeta potential had a profound effect on storage modulus. It was found that stronger negative zeta potential g- $\mathrm{C}_{3} \mathrm{~N}_{4}$ compounds led to stronger hydrogels. ${ }^{64}$ Such an effect can be explained by $\mathrm{g}-\mathrm{C}_{3} \mathrm{~N}_{4}$ sheet repulsion that increases with more negative zeta potentials. A similar effect was already described in the literature for other reinforcing particles. ${ }^{185,188}$ The effect of surface charge was further investigated by our group employing AHPA-modified $\mathrm{g}-\mathrm{C}_{3} \mathrm{~N}_{4}$, which features significantly lower zeta potentials and high dispersibilities due to the sulfonic acid group. ${ }^{193}$ A mixture of AAm, DMA and MBA were used as monomers together with CM-AHPA as initiator. The hydrogels obtained were rather soft with $G^{\prime}$ in the range of 100-200 Pa and contained solid contents below $10 \mathrm{wt} \%$. However, the hydrogels featured remarkable compression properties, e.g. withstand loads above $12 \mathrm{MPa}$ (Fig. 10) and resisted multiple hits with a hammer. Probably, the extreme compressibility is due to the fact that the gels contained highly negatively charged $\mathrm{g}-\mathrm{C}_{3} \mathrm{~N}_{4}$, which shows significant repulsion of the $\mathrm{g}^{-} \mathrm{C}_{3} \mathrm{~N}_{4}$ sheets in compression. In addition, the gels were soft and could dissipate
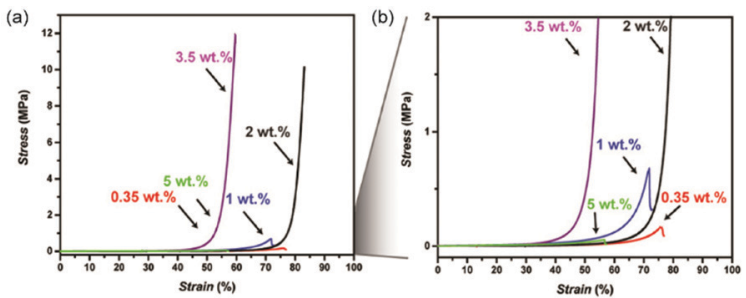

(c)
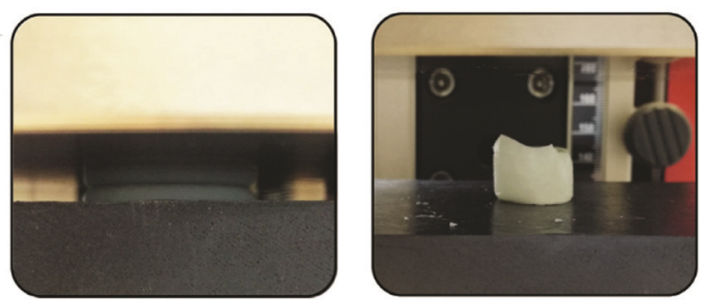

Fig. 10 (a) Compression test results of g- $\mathrm{C}_{3} \mathrm{~N}_{4}$-AHPA ( $\mathrm{g}-\mathrm{C}_{3} \mathrm{~N}_{4}$-3-allyloxy-2hydroxy-1-propanesulfonic acid sodium salt)-based hydrogels (red: $0.35 \mathrm{wt} \%$; blue: 1 wt\%; black: 2 wt\%; violet: 3.5 wt\%; green: 5 wt\%), (b) magnification of compression test results of $\mathrm{g}-\mathrm{C}_{3} \mathrm{~N}_{4}$-AHPA hydrogels, (c) images of $2 \mathrm{wt} \%$ $\mathrm{g}-\mathrm{C}_{3} \mathrm{~N}_{4}$-AHPA hydrogel during (left) and after (right) compression (Reproduced with permission. ${ }^{193}$ Copyright 2019 John Wiley and Sons).

the compressive force over the whole structure by electrostatic coupling. Compression led to a complete flattening of the structure and a return to the initial shape after release of the force. In order to get further insights into the origin of the remarkable compression properties, hydrogels were formed from the individual monomers with MBA. It was found that the DMA-based hydrogels were stronger but less compression resistant, while the AAm-based hydrogels were weaker but more resistant to compression. Swelling the AAm/DMA 

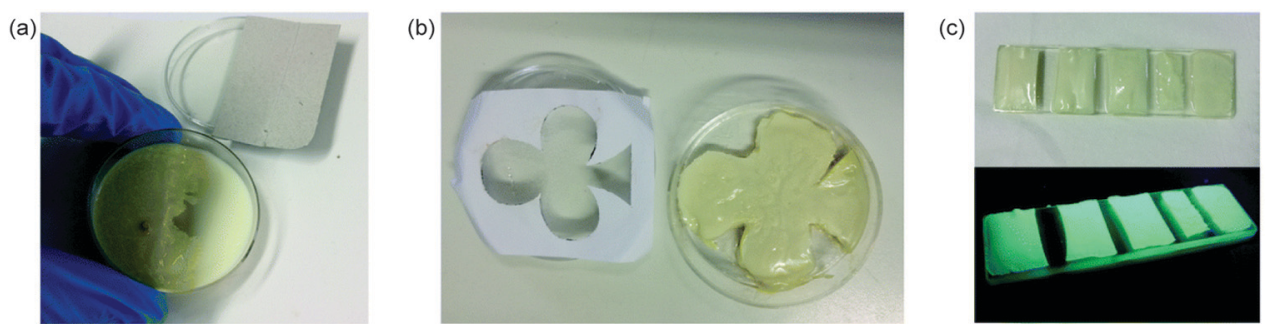

Fig. 11 Spatially controlled photopolymerization for gel formation: (a) formation of a self-standing half-circle, (b) self-standing club shape and (c) photopatterning of stripes on a glass slide (Licensed under CC-BY). ${ }^{196}$

hydrogels with salt solution $\left(\mathrm{NaCl}\right.$ or $\left.\mathrm{CaCl}_{2}\right)$ showed increased strength but less compressibility, which might be due to the screening of the negative charges on the $\mathrm{g}-\mathrm{C}_{3} \mathrm{~N}_{4}$ surface. Hence, the surface charge of $\mathrm{g}-\mathrm{C}_{3} \mathrm{~N}_{4}$ is certainly the main reason for the enhanced compressibility, while the monomer mixture supports compressibility due to enhanced elasticity, which leads to improved distribution of the stress in the network.

Regarding the mechanical properties of the hydrogels, not only the charge on the $\mathrm{g}-\mathrm{C}_{3} \mathrm{~N}_{4}$ matters but also the amount of incorporated $\mathrm{g}-\mathrm{C}_{3} \mathrm{~N}_{4}$. Therefore, EG/water mixtures were used to increase the amount of non-functionalized $\mathrm{g}^{-} \mathrm{C}_{3} \mathrm{~N}_{4}$ during hydrogel formation. ${ }^{196}$ Incorporating $\mathrm{g}-\mathrm{C}_{3} \mathrm{~N}_{4}$ contents up to $4 \mathrm{wt} \%$ led to hydrogels with $G^{\prime}$ of $88 \mathrm{kPa}$ for $2 \mathrm{wt} \%, 430 \mathrm{kPa}$ for $3 \mathrm{wt} \%$ and $729 \mathrm{kPa}$ for $4 \mathrm{wt} \%$ of $\mathrm{g}-\mathrm{C}_{3} \mathrm{~N}_{4}$ at $0.1 \%$ strain, which is a remarkable increase of two orders of magnitude compared to the first hydrogels with $0.6 \mathrm{wt} \% \mathrm{~g}-\mathrm{C}_{3} \mathrm{~N}_{4}$. In addition to enhanced mechanical performance, hydrogelation was much faster with higher $\mathrm{g}-\mathrm{C}_{3} \mathrm{~N}_{4}$ content which proves $\mathrm{g}-\mathrm{C}_{3} \mathrm{~N}_{4}$ acts as photoinitiator. As the hydrogel formation is photoinitiated, patterning was investigated as well. For that, parts of the reaction mixture were covered with a photomask to obtain an inversely shaped hydrogel (Scheme 5b and Fig. 11). The success of such experiments also proves that there is no significant radical transfer to dark area (solution) and the polymerization takes place only in the illuminated area via $\mathrm{g}-\mathrm{C}_{3} \mathrm{~N}_{4}$ initiation. In order to enable the fabrication of hydrogels with a broader range of monomers, e.g. charged monomers, our group utilized g- $\mathrm{C}_{3} \mathrm{~N}_{4}$-PDMA prepolymer formed in EG/water mixture without crosslinker. ${ }^{82}$ With prepolymer, hydrogels from 3-sulfopropyl methacrylate potassium salt (SPMA) and DMA were obtained. The SPMA monomer introduces negative charges into the hydrogel structure, which is a useful feature for low friction surfaces. ${ }^{197}$ Hence, hydrogels with both very low friction coefficients (around 0.03) and remarkable compression properties due to g- $\mathrm{C}_{3} \mathrm{~N}_{4}$ incorporation were obtained. This combination of properties is rather uncommon and challenging to achieve but of particular interest for applications, e.g. in artificial cartilage. ${ }^{198}$

\subsection{Utilization of photophysical properties}

The incorporation of $\mathrm{g}-\mathrm{C}_{3} \mathrm{~N}_{4}$ into hydrogels occurs under retention of its photophysical properties in the dispersed state inside of the network (Table 2). As such, various properties are accessible, e.g. photocatalysis or water contaminant degradation. Dong and coworkers obtained acrylamide-based hydrogels for "light filtering" applications. ${ }^{199}$ AAm was utilized as monomer in a visible light induced polymerization. Due to the hydrogen bonding interactions between $g-\mathrm{C}_{3} \mathrm{~N}_{4}$ and PAAm in the hydrogel self-healing was observed after cutting the hydrogel. Similar mechanical properties (compression and tensile) were observed before and after healing. The hydrogels featured high photostability and could be utilized for UV shielding due to the broad absorption of $\mathrm{g}-\mathrm{C}_{3} \mathrm{~N}_{4}$ in the gel. For example, for UVA, UVB and UVC a transmittance of 0 to $28 \%$ was observed, while at $550 \mathrm{~nm}$ a transmittance of $89 \%$ was measured. Thus, these gels might be used as sun-light blockers.

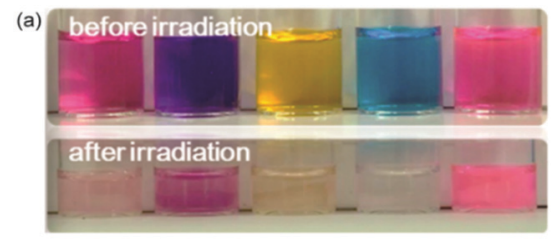

(b)

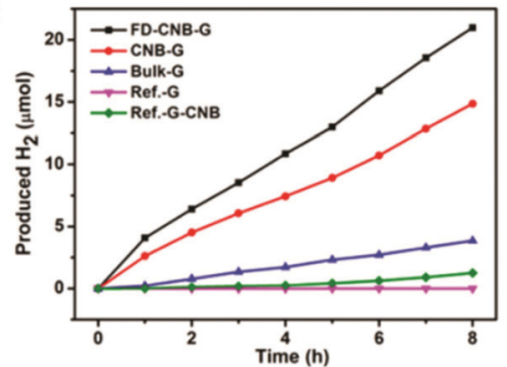

(c)

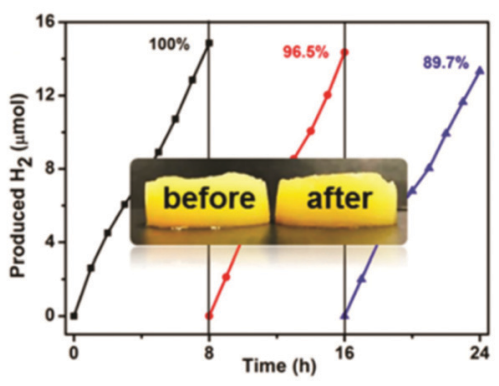

Fig. 12 (a) Photodegradation of various dyes catalyzed by a $\mathrm{g}-\mathrm{C}_{3} \mathrm{~N}_{4}$ hydrogel (congo red, crystal violet, methyl orange, $M B$, and $\mathrm{RhB}$, from left to right). (b) Kinetics of $\mathrm{H}_{2}$ production from water with $\mathrm{g}-\mathrm{C}_{3} \mathrm{~N}_{4}$ hydrogels (FD-CNB-G: freeze dried $\mathrm{g}-\mathrm{C}_{3} \mathrm{~N}_{4}$-based hydrogel and $\mathrm{CNB}-\mathrm{G}$ : $\mathrm{g}-\mathrm{C}_{3} \mathrm{~N}_{4}$ based hydrogel) and references (Bulk-G: hydrogel from melamine-derived g- $\mathrm{C}_{3} \mathrm{~N}_{4}$; ref.-G: hydrogel without g- $\mathrm{C}_{3} \mathrm{~N}_{4}$ incorporation; ref.-G-CNB: reference gel after adsorption of $\mathrm{g}-\mathrm{C}_{3} \mathrm{~N}_{4}$ suspension) under white LED irradiation. (c) Cycling measurements of $\mathrm{H}_{2}$ generation via wet $\mathrm{g}-\mathrm{C}_{3} \mathrm{~N}_{4}$ hydrogel (the inset shows the $\mathrm{g}-\mathrm{C}_{3} \mathrm{~N}_{4}$ hydrogel before and after $\mathrm{H}_{2}$ production) (Reprinted with permission. ${ }^{191}$ Copyright 2017 American Chemical Society). 
Shalom and coworkers formed $\mathrm{g}-\mathrm{C}_{3} \mathrm{~N}_{4}$-based hydrogels for photocatalytic applications (Fig. 12a). ${ }^{191}$ For example dye degradation reactions could be performed easily. Several dyes were probed as reference compounds for other impurities in waste water. Depending on the type, absorption in the gel proceed with different efficiency, which was mainly attributed to ionic interactions. In addition, hydrogen evolution could be performed after addition of platinum cocatalyst (Fig. 12b) and the catalytic hydrogel could be recycled easily (Fig. 12c). Another hydrogel for waste water treatment was described by Yao and coworkers. ${ }^{200}$ In this case, bentonite, g- $\mathrm{C}_{3} \mathrm{~N}_{4}$, AAm and MBA were combined to form hydrogel monoliths via thermal polymerization. Finally, the monoliths were cut into small cubes, and adsorption of tetracycline was tested. The incorporation of bentonite led to enhanced adsorption of the organic contamination. In the next step, tetracycline was degraded via visible light irradiation. Furthermore, adsorption and degradation were studied in the flow process that showed a high removal efficiency and cycling stability.

Another photocatalytic process employing $\mathrm{g}-\mathrm{C}_{3} \mathrm{~N}_{4}$-based hydrogels was presented by Lamkaho and Randorn. ${ }^{201}$ A PAAm hydrogel was formed via photopolymerization of AAm and MBA under UV light. Finally, the hydrogel was utilized for the photocatalytic reduction of $\mathrm{Cr}(\mathrm{vi})$ to $\mathrm{Cr}$ (III). Cui and coworkers described a hydrogel formed from $\mathrm{g}-\mathrm{C}_{3} \mathrm{~N}_{4}$, graphene and $\mathrm{PPy} .{ }^{202}$ Improvements of the photocatalytic properties were obtained via graphene as electron transporter and PPy as hole transporter. The obtained hydrogels were utilized for photodegradation of phenol and reduction/adsorption of $\mathrm{Cr}(\mathrm{VI})$. Tu and coworkers introduced another application of $\mathrm{g}-\mathrm{C}_{3} \mathrm{~N}_{4}$ based hydrogels. An AAm/acrylic acid-based hydrogel was formed via thermal initiation that could be utilized as sensor for $\mathrm{Ag}^{+}$ions. ${ }^{203}$ Due to the acrylic acid incorporation, the hydrogels were $\mathrm{pH}$ sensitive, i.e. the swelling state changed according to $\mathrm{pH}$. Moreover, the hydrogels showed fluorescent behavior because of the $\mathrm{g}-\mathrm{C}_{3} \mathrm{~N}_{4}$ incorporation. The fluorescence could in turn be utilized for sensing. The change in fluorescence after addition of various metal ions was tested, and in the case of $\mathrm{Ag}^{+}$a significant quenching effect was observed down to concentrations of $6.31 \mu \mathrm{M}$. Notably, the detection of $\mathrm{Ag}^{+}$was still possible when other contaminant ions were present.

\subsection{Blending and supramolecular hydrogels}

In addition to covalent hydrogels formed via polymerization, g- $\mathrm{C}_{3} \mathrm{~N}_{4}$ was incorporated into hydrogels via blending or supramolecular interactions as well (Scheme $5 \mathrm{c}$ and Table 2). For example, Park and coworkers presented the combination of g- $\mathrm{C}_{3} \mathrm{~N}_{4}$ and peptide materials. ${ }^{204}$ In those experiments, Fmocdiphenylalanine (FMOCDPA) was utilized to undergo self-assembly in the presence of $\mathrm{g}-\mathrm{C}_{3} \mathrm{~N}_{4}$ yielding a hydrogel. The formed hydrogel was utilized to reduce $\mathrm{NAD}^{+}$to $\mathrm{NADH}$. Moreover, the incorporation of an enzyme facilitated the combination of photo and enzymatic catalysis. A remarkable hydrogel was described by

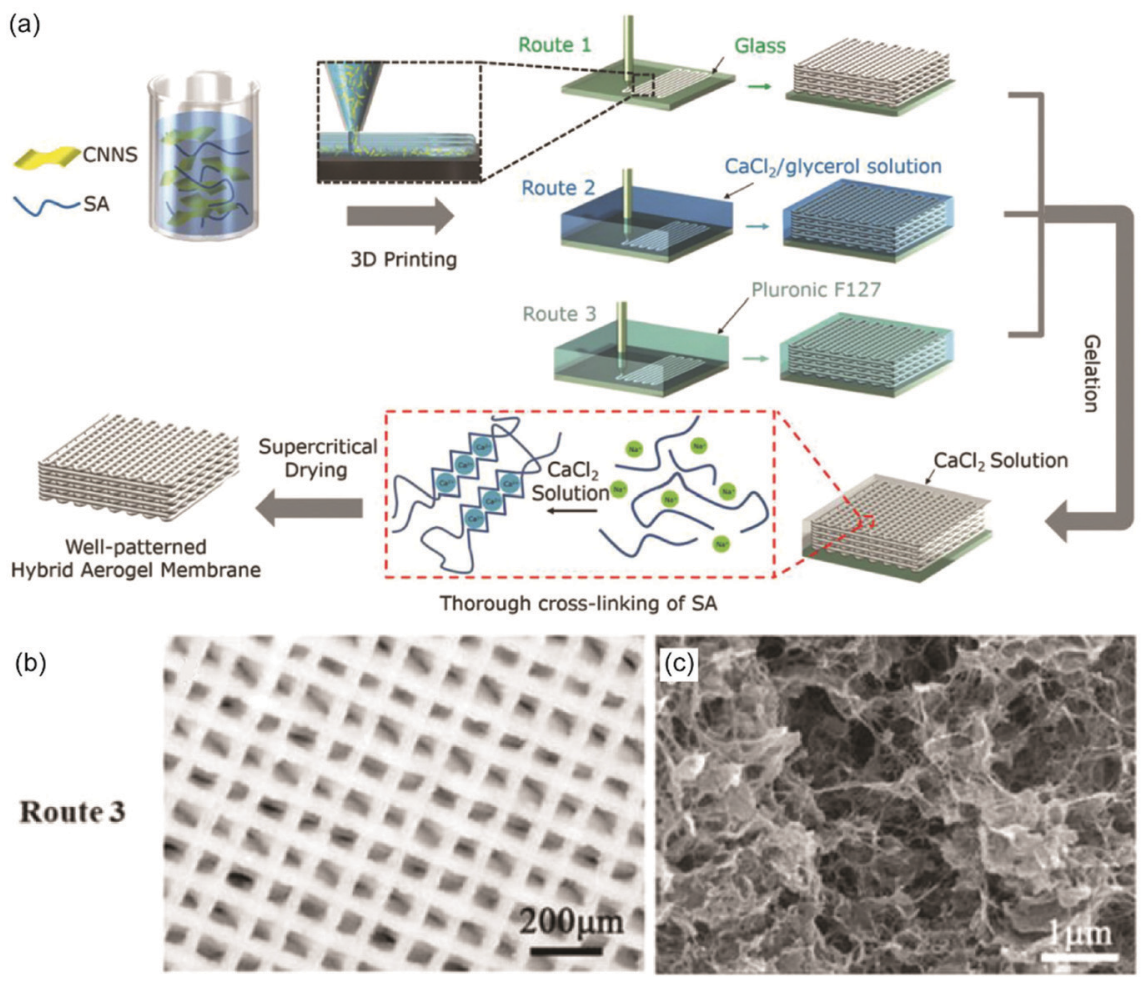

Fig. 13 (a) Schematic illustration of the 3D fabrication process: a highly concentrated homogeneous CNNS-SA (g- $\mathrm{C}_{3} \mathrm{~N}_{4}$ nano sheet-sodium alginate) ink was extruded and directly printed onto a glass substrate covered with a layer of Vaseline (Route 1 ), into a reservoir composed of a CaCl $2 / \mathrm{glycerol} \mathrm{solution}$ (Route 2) or Pluronic F127 (Route 3). Subsequently, the printed lattices were submerged in a $\mathrm{CaCl}_{2}$ aqueous solution overnight to crosslink the SA. (b) Optical image of a woodpile structure (mass ratio CN : SA =1:2) printed via Pluronic F127 (Route 3 ) and (c) a cross-sectional SEM image (Reprinted with permission. ${ }^{205}$ Copyright 2018 John Wiley and Sons). 
Fan and coworkers, who combined g- $\mathrm{C}_{3} \mathrm{~N}_{4}$ with the $\mathrm{Ca}^{2+} /$ alginate supramolecular hydrogel and 3D printing (Fig. 13a). ${ }^{205}$ Hence, 3D hydrogel scaffolds were obtained that could be utilized for photocatalytic tasks. A carbon nitride nanosheet/sodium alginate (CNNSSA)-based ink was printed and crosslinked in $\mathrm{CaCl}_{2} /$ glycerol solution (Fig. 13b and c). Inclusion of gold nanopyramids in such 3D scaffolds boosted the photocatalytic activity for solar wastewater remediation. Thus, the gel architecture could be utilized to tailor the catalysis efficiency via enhanced substrate transport. Ayajan and coworkers presented a gel from $\mathrm{g}-\mathrm{C}_{3} \mathrm{~N}_{4}$ and ionic liquids (IL) forming an amphiphilic network that was utilized as $\mathrm{H}_{2} \mathrm{~S}$ gas sensor at ambient temperature. ${ }^{206}$ ILs served as exfoliating agent for $\mathrm{g}-\mathrm{C}_{3} \mathrm{~N}_{4}$ sheets at high temperatures, and gel formation was observed at $200{ }^{\circ} \mathrm{C}$ after $24 \mathrm{~h}$, where exfoliated $\mathrm{g}-\mathrm{C}_{3} \mathrm{~N}_{4}$ nanosheets assembled in the IL matrix.

A hydrogel solely formed from $\mathrm{g}-\mathrm{C}_{3} \mathrm{~N}_{4}$ was investigated by Zhang and coworkers. ${ }^{207}$ Here, g- $\mathrm{C}_{3} \mathrm{~N}_{4}$ was partially hydrolyzed in sodium hydroxide solution. The obtained material formed reversible hydrogel structures via bubbling with $\mathrm{CO}_{2}$ or $\mathrm{N}_{2}$ that could be utilized for selective dye absorption. In the presence of agar, heating-cooling polymerization yielded hydrogels including g- $\mathrm{C}_{3} \mathrm{~N}_{4} \cdot{ }^{208}$ The agar-based hydrogels were further utilized for effective photocatalytic degradation due to enhanced adsorption capacity. In a similar way, Zhu and coworkers utilized a g- $\mathrm{C}_{3} \mathrm{~N}_{4} /$ agar hydrogel for photocatalytic tasks. ${ }^{209}$ Therefore, g- $\mathrm{C}_{3} \mathrm{~N}_{4}$ and agar were dispersed in water and heated. After cooling a hydrogel was obtained that was used for the photodegradation of MB and phenol. A significant activity was obtained due to the adsorptive behaviour of the hydrogel.

\section{Conclusion and outlook}

Combining exfoliated $\mathrm{g}-\mathrm{C}_{3} \mathrm{~N}_{4}$ nanosheets with polymers is a recent hotspot of materials research, thus enabling many advanced functionalities and hybrid materials with unusual properties extending the previous range of the possible. The development is mainly driven by typical g- $\mathrm{C}_{3} \mathrm{~N}_{4}$ properties, such as photoinitiation, photocatalysis, or photoluminescence. However, it turned out that these properties are significantly improved or optimized in the polymer hybrids, which is due to improved delamination, but also due to synergies of the two sides. Introducing for instance conducting polymers to $\mathrm{g}-\mathrm{C}_{3} \mathrm{~N}_{4}$ enables overcoming the drawback of low electron conductivity of $\mathrm{g}-\mathrm{C}_{3} \mathrm{~N}_{4}$, and hence the photocatalytic or $\mathrm{H}_{2}$ evolution properties of $\mathrm{g}-\mathrm{C}_{3} \mathrm{~N}_{4}$ are promoted. In biosensor systems, polymer functionalized $\mathrm{g}-\mathrm{C}_{3} \mathrm{~N}_{4}$ has shown an improved sensitivity and selectivity, which we attribute to improved dispersion and access to the sensing sites. Polymer modified g- $\mathrm{C}_{3} \mathrm{~N}_{4}$ showed enhanced dispersibility and processability, and for instance can be employed in film formation.

On the other hand, $\mathrm{g}-\mathrm{C}_{3} \mathrm{~N}_{4}$ with its multiple properties brings advantages to polymer materials as well. For example, doping the polymer matrix with $\mathrm{g}-\mathrm{C}_{3} \mathrm{~N}_{4}$ enhances the performance of electrode materials in energy storage and improves stability as well as efficiency compared to the pure polymer matrix. Photoinitiation with $\mathrm{g}-\mathrm{C}_{3} \mathrm{~N}_{4}$ facilitates polymerization in solution and on $\mathrm{g}-\mathrm{C}_{3} \mathrm{~N}_{4}$ to obtain $\mathrm{g}-\mathrm{C}_{3} \mathrm{~N}_{4} /$ polymer nanocomposites with inherent photoluminescence that can be applied for various applications. In addition, combination of $\mathrm{g}-\mathrm{C}_{3} \mathrm{~N}_{4}$ with polymers enhances the thermal and mechanical properties of polymer materials. In the realm of bulk soft materials, $\mathrm{g}-\mathrm{C}_{3} \mathrm{~N}_{4}$ is particularly useful as reinforcer in hydrogels and $g-\mathrm{C}_{3} \mathrm{~N}_{4} /$ hydrogel hybrids can be obtained. Overall, the plethora of monomer combinations and $\mathrm{g}-\mathrm{C}_{3} \mathrm{~N}_{4}$ types allows the fabrication of tailored hydrogel materials with very unusual and most useful properties, e.g. ultralow friction, being thermoresponsive, or tough but compressible. Indeed, the storage modulus of hydrogels could be varied over a broad range (approximately $7 \mathrm{kPa}$ to $700 \mathrm{kPa}$ ) via $g-\mathrm{C}_{3} \mathrm{~N}_{4}$ content and type, only, while the toughness of the material could be adjusted by monomer mixtures, e.g. AAm and DMA. By inherent photopolymerization, reinforced hydrogels can be obtained also in a spatially controlled way and directions of additive manufacturing are certainly a promising approach a toolbox is needed for. ${ }^{210,211}$

Polymers might pave the way for novel applications for g- $\mathrm{C}_{3} \mathrm{~N}_{4}$, however some main issues still need to be addressed. Although promising results were reported so far, the research for $\mathrm{g}-\mathrm{C}_{3} \mathrm{~N}_{4} /$ polymer hybrids is still in the infant stage, and further investigations and developments are still required. To date, there are a number of issues, which need to be resolved for improved combination of $\mathrm{g}-\mathrm{C}_{3} \mathrm{~N}_{4}$ and polymer. For example, most of the research reported utilizes the simple blending method of fabrication, thus connection between polymer and $\mathrm{g}^{-} \mathrm{C}_{3} \mathrm{~N}_{4}$ is enabled by physical interaction, only, which may cause restrictions for the future commercial application. Moreover, the synthesis process mainly depends on organic solvents, which is not environment friendly when expanded to commercial scale, thus solvent-free, mechanochemical and green routes should be developed in the future research. In oxygen evolution and organic synthesis, g- $\mathrm{C}_{3} \mathrm{~N}_{4}$ is also of great significance as a photocatalyst. Nevertheless, g- $\mathrm{C}_{3} \mathrm{~N}_{4}$ /polymer hybrids are rarely applied in these areas so far. As such, one can expect significant outcomes in the future in organic synthesis and oxygen evolution. Overall, g- $\mathrm{C}_{3} \mathrm{~N}_{4}$ has a promising future especially in energy conversion and storage, and enhancing surface area of $\mathrm{g}-\mathrm{C}_{3} \mathrm{~N}_{4}$ by polymers might become key for utilization of $\mathrm{g}-\mathrm{C}_{3} \mathrm{~N}_{4}$ in batteries, supercapacitors and other high-efficiency energy conversion devices.

Polymers have opened up new doors for $\mathrm{g}-\mathrm{C}_{3} \mathrm{~N}_{4}$ which could not be imagined seven years ago. Previously, dispersibility and processability issues were the main problems for integration of g- $\mathrm{C}_{3} \mathrm{~N}_{4}$ materials, however with the current ideas in mind dispersibility becomes less of an issue. Ultimately, $\mathrm{g}-\mathrm{C}_{3} \mathrm{~N}_{4}$ is a sustainable and cheap alternative for other semiconductors, and we believe that with precise tailoring of both $g-\mathrm{C}_{3} \mathrm{~N}_{4}$ properties and design of a surrounding polymer, g- $\mathrm{C}_{3} \mathrm{~N}_{4}$ will play an increasingly important role both in academia and in the industry of the future.

\section{Conflicts of interest}

There are no conflicts to declare. 


\section{Acknowledgements}

The authors are grateful for funding from Max-Planck society and the University of Glasgow as well as funding for Open Access from the University of Glasgow.

\section{Notes and references}

1 D. Larcher and J. M. Tarascon, Nat. Chem., 2014, 7, 19.

2 Y. Zhu, C. Romain and C. K. Williams, Nature, 2016, 540, 354.

3 Y. Zheng, L. Lin, B. Wang and X. Wang, Angew. Chem., Int. Ed., 2015, 54, 12868-12884.

4 D. Esposito and M. Antonietti, Chem. Soc. Rev., 2015, 44, 5821-5835.

5 F. H. Isikgor and C. R. Becer, Polym. Chem., 2015, 6, 4497-4559.

6 M. Chhowalla, D. Jena and H. Zhang, Nat. Rev. Mater., 2016, 1, 16052.

7 T. M. Brenner, D. A. Egger, L. Kronik, G. Hodes and D. Cahen, Nat. Rev. Mater., 2016, 1, 15007.

8 X. Li, J. Yu, J. Low, Y. Fang, J. Xiao and X. Chen, J. Mater. Chem. A, 2015, 3, 2485-2534.

9 X. Wang, S. Blechert and M. Antonietti, ACS Catal., 2012, 2, 1596-1606.

10 X. Wang, K. Maeda, A. Thomas, K. Takanabe, G. Xin, J. M. Carlsson, K. Domen and M. Antonietti, Nat. Mater., 2008, 8, 76.

11 J. Liu, H. Wang and M. Antonietti, Chem. Soc. Rev., 2016, 45, 2308-2326.

12 G. Algara-Siller, N. Severin, S. Y. Chong, T. Björkman, R. G. Palgrave, A. Laybourn, M. Antonietti, Y. Z. Khimyak, A. V. Krasheninnikov, J. P. Rabe, U. Kaiser, A. I. Cooper, A. Thomas and M. J. Bojdys, Angew. Chem., Int. Ed., 2014, 53, 7450-7455.

13 W. J. Ong, L. L. Tan, Y. H. Ng, S. T. Yong and S. P. Chai, Chem. Rev., 2016, 116, 7159-7329.

14 J. Ran, T. Y. Ma, G. Gao, X.-W. Du and S. Z. Qiao, Energy Environ. Sci., 2015, 8, 3708-3717.

15 S. Hu, F. Li, Z. Fan, F. Wang, Y. Zhao and Z. Lv, Dalton Trans., 2015, 44, 1084-1092.

16 K. K. R. Datta, B. V. S. Reddy, K. Ariga and A. Vinu, Angew. Chem., Int. Ed., 2010, 49, 5961-5965.

17 B. Kurpil, B. Kumru, T. Heil, M. Antonietti and A. Savateev, Green Chem., 2018, 20, 838-842.

18 K. Schwinghammer, B. Tuffy, M. B. Mesch, E. Wirnhier, C. Martineau, F. Taulelle, W. Schnick, J. Senker and B. V. Lotsch, Angew. Chem., Int. Ed., 2013, 52, 2435-2439.

19 G. Zhang, G. Li, Z. A. Lan, L. Lin, A. Savateev, T. Heil, S. Zafeiratos, X. Wang and M. Antonietti, Angew. Chem., Int. Ed., 2017, 56, 13445-13449.

20 J. Yang, C.-R. Han, X.-M. Zhang, F. Xu and R.-C. Sun, Macromolecules, 2014, 47, 4077-4086.

21 N. Cheng, J. Tian, Q. Liu, C. Ge, A. H. Qusti, A. M. Asiri, A. O. Al-Youbi and X. Sun, ACS Appl. Mater. Interfaces, 2013, 5, 6815-6819.

22 R. Kuriki, K. Sekizawa, O. Ishitani and K. Maeda, Angew. Chem., Int. Ed., 2015, 54, 2406-2409.
23 J. Lin, Z. Pan and X. Wang, ACS Sustainable Chem. Eng., 2014, 2, 353-358.

24 K. Xiao, L. Chen, R. Chen, T. Heil, S. D. C. Lemus, F. Fan, L. Wen, L. Jiang and M. Antonietti, Nat. Commun., 2019, 10, 74.

25 K. Xiao, B. Kumru, L. Chen, L. Jiang, B. V. K. J. Schmidt and M. Antonietti, Beilstein J. Nanotechnol., 2019, 10, 1316-1323.

26 G. Peng, M. Volokh, J. Tzadikov, J. Sun and M. Shalom, Adv. Energy Mater., 2018, 8, 1800566.

27 X. Chen, Q. Liu, Q. Wu, P. Du, J. Zhu, S. Dai and S. Yang, Adv. Funct. Mater., 2016, 26, 1719-1728.

28 T. R. Chetia, M. S. Ansari and M. Qureshi, J. Mater. Chem. A, 2016, 4, 5528-5541.

29 D. Cruz, J. Garcia Cerrillo, B. Kumru, N. Li, J. Dario Perea, B. Schmidt, I. Lauermann, C. J. Brabec and M. Antonietti, J. Am. Chem. Soc., 2019, 140, 17532-17537.

30 J. Xu and M. Antonietti, J. Am. Chem. Soc., 2017, 139, 6026-6029.

31 Y. Shiraishi, S. Kanazawa, Y. Sugano, D. Tsukamoto, H. Sakamoto, S. Ichikawa and T. Hirai, ACS Catal., 2014, 4, 774-780.

32 Y. Chen, W. Huang, D. He, Y. Situ and H. Huang, ACS Appl. Mater. Interfaces, 2014, 6, 14405-14414.

33 P. Gibot, F. Schnell and D. Spitzer, Microporous Mesoporous Mater., 2016, 219, 42-47.

34 D. A. Erdogan, M. Sevim, E. Kisa, D. B. Emiroglu, M. Karatok, E. I. Vovk, M. Bjerring, Ü. Akbey, Ö. Metin and E. Ozensoy, Top. Catal., 2016, 59, 1305-1318.

35 M. Xie, W. Wei, Z. Jiang, Y. Xu and J. Xie, Ceram. Int., 2016, 42, 4158-4170.

36 G. Li, Z. Lian, W. Wang, D. Zhang and H. Li, Nano Energy, 2016, 19, 446-454.

37 J. Fang, H. Fan, M. Li and C. Long, J. Mater. Chem. A, 2015, 3, 13819-13826.

38 Q. Cui, J. Xu, X. Wang, L. Li, M. Antonietti and M. Shalom, Angew. Chem., Int. Ed., 2016, 55, 3672-3676.

39 K. Xiao, B. Tu, L. Chen, T. Heil, L. Wen, L. Jiang and M. Antonietti, Angew. Chem., Int. Ed., 2019, 58, 12574-12579.

40 D. Xiao, D. Yuan, H. He and J. Lu, Luminescence, 2013, 28, 612-615.

41 J. Bian, Q. Li, C. Huang, J. Li, Y. Guo, M. Zaw and R.-Q. Zhang, Nano Energy, 2015, 15, 353-361.

42 M. Shalom, S. Inal, C. Fettkenhauer, D. Neher and M. Antonietti, J. Am. Chem. Soc., 2013, 135, 7118-7121.

43 J. Barrio and M. Shalom, ChemCatChem, 2018, 10, 5573-5586.

44 K. S. Lakhi, W. S. Cha, S. Joseph, B. J. Wood, S. S. Aldeyab, G. Lawrence, J.-H. Choy and A. Vinu, Catal. Today, 2015, 243, 209-217.

45 M. Groenewolt and M. Antonietti, Adv. Mater., 2005, 17, 1789-1792.

46 Y. Wang, X. Wang, M. Antonietti and Y. Zhang, ChemSusChem, 2010, 3, 435-439.

47 J. Zhou, Y. Yang and C.-y. Zhang, Chem. Commun., 2013, 49, 8605-8607.

48 J. Zhang, G. Zhang, X. Chen, S. Lin, L. Möhlmann, G. Dołega, G. Lipner, M. Antonietti, S. Blechert and X. Wang, Angew. Chem., Int. Ed., 2012, 51, 3183-3187. 
49 Y. Chen, F. Ding, A. Khaing, D. Yang and Z. Jiang, Appl. Surf. Sci., 2019, 757-764.

50 J. Barrio, L. Lin, P. Amo-Ochoa, J. Tzadikov, G. Peng, J. Sun, F. Zamora, X. Wang and M. Shalom, Small, 2018, 14, 1800633.

51 J. Barrio and M. Shalom, ACS Appl. Mater. Interfaces, 2018, 10, 39688-39694.

52 T. Jordan, N. Fechler, J. Xu, T. J. K. Brenner, M. Antonietti and M. Shalom, ChemCatChem, 2015, 7, 2826-2830.

53 Q. Cao, Q. Cui, Y. Yang, J. Xu, C. Han and L. Li, Chem. Eur. J., 2018, 24, 2286-2291.

54 B. Kiskan, J. Zhang, X. Wang, M. Antonietti and Y. Yagci, ACS Macro Lett., 2012, 1, 546-549.

55 M. Al-Naji, B. Puertolas, B. Kumru, D. Cruz, M. Baumel, B. V. K. J. Schmidt, N. V. Tarakina and J. Perez-Ramirez, ChemSusChem, 2019, 12, 2628-2636.

56 S. Dadashi-Silab, M. A. Tasdelen, B. Kiskan, X. Wang, M. Antonietti and Y. Yagci, Macromol. Chem. Phys., 2014, 215, 675-681.

57 B. Kiskan, J. Zhang, X. Wang, M. Antonietti and Y. Yagci, ACS Macro Lett., 2012, 1, 546-549.

58 Q. Cao, T. Heil, B. Kumru, M. Antonietti and B. V. K. J. Schmidt, Polym. Chem., 2019, 10, 5315-5323.

59 D. J. Martin, K. Qiu, S. A. Shevlin, A. D. Handoko, X. Chen, Z. Guo and J. Tang, Angew. Chem., Int. Ed., 2014, 53, 9240-9245.

60 D. J. Martin, P. J. Reardon, S. J. Moniz and J. Tang, J. Am. Chem. Soc., 2014, 136, 12568-12571.

61 Q. Fu, Q. Ruan, T. G. McKenzie, A. Reyhani, J. Tang and G. G. Qiao, Macromolecules, 2017, 50, 7509-7516.

62 L. Zhang, G. Ye, X. Huo, S. Xu, J. Chen and K. Matyjaszewski, ACS Omega, 2019, 4, 16247-16255.

63 B. Kumru, J. Mendoza Mesa, M. Antonietti and M. Al-Naji, ACS Sustainable Chem. Eng., 2019, 7, 17574-17579.

64 B. Kumru, M. Shalom, M. Antonietti and B. V. K. J. Schmidt, Macromolecules, 2017, 50, 1862-1869.

65 E. G. Gillan, Chem. Mater., 2000, 12, 3906-3912.

66 J. Sun, R. Phatake, A. Azoulay, G. Peng, C. Han, J. Barrio, J. Xu, X. Wang and M. Shalom, Chem. - Eur. J., 2018, 24, 14921-14927.

67 H. Arazoe, D. Miyajima, K. Akaike, F. Araoka, E. Sato, T. Hikima, M. Kawamoto and T. Aida, Nat. Mater., 2016, 15, 1084.

68 N. Karjule, R. Phatake, M. Volokh, I. Hod and M. Shalom, Small Methods, 2019, 1900401.

69 G. Peng, L. Xing, J. Barrio, M. Volokh and M. Shalom, Angew. Chem., Int. Ed., 2018, 57, 1186-1192.

70 X. She, H. Xu, Y. Xu, J. Yan, J. Xia, L. Xu, Y. Song, Y. Jiang, Q. Zhang and H. Li, J. Mater. Chem. A, 2014, 2, 2563-2570.

71 Q. Han, B. Wang, Y. Zhao, C. Hu and L. Qu, Angew. Chem., Int. Ed., 2015, 54, 11433-11437.

72 L. Chen, D. Huang, S. Ren, T. Dong, Y. Chi and G. Chen, Nanoscale, 2013, 5, 225-230.

73 P. Niu, L. Zhang, G. Liu and H.-M. Cheng, Adv. Funct. Mater., 2012, 22, 4763-4770.

74 S. Yang, Y. Gong, J. Zhang, L. Zhan, L. Ma, Z. Fang, R. Vajtai, X. Wang and P. M. Ajayan, Adv. Mater., 2013, 25, 2452-2456.
75 J. K. Kim, S. Park, R. J. Yoo, H. J. Jeong, J. Oh, Y. J. Lee, S. Park and D. W. Kim, Chem. - Eur. J., 2018, 24, 3506-3511.

76 B. Kumru, M. Antonietti and B. V. K. J. Schmidt, Langmuir, 2017, 33, 9897-9906.

77 Y. Shi, B. Wang, L. Duan, Y. Zhu, Z. Gui, R. K. K. Yuen and Y. Hu, Ind. Eng. Chem. Res., 2016, 55, 7646-7654.

78 Q. Cui, J. Xu, X. Wang, L. Li, M. Antonietti and M. Shalom, Angew. Chem., Int. Ed., 2016, 55, 3672-3676.

79 X. Bu, J. Li, S. Yang, J. Sun, Y. Deng, Y. Yang, G. Wang, Z. Peng, P. He, X. Wang, G. Ding, J. Yang and X. Xie, ACS Appl. Mater. Interfaces, 2016, 8, 31419-31425.

80 R. B. N. Baig, S. Verma, M. N. Nadagouda and R. S. Varma, Sci. Rep., 2016, 6, 39387.

81 Y. Zheng, Z. Zhang, C. Li and S. Proulx, Mater. Res. Bull., 2016, 84, 46-56.

82 B. Kumru, V. Molinari, M. Hilgart, F. Rummel, M. Schäffler and B. V. K. J. Schmidt, Polym. Chem., 2019, 10, 3647-3656.

83 B. Kumru, D. Cruz, T. Heil, B. V. K. J. Schmidt and M. Antonietti, J. Am. Chem. Soc., 2018, 140, 17532-17537.

84 B. J. Blaiszik, S. L. B. Kramer, S. C. Olugebefola, J. S. Moore, N. R. Sottos and S. R. White, Annu. Rev. Mater. Res., 2010, 40, 179-211.

85 M. A. Stuart, W. T. Huck, J. Genzer, M. Muller, C. Ober, M. Stamm, G. B. Sukhorukov, I. Szleifer, V. V. Tsukruk, M. Urban, F. Winnik, S. Zauscher, I. Luzinov and S. Minko, Nat. Mater., 2010, 9, 101-113.

86 L. S. Nair and C. T. Laurencin, Prog. Polym. Sci., 2007, 32, 762-798.

87 Y. Wang and X. Jing, Polym. Adv. Technol., 2005, 16, 344-351.

88 J. Zhang, M. Zhang, L. Lin and X. Wang, Angew. Chem., Int. Ed., 2015, 54, 6297-6301.

89 Z. Zhao, Y. Sun and F. Dong, Nanoscale, 2015, 7, 15-37.

90 A. C. Balazs, T. Emrick and T. P. Russell, Science, 2006, 314, 1107.

91 T. Kuilla, S. Bhadra, D. Yao, N. H. Kim, S. Bose and J. H. Lee, Prog. Polym. Sci., 2010, 35, 1350-1375.

92 S. Patnaik, D. P. Sahoo and K. Parida, in Nanocomposites for Visible Light-induced Photocatalysis, ed. M. M. Khan, D. Pradhan and Y. Sohn, Springer International Publishing, Cham, 2017, pp. 251-294, DOI: 10.1007/978-3-319-62446-4_9.

93 Y. Zhang, F. Mao, H. Yan, K. Liu, H. Cao, J. Wu and D. Xiao, J. Mater. Chem. A, 2015, 3, 109-115.

94 Y. Sui, J. Liu, Y. Zhang, X. Tian and W. Chen, Nanoscale, 2013, 5, 9150-9155.

95 F. He, G. Chen, Y. Yu, S. Hao, Y. Zhou and Y. Zheng, ACS Appl. Mater. Interfaces, 2014, 6, 7171-7179.

96 H. Yan and Y. Huang, Chem. Commun., 2011, 47, 4168-4170.

97 A. Li, Q. Cao, G. Zhou, B. V. K. J. Schmidt, W. Zhu, X. Yuan, H. Huo, J. Gong and M. Antonietti, Angew. Chem., Int. Ed., 2019, 58, 14549-14555.

98 S. Roy and E. Reisner, Angew. Chem., Int. Ed., 2019, 58, 12180-12184.

99 K. Pandiselvi, H. Fang, X. Huang, J. Wang, X. Xu and T. Li, J. Hazard. Mater., 2016, 314, 67-77.

100 H. Lachheb, E. Puzenat, A. Houas, M. Ksibi, E. Elaloui, C. Guillard and J.-M. Herrmann, Appl. Catal., B, 2002, 39, 75-90. 
101 S. Xiao, Z. Wang, H. Ma, H. Yang and W. Xu, Adv. Powder Technol., 2014, 25, 574-581.

102 M. Panizza and G. Cerisola, Chem. Rev., 2009, 109, 6541-6569. 103 C. P. Athanasekou, N. G. Moustakas, S. Morales-Torres, L. M. Pastrana-Martínez, J. L. Figueiredo, J. L. Faria, A. M. T. Silva, J. M. Dona-Rodriguez, G. E. Romanos and P. Falaras, Appl. Catal., B, 2015, 178, 12-19.

104 Y. Zhao, Y. Zhang, A. Liu, Z. Wei and S. Liu, ACS Appl. Mater. Interfaces, 2017, 9, 4006-4014.

105 Y. Huang, H. Li, M. S. Balogun, W. Liu, Y. Tong, $\mathrm{X}$. Lu and H. Ji, ACS Appl. Mater. Interfaces, 2014, 6, 22920-22927.

106 W. Jiang, W. Luo, R. Zong, W. Yao, Z. Li and Y. Zhu, Small, 2016, 12, 4370-4378.

107 L. Ge, C. Han and J. Liu, J. Mater. Chem., 2012, 22, 11843-11850. 108 B. Vellaichamy and P. Periakaruppan, Ind. Eng. Chem. Res., 2018, 57, 6684-6695.

109 X. Bu, Y. Lu, S. Chen, D. Li, Z. Zhang and P. Qian, Chem. Eng. Sci., 2019, 355, 299-308.

110 T. Xu, F. Wu, Y. Gu, Y. Chen, J. Cai, W. Lu, H. Hu, Z. Zhu and W. Chen, RSC Adv., 2015, 5, 86505-86512.

111 N. H. Alias, J. Jaafar, S. Samitsu, N. Yusof, M. H. D. Othman, M. A. Rahman, A. F. Ismail, F. Aziz, W. N. W. Salleh and N. H. Othman, Chemosphere, 2018, 204, 79-86.

112 X. Zhou, C. Shao, S. Yang, X. Li, X. Guo, X. Wang, X. Li and Y. Liu, ACS Sustainable Chem. Eng., 2018, 6, 2316-2323.

113 D. Qin, W. Lu, Z. Zhu, N. Li, T. Xu, G. Wang and W. Chen, Ind. Eng. Chem. Res., 2017, 56, 11151-11160.

114 S. Chen, W. Lu, J. Han, H. Zhong, T. Xu, G. Wang and W. Chen, Chem. Eng. J., 2019, 359, 119-129.

115 D. Qin, W. Lu, X. Wang, N. Li, X. Chen, Z. Zhu and W. Chen, ACS Appl. Mater. Interfaces, 2016, 8, 25962-25970.

116 Y. Chen, W. Lu, X. Wang and W. Chen, Appl. Surf. Sci., 2018, 453, 110-119.

117 C. Zhang, Y. Li, D. Shuai, Y. Shen, W. Xiong and L. Wang, Chemosphere, 2019, 214, 462-479.

118 R. Li, Y. Ren, P. Zhao, J. Wang, J. Liu and Y. Zhang, J. Hazard. Mater., 2019, 365, 606-614.

119 L. Ghalamchi, S. Aber, V. Vatanpour and M. Kian, Chem. Eng. Res. Des., 2019, 147, 443-457.

120 J. Tian, Q. Liu, C. Ge, Z. Xing, A. M. Asiri, A. O. Al-Youbi and X. Sun, Nanoscale, 2013, 5, 8921-8924.

121 Q. Cui, J. Xu, X. Wang, L. Li, M. Antonietti and M. Shalom, Angew. Chem., Int. Ed., 2016, 55, 3672-3676.

122 X. Ou, X. Tan, X. Liu, Q. Lu, S. Chen and S. Wei, Biosens. Bioelectron., 2015, 70, 89-97.

123 Q. Lu, J. Zhang, X. Liu, Y. Wu, R. Yuan and S. Chen, Analyst, 2014, 139, 6556-6562.

124 B. K. Shrestha, R. Ahmad, S. Shrestha, C. H. Park and C. S. Kim, Biosens. Bioelectron., 2017, 94, 686-693.

125 Y. Liu, H. Ma, Y. Zhang, X. Pang, D. Fan, D. Wu and Q. Wei, Biosens. Bioelectron., 2016, 86, 439-445.

126 H. Pu, Q. Liu, L. Qiao and Z. Yang, Polym. Eng. Sci., 2005, 45, 1395-1400.

127 A. Bozkurt and W. H. Meyer, J. Polym. Sci., Part B: Polym. Phys., 2001, 39, 1987-1994.
128 Y. Huang, L. Chuang, A. M. Kannan and C. Lin, J. Power Sources, 2009, 186, 22-28.

129 S. Lu, R. Xiu, X. Xu, D. Liang, H. Wang and Y. Xiang, J. Membr. Sci., 2014, 464, 1-7.

130 N. G. Sahoo, Y. Pan, L. Li and S. H. Chan, Adv. Mater., 2012, 24, 4203-4210.

131 D. He, H. Tang, Z. Kou, M. Pan, X. Sun, J. Zhang and S. Mu, Adv. Mater., 2017, 29.

132 P. Velayutham and A. K. Sahu, J. Phys. Chem. C, 2018, 122, 21735-21744.

133 G. Zou, W. Wu, C. Cong, X. Meng, K. Zhao and Q. Zhou, RSC Adv., 2016, 6, 106237-106247.

134 H. Bai, H. Wang, J. Zhang, C. Wu, J. Zhang, Y. Xiang and S. Lu, J. Membr. Sci., 2018, 558, 26-33.

135 M. Gang, G. He, Z. Li, K. Cao, Z. Li, Y. Yin, H. Wu and Z. Jiang, J. Membr. Sci., 2016, 507, 1-11.

136 W. Dai, Y. Shen, Z. Li, L. Yu, J. Xi and X. Qiu, J. Mater. Chem. A, 2014, 2, 12423-12432.

137 L. Semiz, N. Demirci Sankir and M. Sankir, J. Membr. Sci., 2014, 468, 209-215.

138 L. Cao, Q. Sun, Y. Gao, L. Liu and H. Shi, Electrochim. Acta, 2015, 158, 24-34.

139 F. Wang, G. Wang, J. Zhang, B. Li, J. Zhang, J. Deng, J. Chen and R. Wang, J. Electroanal. Chem., 2017, 797, 107-112.

140 Z. Mai, H. Zhang, X. Li, S. Xiao and H. Zhang, J. Power Sources, 2011, 196, 5737-5741.

141 R. Niu, L. Kong, L. Zheng, H. Wang and H. Shi, J. Membr. Sci., 2017, 525, 220-228.

142 C. Wu, S. Lu, J. Zhang and Y. Xiang, Phys. Chem. Chem. Phys., 2018, 20, 7694-7700.

$143 \mathrm{~J} . \mathrm{Hu}, \mathrm{J}$. Tian and C. Li, ACS Appl. Mater. Interfaces, 2017, 9, 11615-11625.

144 P. Praveena, M. Sheril Ann, S. Dhanavel, D. Kalpana, T. Maiyalagan, V. Narayanan and A. Stephen, J. Mater. Sci.: Mater. Electron., 2019, 30, 8736-8750.

145 F. Li, Y. Dong, Q. Dai, T. T. Nguyen and M. Guo, Vacuum, 2019, 161, 283-290.

146 J. Ma, X.-Y. Tao, S.-X. Zhou, X.-Z. Song, Y.-B. Zhu, L.-T. Guo, Z.-S. Liu, H.-L. Fan and X.-Y. Wei, J. Electroanal. Chem., 2019, 835, 346-353.

147 X. Chen, X. Zhu, Y. Xiao and X. Yang, J. Electroanal. Chem., 2015, 743, 99-104.

148 R. A. Senthil, J. Theerthagiri, J. Madhavan, K. Murugan, P. Arunachalam and A. K. Arof, J. Solid State Chem., 2016, 242, 199-206.

149 X. Chen, Q. Liu, Q. Wu, P. Du, J. Zhu, S. Dai and S. Yang, Adv. Funct. Mater., 2016, 26, 1719-1728.

150 J. Xu, T. J. Brenner, L. Chabanne, D. Neher, M. Antonietti and M. Shalom, J. Am. Chem. Soc., 2014, 136, 13486-13489.

151 S. Barman and M. Sadhukhan, J. Mater. Chem. A, 2012, 22, 21832-21837.

152 K. Xiao, P. Giusto, L. Wen, L. Jiang and M. Antonietti, Angew. Chem., Int. Ed., 2018, 57, 10123-10126.

153 C. Tang, A. Tracz, M. Kruk, R. Zhang, D. M. Smilgies, K. Matyjaszewski and T. Kowalewski, J. Am. Chem. Soc., 2005, 127, 6918-6919. 
154 X. Zhang, X. Xie, H. Wang, J. Zhang, B. Pan and Y. Xie, J. Am. Chem. Soc., 2013, 135, 18-21.

155 Q. Cao, B. Kumru, M. Antonietti and B. V. K. J. Schmidt, Macromolecules, 2019, 52, 4989-4996.

156 Y. Shi, S. Jiang, K. Zhou, C. Bao, B. Yu, X. Qian, B. Wang, N. Hong, P. Wen, Z. Gui, Y. Hu and R. K. Yuen, ACS Appl. Mater. Interfaces, 2014, 6, 429-437.

157 B. Kumru, J. Barrio, J. Zhang, M. Antonietti, M. Shalom and B. V. K. J. Schmidt, ACS Appl. Mater. Interfaces, 2019, 11, 9462-9469.

158 C. Han, Q. Cui, P. Meng, E. R. Waclawik, H. Yang and J. Xu, Langmuir, 2018, 34, 10135-10143.

159 Y. Luo, Y. Yang, Q. Cui, R. Peng, R. Liu, Q. Cao and L. Li, ACS Appl. Bio Mater., 2019, 2, 5127-5135.

160 J. Poostforooshan, A. Badiei, M. Kolahdouz and A. P. Weber, ACS Appl. Mater. Interfaces, 2016, 8, 21731-21741.

161 Y. Lu, X. Pan, N. Li, Z. Hu and S. Chen, Appl. Surf. Sci., 2019, 144071.

162 C. Duan, D. Yuan, Z. Yang, S. Li, L. Tao, Q. Wang and T. Wang, Composites, Part A, 2018, 113, 200-208.

163 M. Khalifa, A. Mahendran and S. Anandhan, J. Polym. Res., 2019, 26, 73.

164 Y. Shi, B. Wang, L. Duan, Y. Zhu, Z. Gui, R. K. K. Yuen and Y. Hu, Ind. Eng. Chem. Res., 2016, 55, 7646-7654.

165 Y. Shi, L. Wang, L. Fu, C. Liu, B. Yu, F. Yang and Y. Hu, J. Colloid Interface Sci., 2019, 539, 1-10.

166 K. Myllymaa, S. Myllymaa, H. Korhonen, M. J. Lammi, H. Saarenpaa, M. Suvanto, T. A. Pakkanen, V. Tiitu and R. Lappalainen, J. Mater. Sci.: Mater. Med., 2009, 20, 2337-2347.

167 Y. Shi, Z. Gui, B. Yu, R. K. K. Yuen, B. Wang and Y. Hu, Composites, Part B, 2015, 79, 277-284.

168 B. Lei, Y. Zhang, Y. He, Y. Xie, B. Xu, Z. Lin, L. Huang, S. Tan, M. Wang and X. Cai, Mater. Des., 2015, 66, 103-109.

169 S. He, J. Wang, M. Yu, Y. Xue, J. Hu and J. Lin, Polymers, 2019, 11.

170 B. Song, T. Wang, H. Sun, H. Liu, X. Mai, X. Wang, L. Wang, N. Wang, Y. Huang and Z. Guo, Compos. Sci. Technol., 2018, 167, 515-521.

171 E. A. Appel, X. J. Loh, S. T. Jones, F. Biedermann, C. A. Dreiss and O. A. Scherman, J. Am. Chem. Soc., 2012, 134, 11767-11773.

172 J. Zhu and R. E. Marchant, Expert Rev. Med. Devices, 2011, 8, 607-626.

173 T. R. Hoare and D. S. Kohane, Polymer, 2008, 49, 1993-2007.

174 H. Yuk, S. Lin, C. Ma, M. Takaffoli, N. X. Fang and X. Zhao, Nat. Commun., 2017, 8, 14230.

175 X. Dai, Y. Zhang, L. Gao, T. Bai, W. Wang, Y. Cui and W. Liu, Adv. Mater., 2015, 27, 3566-3571.

176 P. Samaddar, S. Kumar and K.-H. Kim, Polym. Rev., 2019, 59, 418-464.

177 W. Guo, C. H. Lu, R. Orbach, F. Wang, X. J. Qi, A. Cecconello, D. Seliktar and I. Willner, Adv. Mater., 2015, 27, 73-78.

178 A. Nakayama, A. Kakugo, J. P. Gong, Y. Osada, M. Takai, T. Erata and S. Kawano, Adv. Funct. Mater., 2004, 14, 1124-1128.

179 B. G. Cooper, R. C. Stewart, D. Burstein, B. D. Snyder and M. W. Grinstaff, Angew. Chem., Int. Ed., 2016, 55, 4226-4230.
180 T. Murakami, B. V. K. J. Schmidt, H. R. Brown and C. J. Hawker, Macromolecules, 2015, 48, 7774-7781.

181 A. Bin Imran, K. Esaki, H. Gotoh, T. Seki, K. Ito, Y. Sakai and Y. Takeoka, Nat. Commun., 2014, 5, 5124.

182 A. Agrawal, N. Rahbar and P. D. Calvert, Acta Biomater., 2013, 9, 5313-5318.

183 M. Fukasawa, T. Sakai, U.-i. Chung and K. Haraguchi, Macromolecules, 2010, 43, 4370-4378.

184 O. Okay and W. Oppermann, Macromolecules, 2007, 40, 3378-3387.

185 S. Tamesue, M. Ohtani, K. Yamada, Y. Ishida, J. M. Spruell, N. A. Lynd, C. J. Hawker and T. Aida, J. Am. Chem. Soc., 2013, 135, 15650-15655.

186 J. Djonlagic, A. Lancuski, M. S. Nikolic, J. Rogan, S. Ostojic and Z. Petrovic, J. Appl. Polym. Sci., 2017, 134, 44535.

187 Q. Wang, J. L. Mynar, M. Yoshida, E. Lee, M. Lee, K. Okuro, K. Kinbara and T. Aida, Nature, 2010, 463, 339.

188 M. Liu, Y. Ishida, Y. Ebina, T. Sasaki, T. Hikima, M. Takata and T. Aida, Nature, 2015, 517, 68.

189 C. Hu, Y.-R. Lin and H.-C. Yang, ChemSusChem, 2019, 12, 1794-1806.

190 J. Liu, T. An, Z. Chen, Z. Wang, H. Zhou, T. Fan, D. Zhang and M. Antonietti, J. Mater. Chem. A, 2017, 5, 8933-8938.

191 J. Sun, B. V. K. J. Schmidt, X. Wang and M. Shalom, ACS Appl. Mater. Interfaces, 2017, 9, 2029-2034.

192 M. Zarei, H. Ahmadzadeh, E. K. Goharshadi and A. Farzaneh, Anal. Chim. Acta, 2015, 887, 245-252.

193 B. Kumru, V. Molinari, R. Dünnebacke, K. G. Blank and B. V. K. J. Schmidt, Macromol. Rapid Commun., 2018, 40, 1800712.

194 H. Li, L. Wang, Y. Liu, J. Lei and J. Zhang, Res. Chem. Intermed., 2016, 42, 3979-3998.

195 Y. Zheng, Y. Jiao, J. Chen, J. Liu, J. Liang, A. Du, W. Zhang, Z. Zhu, S. C. Smith, M. Jaroniec, G. Q. Lu and S. Z. Qiao, J. Am. Chem. Soc., 2011, 133, 20116-20119.

196 B. Kumru, V. Molinari, M. Shalom, M. Antonietti and B. V. K. J. Schmidt, Soft Matter, 2018, 14, 2655-2664.

197 J. P. Gong, T. Kurokawa, T. Narita, G. Kagata, Y. Osada, G. Nishimura and M. Kinjo, J. Am. Chem. Soc., 2001, 123, 5582-5583.

198 M. M. Blum and T. C. Ovaert, Mater. Sci. Eng., C, 2013, 33, 4377-4383.

199 B. Ye, C. Yao, M. Yan, H. Zhang, F. Xi, J. Liu, B. Li and X. Dong, Macromol. Mater. Eng., 2018, 1800500.

200 Q. Hao, T. Chen, R. Wang, J. Feng, D. Chen and W. Yao, J. Cleaner Prod., 2018, 197, 1222-1230.

201 S. Lamkhao and C. Randorn, J. Photopolym. Sci. Technol., 2017, 30, 425-429.

202 Y. Liang, X. Wang, W. An, Y. Li, J. Hu and W. Cui, Appl. Surf. Sci., 2019, 466, 666-672.

203 M. Li, H. Liao, Q. Deng, Y. Wu, F. Xiao, X. Wei and D. Tu, J. Macromol. Sci., Part A: Pure Appl. Chem., 2018, 55, 408-413.

204 J. W. Ko, W. S. Choi, J. Kim, S. K. Kuk, S. H. Lee and C. B. Park, Biomacromolecules, 2017, 18, 3551-3556.

205 P. He, X. Tang, L. Chen, P. Xie, L. He, H. Zhou, D. Zhang and T. Fan, Adv. Funct. Mater., 2018, 28, 1801121. 
206 J. Yan, M.-T. F. Rodrigues, Z. Song, H. Li, H. Xu, H. Liu, J. Wu, Y. Xu, Y. Song, Y. Liu, P. Yu, W. Yang, R. Vajtai, H. Li, S. Yuan and P. M. Ajayan, Adv. Funct. Mater., 2017, 27, 1700653.

207 Y. Zhang, Z. Zhou, Y. Shen, Q. Zhou, J. Wang, A. Liu, S. Liu and Y. Zhang, ACS Nano, 2016, 10, 9036-9043.

208 L. Tan, C. Yu, M. Wang, S. Zhang, J. Sun, S. Dong and J. Sun, Appl. Surf. Sci., 2019, 467-468, 286-292.
209 M. Zhang, W. Jiang, D. Liu, J. Wang, Y. Liu, Y. Zhu and Y. Zhu, Appl. Catal., B, 2016, 183, 263-268.

210 D. Gräfe, A. Wickberg, M. M. Zieger, M. Wegener, E. Blasco and C. Barner-Kowollik, Nat. Commun., 2018, 9, 2788.

211 S. C. Ligon, R. Liska, J. r. Stampfl, M. Gurr and R. Mülhaupt, Chem. Rev., 2017, 117, 10212-10290. 